\title{
HANDBOOK FOR RECLAMATION OF PLACER MINED STREAM ENVIRONMENTS IN WESTERN MONTANA
}

\section{JUL 1 广 2001}

MONTANA STATE LIBRARY.
1515 E. 6th AVE.

HELENA, MONTANA 59620 


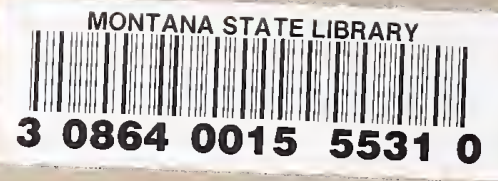




\title{
HANDBOOK FOR RECLAMATION OF PLACER MINED STREAM ENVIRONMENTS \\ IN WESTERN MONTANA
}

\author{
Prepared for \\ US Environmental Protection Agency \\ Region VIII, Montana Office \\ Federal Building \\ 301 South Park, Drawer 10096 \\ Helena, MT 59626-0096 \\ (406) 449-5486
}

March 15, 1991

Submitted By

INTER-FT,UVE, Inc.

1020 Wasco St., Suite 1 Hood River, OR 97031 (503) 386-9003 (503) 386-9241 FAX
25 N. Willson Ave., Suite 5 Bozeman, MT 59715 (406) $586-6926$ (406) 586-8445 FAX
P. O. Box 28147 Lakewood, CO 80228 (303) 692-8835 (303) 692-8835 FAX 
Digitized by the Internet Archive in 2016 
This report was produced for the U.S. Environmental Protection Agency (EPA), under contract, by Inter-Fluve, Inc. Approval of this report for publication by EPA does not signify that the contents necessarily reflect the view and policies of the EPA, nor does mention of trade names of commercial products constitute endorsement or recommendation for use. 



\section{TABLE OF CONTENTS}

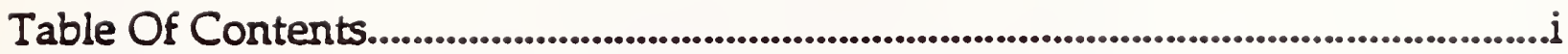

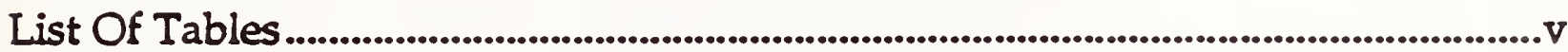

List Of Figures .....................................................................................................................................vi

Acknowledgements......................................................................................................................vi

1.0 Executive Summary.......................................................................................................1

20 Introduction ............................................................................................................................2

2.1 Objectives And Scope Of Report........................................................2

2.2 Handbook Organization............................................................................3

3.0 Placer Mining And Reclamation In Montana.....................................................5

3.1 Geographical And Historical Context.......................................................5

3.2 State And Federal Oversight .......................................................................7

3.2.1 Montana Department Of State Lands.....................................7

3.2.2 United States Forest Service......................................................8

3.2.3 Bureau Of Land Management................................................9

3.2.4 County Conservation Districts.....................................................9

3.2.5 Montana Department Of Health And

Environmental Services ..................................................10

3.2.6 United States Environmental Protection Agency ...............11

3.2.7 Montana Bureau Of Mines And Geology...............................11

4.0 Planning For Stream Reclamation .......................................................................12

5.0 Pre-mining Data Necessary For Effective Stream Reclamation ...................14

5.1 Introduction .......................................................................................14

5.2 Assessment Of Channel And Floodplain Condition For Prior

Disturbance..................................................................................................14

5.2.1 Recognition Of Undisturbed Sites................................................14

5.2.2 Recognition Of Disturbed Sites.................................................15

5.3 Methods Of Data Collection For Undisturbed Sites ........................... 16

5.3.1 Introduction ..................................................................................16

5.3.2 Basic Background Research Needs.........................................17

5.3.2.1 Plan Map Of Site..............................................................17

5.3.2.2 Hydrologic Information ..........................................17

5.3.2.3 General Channel And Biological Information.....................................................................18

5.3.3 Field Data......................................................................................19

5.3.3.1 Determination Of Valley Slope And

Channel Grade.

5.3.3.2 Evaluation Of Channel Planform...........................19

5.3.3.2.1 Typical Channel Patterns In Montana. 


\subsection{Measurement Of Planform}

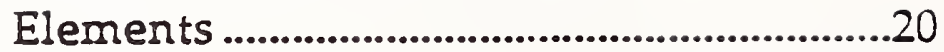

Sinuosity................................................................20

Meanders ............................................................22

5.3.3.2.3 Valley Cross-Section....................................22

5.3.3.2.4 Channel Geometry ........................................25

Measurement Methods ....................................25

Pool-Riffle Sequences...................................27

5.3.3.2.5 Survey Of Channel Substrate....................227

Purpose.................................................................27

Methodology....................................................30

5.3.3.2.6 Survey Of Active Floodplain And

Riparian Area ................................................31

Floodplain Measurement

Methodology

Riparian Area Vegetative

Documentation .................................................332

Streamside Cover.................................32

Distance From The Stream.................34

5.3.3.3 Evaluation Of Fisheries And Wildlife.....................34

5.4 Methods Of Data Collection For Disturbed Sites...............................36

5.4.1 Introduction.....................................................................................36

5.4.2 Methodology .....................................................................................36

6.0 Utilizing Field Data To Develop A Reclamation Plan .................................38

6.1 Introduction..................................................................................................38

6.2 Reclamation Design For Undisturbed Sites.......................................38

6.21 Base Planning Maps ..................................................................38

6.2.2 Designation Of Mining Panels.............................................39

6.2.3 Incorporating Field Data Into Reclamation Plan Map.......42

6.2.3.1 Locating Stream Channel On Plan Map.................42

6.2.3.2 Valley Slope ......................................................................42

6.2.3.3 Channel Grade.............................................................44

6.2.3.4 Channel Geometry ..................................................44

6.2.3.5 Channel Substrate Design ............................................44

6.2.3.6 Vegetation....................................................................44

6.3 Reclamation Design Of Previously Disturbed Sites ...........................47

6.3.1 Assessment Of Site Potential......................................................48

6.3.2 Base Plan Map.............................................................................48

6.3.3 Incorporating Data Into Reclamation Plar. Ma ${ }_{1}^{-}$...................48

6.3.3.1 Designing Average Valley Grade ............................48

6.3.3.2 Designing Channel Grade.......................................49

6.3.3.3 Location Of Reclaimed Channel...............................49 
6.3.3.4 Designing Channel Geometry................................51

6.3.3.4.1 Representative Reach Information

Available.

6.3.3.4.2 Representative Reach Information

Unavailable.

6.3.3.5 Designing Channel Substrate..................................55

6.3.3.6 Designing Floodplains............................................58

6.3.3.6.1 Representative Reach Information

Available.

6.3.3.6.2 Representative Reach Information

Unavailable.

6.3.3.8 Vegetative Plan

6.3.3.7 Designing Around Site Anomalies ........................62

7.0 Incorporation Of Reclamation Activities With Mining Operations.........64

7.1 Introduction ......................................................................................64

7.2 Sequence Of Mining Operation ............................................................65

7.2.1 Review Of Operation And Reclamation Goals....................65

7.2.2 Mobilization And Set-up .........................................................65

7.2 .3 Stream Relocation ....................................................................66

7.2.4 Siting Of Excavations .....................................................................66

7.2 .5 Material Handling .........................................................................67

7.2.6 Material Mixing..........................................................................70

7.3 Reclamation Of Mining Panel .............................................................71

7.3.1 Bringing The Mining Panel To Rough Grade......................71

7.3.2 Channel Construction .....................................................................73

7.3.3 Channel Excavation ....................................................................73

7.3.4 Backfilling Channel With Substrate.........................................74

7.3.5 Woody Debris Placements .......................................................75

7.3.6 Placing Erosion Blanket For Bank Protection.......................75

7.3.7 Placing Rock Roughness Elements In Riffles.......................75

7.3.8 Maintaining Designed Channel Grade ....................................78

7.3.9 Channel Bank Revegetation With Willow Plantings.......78

7.3.10 Floodplain Rehabilitation..........................................................79

7.3.11 Reclamation Monitoring ..........................................................80

8.0 Costs Associated With Placer Mining And Reclamation ...............................81

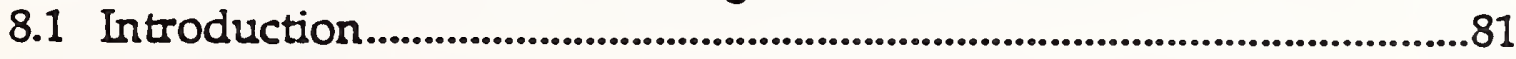

8.2 Operator Costs Verses Contractor Costs ...................................................82

8.3 Establishing Bond Amounts ..........................................................................82

8.4 Pre-mining Reclamation Data Collection And Analysis Cosis

8.4.1 Professional Services.............................................................83

8.4.2 Aerial Photographs..................................................................84

8.4.3 Field Measurement Tools.......................................................84

8.5 Reclamation Design/Permit Acquisition Costs ....................................84

8.6 Mining And Reclamation Costs..............................................................85

8.6.1 Site Preparation Costs ...................................................................86 
8.6.2 Rough Grade Costs .......................................................................86

8.6.3 Finished Grade Costs............................................................89

8.6.3.1 Streams...........................................................................89

8.6.3.2 Ponds And Wetlands.............................................91

8.7 Revegetation Costs ..........................................................................................91

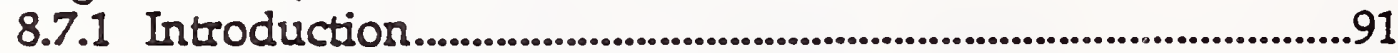

8.7.2 Seed .................................................................................................92

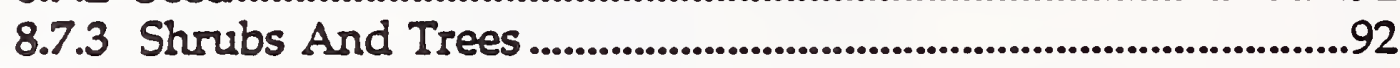

8.7.4 Emergent Vegetation .....................................................................93

8.7.5 Erosion Control Methods..........................................................93

8.8 Monitoring Costs .............................................................................................994

8.9 Maintenance And Operation Costs.....................................................95

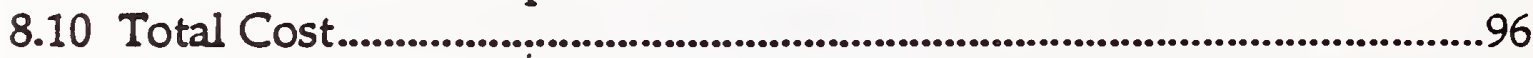

8.11 Sources Of Cost Information...................................................................96

9.0 Summary .................................................................................................................101

10.0 References Cited .......................................................................................................102

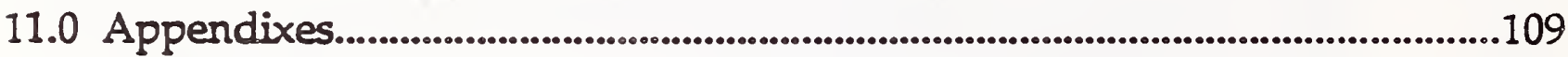

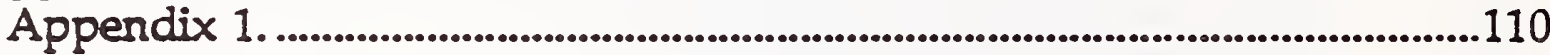

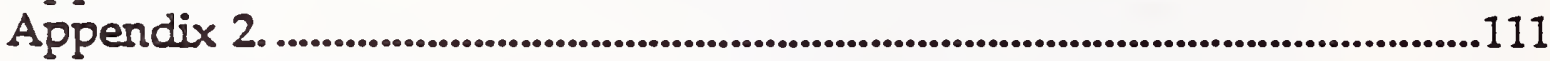

Appendix 3...........................................................................................................112

Appendix 4....................................................................................................113

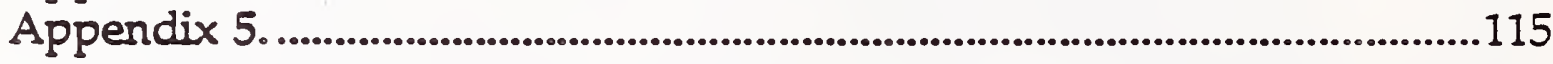

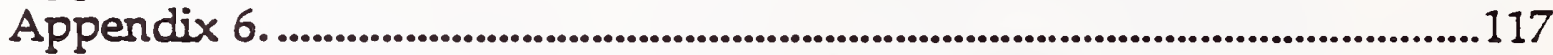

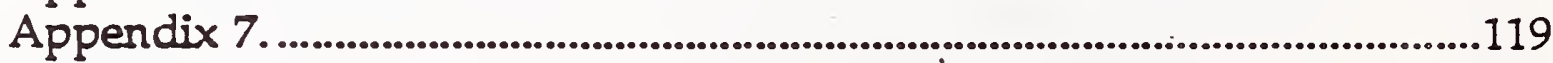

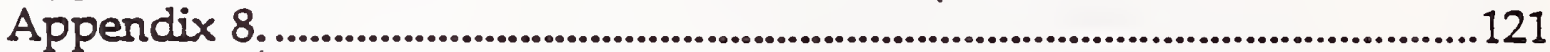

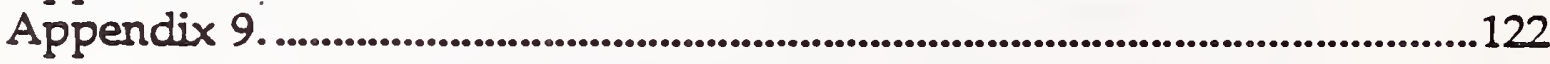




\section{LIST OF TABLES}

Table 1. General descriptions of channel bed and bank substrates for visual survey.

Table 2 Example determination of plant types found in a riparian setting and associated cover provided.

Table 3. Design and feasibility costs per lineal foot of stream incurred or estimated for placer mine projects in stream environments. Seé Table 14 for source details.

Table 4. Cost per acre for site clearing and stockpiling topsoil based on contractor costs (derived from Smit 1991).

Table 5. Approximate contractor cost per cubic yard for buik excavation of material moved by heavy equipment (derived from Smit 1991).

Table 6. Average cost per week and month by heavy equipment type, based on contract and rental rates (USDA 1989

Table 7. Average total cost on a per foot basis for stream reconstruction associated with placer mining and other major environmental disturbances.

Table 8. Reported costs for various seeding methods. See Table 14 for source details.

Table 9. Reported costs for planting and protecting rooted stock. See Table 14 for source details.

Table 10. Approximate costs for planting tubers of emergent species on 1 foot centers under ideal conditions (material costs from Kester's Wild Game Food Nurseries, Inc. 1990). Figures are based on labor costs of less than $0.5 \%$ per square foot.

Table 11. Estimated costs per square yard for installation of various erosion control fabrics under different applications using a three person crew.

Table 72. Total costs for a variety of placer mine reclamation projects in the Pacific Northwest. See Table 14 for source details.

Table 13. Probable costs for a hypothetical small-scale placer mine reclamation project, comparing those for reclamation concurrent with and following mining. Figures are bass-t on cost information collected as part of this docum r.t.

Table 14. Probable costs for a hypothetical large-scale placer mine reclamation project, comparing those for redamation concurrent with and following mining. Figures are based on cost information collected as part of this document.

Table 15. Persons responding to request for placer mine information. Some contacts are second-hand. 


\section{LIST OF FIGURES}

Figure 1. Historic and current areas of placer mine activities in western Montana.

Figure 2. (a) Calculation of stream sinuosity and (b) channel planview illustration for a range of sinuosity indexes most frequently encountered in mountain stream environments (modified from from Dunne and Leopold 1978).

Figure 3. Generalized degrees of meander regularity in natural streams (modified from Krighton 1984).

Figure 4. Schematic of standard meander bend parameters .24

Figure 5. Longitudinal profile and associated planview of channel bed elevations giving rise to repeating pool-riffle sequences (from Dunne and Leopold 1978).

Figure 6. Plotted cross-section of channel identifying top of banks, edge of active channel and maximum channel depth.

Figure 7. Approximate measurement points for cross-sectional information in a pool.

Figure 8. Plotted valley cross-section identifying active channel, floodplain terraces and valley slopes.

Figure 9. Conceptual illustration of vegetative stratification associated with riparian areas.

Figure 10. Initial plan map identifying surface ground conditions and property ownership.

Figure 11. Plan map showing location of designated mining panels.........41

Figure 12. Plan and profile depicting information collected within representative reaches, including valley and channel grades and cross-section locations.

Figure 13. Representation of measured channel cross-section with associated reach slopes.

Figure 14. Schematic drawing of designed channel bed cross-section detailing substrate sizes and placement.

Figure 15. Illustrative trapezoidal cross-section of a riffle and commonly encountered cross-sectional shapes of a pool.........56

Figure 16. A range of shear stresses generated by bankfull discharges and counterpart shear stresses for $\mathrm{uindian}$ particles in the armor layer (derived from Aiddrews 1983)

Figure 17. Illustration of generic large woody debris placements to promote pool formation and dissipation of stream energy.

Figure 18. Illustration of generalized placement of large roughness elements (rocks and boulders) in the reconstructed channel. 


\section{ACKNOWLEDGEMENTS}

This document is the result of the work of many persons dedicated to improving the state of placer mine reclamation in the state of Montana. Without the assistance of these many contributors this report would be much more limited in scope. Thanks go out to all those who patiently answered our questions, candidly shared insights, accompanied us into the field, and reviewed the draft reports. We hope this document will answer some of the questions it was designed to address.

Thanks are also due to everyone who contributed to the editing of the text. Notable thanks go to our compatriot at Inter-Fluve, Inc., Robert O'Brien, Fluvial Geomorphologist, both for his help in contributing to the sections on stream channel design and his patient editing of the draft manuscript. Thanks also to Karen Schunke for her artwork.

Several individuals played a vital role in the formulation and preparation of this document. Steve Potts, project officer with the U.S. Environmental Protection Agency and Glen Phillips with the Montana Department of Fish, Wildlife and Parks. Glen laid much of the groundwork for our efforts by identifying many of the current problems with the state of placer reclamation in Montana. Always perseverant, Steve worked with the state resource and regulatory agencies to formulate a usable scope for this report, and provided continual technical support and encouragement. Valuable commentary on the draft reports was provided by both Robin McCulloch of the Montana Bureau of Mines and Geology and Pete Strazdas of the Montana Department of State Lands.

For those readers actively involved with placer mine reclamation, we would like to request that you send any further reclamation cost or other information you may collect to us at Inter-Fluve, Inc or to the Montana office of U.S. Environmental Protection Agency; this material can be added to the text should future revisions occur.

Scott Gillilan

Dale E. Miller 


\section{LIST OF FIGURES}

Figure 1. Historic and current areas of placer mine activities in western Montana.

Figure 2. (a) Calculation of stream sinuosity and (b) channel planview illustration for a range of sinuosity indexes most frequently encountered in mountain stream environments (modified from from Dunne and Leopold 1978).

Figure 3. Generalized degrees of meander regularity in natural streams (modified from Krighton 1984).

Figure 4. Schematic of standard meander bend parameters

Figure 5. Longitudinal profile and associated planview of channel bed elevations giving rise to repeating pool-riffle sequences (from Dunne and Leopold 1978).

Figure 6. Plotted cross-section of channel identifying top of banks, edge of active channel and maximum channel depth.

Figure 7. Approximate measurement points for cross-sectional information in a pool.

Figure 8. Plotted valley cross-section identifying active channel, floodplain terraces and valley slopes.

Figure 9. Conceptual illustration of vegetative stratification associated with riparian areas.

Figure 10. Initial plan map identifying surface ground conditions and property ownership.

Figure 11. Plan map showing location of designated mining panels........41

Figure 12. Plan and profile depicting information collected within representative reaches, including valley and channel grades and cross-section locations.

Figure 13. Representation of measured channel cross-section with associated reach slopes.

Figure 14. Schematic drawing of designed channel bed cross-section detailing substrate sizes and placement.

Figure 15. Illustrative trapezoidal cross-section of a riffle and commonly encountered cross-sectional shapes of a pool.........56

Figure 16. A range of shear stresses generated by bankfull discharges and counterpart shear stresses for iindian particles in the armor layer (derived from Aildrews 1983)

Figure 17. Illustration of generic large woody debris placements to promote pool formation and dissipation of stream energy.

Figure 18. Illustration of generalized placement of large roughness elements (rocks and boulders) in the reconstructed channel. 


\section{ACKNOWLEDGEMENTS}

This document is the result of the work of many persons dedicated to improving the state of placer mine reclamation in the state of Montana. Without the assistance of these many contributors this report would be much more limited in scope. Thanks go out to all those who patiently answered our questions, candidly shared insights, accompanied us into the field, and reviewed the draft reports. We hope this document will answer some of the questions it was designed to address.

Thanks are also due to everyone who contributed to the editing of the text. Notable thanks go to our compatriot at Inter-Fluve, Inc., Robert O'Brien, Fluvial Geomorphologist, both for his help in contributing to the sections on stream channel design and his patient editing of the draft manuscript. Thanks also to Karen Schunke for her artwork.

Several individuals played a vital role in the formulation and preparation of this document. Steve Potts, project officer with the U.S. Environmental Protection Agency and Glen Phillips with the Montana Department of Fish, Wildlife and Parks. Glen laid much of the groundwork for our efforts by identifying many of the current problems with the state of placer reclamation in Montana. Always perseverant, Steve worked with the state resource and regulatory agencies to formulate a usable scope for this report, and provided continual technical support and encouragement. Valuable commentary on the draft reports was provided by both Robin McCulloch of the Montana Bureau of Mines and Geology and Pete Strazdas of the Montana Department of State Lands.

For those readers actively involved with placer mine reclamation, we would like to request that you send any further reclamation cost or other information you may collect to us at Inter-Fluve, Inc or to the Montana office of U.S. Environmental Protection Agency; this material can be added to the text should future revisions occur.

Scott Gillilan

Dale E. Miller 



\subsection{EXECUTIVE SUMMARY}

This document specifically addresses placer mine reclamation associated with stream environments in western Montana. The historical and geographical background of placer activity are briefly described, as are the roles of state and federal agencies involved in the regulation of mining. The document then follows the step-by-step procedures required to design and implement reclamation within the context of an active placer mine. It outlines the specific data that should be collected before the onset of mining, from which a reclamation plan can then be developed. Realizing that each reclamation site is uniquely different and subject to many different placer mining practices, the report discusses some general guidelines, techniques, and considerations required to undertake reclamation concurrent with mining. Throughout these steps, reclamation focuses on returning mined areas to natural predisturbed stream and watershed environments within the limitations of the sites.

It has been noted that the majority of currently active placer mines in Montana are localized to floodplains, historic fluvial benches, and other "dry" areas. The reclamation of these sites may require techniques similar to or different from those outlined in this report. .However, consideration of these sites' role in and contribution to the greater watershed's stability and function should be a critical element of their planned and executed reclamation. Justification for this report's emphasis on reclamation of placer mines in the stream environment is based on: 1) the specialized techniques necessary for reclamation in these areas, 2) the increasing values being placed on Montana's flowing water resources, and 3) a perceived likelihood that the increasing value of gold over time may result in an increase in placer activity in the state.

Also contained within this handbook are specific costs for various aspects of placer mine.reclamation which are based on the compilation of figures from resource and regulatory agencies and the private sector. The intention is to provide the reader with an appreciation of the complexities and associated costs for terrestrial and aquatic reclamation.

A companion report to ih is handbook (Reolelatory Considerations Regarding Placer Mine Reclanictiun Of Stream Enoiionments In Montana) was also compiled and is devoted to summarizing and evaluating the feedback and observations received or made by Inter-Fluve, Inc., during the formulation of this report. These findings focus primarily on the administrative and legislative aspects relating to reclamation implementation and regulatory enforcement. Hopefully, this critical examination will promote re-evaluation of existing procedural, regulatory, and operational reclamation guidelines. 



\section{INTRODUCTION}

\subsection{OBJECTIVES AND SCOPE OF REPORT}

The principal objective of this report is to facilitate informed participation in placer mine reclamation as it relates to the stream environment. Due to the technical nature of the information contained herein, the primary audience for this report is intended to be resource agency personnel. However, it should be accessible to a wide audience, including miners, operators, consultants, law makers and administrators.

A review of available placer mine reclamation literature revealed either overly simplistic and narrowly applicable guidelines, geographically unique, or highly technical and academic reclamation prescriptions with varying application value (Simons and Li \& Associates 1989; Rundquist et al. 1986; Bureau of Land Management 1989). Because reclamation prescriptions are only useful if they can be successfully integrated into a workable mining operation, the format of this report follows a practical approach to stream reclamation, from a detailed look at preliminary planning, to ways in which mining and reclamation plans can be managed concurrently, up to the completion of reclamation. These prescriptions are the result of a synthesis of appropriate literature; meetings and correspondence with miners, reclamation professionals, and resource agency personnel throughout Montana and the western U.S.; field reviews of active and abandoned placer operations; and the experience of Inter-Fluve, Inc.

This report also explores the range of financial costs associated with different reclamation scenarios. Due to the unique nature of individual reclamation sites, it is difficult to assign absolute costs associated with the reclamation of a generic acre or length of stream channel. The formulation of reclamation costs is complicated by the fact there there is no accepted standard for site reclamation and no accepted consensus of what constitutes reclamation. While some sites are considered reclaimed after the completion of simple grading activities, other projects entail restoration of hydrologic integrity and the relocation or construction of stream channels capable of supporting a wild fishery. Clearly, the costs associated with these two scenarios differ by a wide marrin. Additionally, reclamation costs are intimately tied to the degree of reclamation activity that is concurrent with mining. The reclamation of an abandoned and unreclaimed mine site will therefore require more resources than a site that was reclaimed during mining activity.

Although the scope of this report is constrained to placer mine reclamation in Montana, many aspects are applicable to other states and regions. Furthermore, the focus of this report concerns the reconstruction and 
rehabilitation of the stream environment. Based on field evaluations, it is apparent that placer mine reclamation, including the re-establishment of hydrologically stable drainages, functional floodplains, riparian zones and ecologically sound aquatic habitat, has been rarely realized in the state of Montana. The failure to address these issues continues to produce water quality problems, impacts to fisheries, litigation and adverse public perceptions of placer mining. Thus one goal of this handbook is to outline ways to improve the quality of future placer mining reclamation in stream environments.

In cases where placer mine activities involve the modification or reconstruction of stream environments, it is desirable to reclaim aquatic resources. However, effective restoration of aquatic resources, particularly in relatively pristine areas, is a highly specialized undertaking that requires planning and construction techniques that may be beyond operator or agency expertise. For example, many traditional approaches to aquatic habitat enhancement, such as the placement of in-channel log drop structures, gabions and jetties, may not actually benefit the resource (Hamilton 1989). Thus, this report outlines the steps required for fundamental channel reconstruction, focusing on techniques to preserve or create channel forms commonly associated with good aquatic habitat. These techniques will result in a channel that has a higher likelihood of forming and maintaining viable habitat over time than some highly engineered channels. It should be noted, however, that the creation of quality aquatic habitat involves many factors beyond channel reconstruction. Enhancement goals beyond those outlined in this report may warrant different or additional approaches.

There are few guidelines in the literature useful for the construction of stable, natural channels in placer mined mountainous environments. Consequently, channel designs and construction techniques presented in this report are based largely on the experience of Inter-Fluve, Inc., which has constructed miles of channels in a variety of environments. Channel construction in placer mined areas should be approached with full appreciation for factors complicating the creation of stable and biologically functional channels, including the occurrence of unusually large floods which can dramatically alter new channels.

\subsection{HANDBOOK ORGANIZATION}

The handbook is organized into the following sections.

1). Placer Mining and Reclamation In Montana. Briefly describes the historical and geographical background of placer mining in the state, identifies the number of currently active placer mines, and lists the state and federal agencies involved in mine administration and regulation. 
2). Planning For Stream Reclamation. Focuses on the critical need for stream reclamation planning prior to commencement of mining activities.

3). Necessary Pre-Mining Data For Effective Stream Reclamation. The most technical section, concerning specific data and methods of collection needed to generate an effective reclamation plan in undisturbed and previously disturbed basins or sites.

4). Using Field Data To Develop A Reclamation Plan. Describes how premining information is used in the generation of a reclamation plan.

5). Incorporation of Reclamation Actioities With Mining Operations. The concept of reclamation concurrent with mining is explored.

6). Reclamation Costs. Addresses economic costs associated with mining and subsequent reclamation of stream environments.

Additional information is included in appendixes to this document. In order to acquaint the reader with technical terms to which they may not be familiar, a glossary is included with this report as Appendix 1. For those unfamiliar with a mining and reclamation plan, Appendix 2 is an outline of the elements that are sometimes included in such a plan. Appendix 3 is a draft copy of the Board of Land Commissioners and Department of State Lands Small Miner Placer, Dredge and Cyanide Rules. State regulations (26.4.101 ARM) regarding reclamation of mined sites are presented in Appendix 4. Appendixes 5 and 6 outline mining regulations administered by the US Forest Service, while Appendix 7 outlines Bureau of Land Management reclamation standards. Appendix 8 is a legal document relating to resource agency regulatory interaction. Appendix 9 contains the Environmental Protection Agency's Gold Placer Mine Effluent Guidelines (40 CFR 440.140148). All appendixes are further described in the section State And Federal Oversight. 



\subsection{PLACER MINING AND RECLAMATION IN MONTANA}

\subsection{GEOGRAPHICAL AND HISTORICAL CONTEXT}

Most placer gold in Montana is derived from intrusive mineral accumulations that were subsequently concentrated by glacial and post-glacial fluvial activity. Placer gold in Montana typically occurs as nuggets, flakes, and dust associated with valley flats, terraces and related depositional areas (Phillips and Humphrey 1987).

Placer gold was first discovered in Montana in 1852 (Lyden 1948). Using sluices, dredges, tunneling methods (drifting) and hydraulics, a significant number of drainages in southwestern Montana were heavily mined during the "boom years" between 1852 and the 1885. A great deal of this placer activity occurred in Broadwater, Jefferson, Lewis and Clark, Meagher, Powell, Granite, Beaverhead, Silverbow, Mineral, Missoula and Madison Counties (Figure 1). Intermediate intensity placer mining continued in Montana until the 1940s (Phillips and Humphrey 1987) and also included Sanders, Ravalli, Phillips, Park, Missoula, Lincoln, Fergus, and Gallatin counties (Figure 1). Activity since the 1940's has been sporadic, rising and falling in conjunction with gold prices.

Much of the current placer activity in the state occurs in the same drainages that were historically mined (Figure 1). While some operations focus on reworking old dredge and sluice tailings, others exploit overlooked or previously inaccessible pockets of undisturbed fluvial deposits. Consequently, placer gold deposits in western Montana have been extensively worked and re-worked over the years.

Because historic mining was conducted with little concern for the environment, reclamation of mined sites generally did not occur. Most placered drainages display a "crazy quilt" type of surface topography that reflects different periods of mining activity. These surfaces are characterized by large dredge piles, over-steepened valley walls, and discontinuous streams that frequently pool behind dredge piles and braid over wide flats. Drainage morphology seldom reflects pristine conditions, and most channels are not in equilibrium with valley gradients. These areas are often in different stages of vegetative recovery, with opportunistic cottonwoods, alder and some coniters capitalizing on these disturbed conditions. Discontinuous recovery continues to be exacerbated by recent mining activity. Although the degree of ground disturbance attributable to recent placer operation is of lesser magnitude than historically placered areas, many of these sites have been mined without much regard to reclamation. 



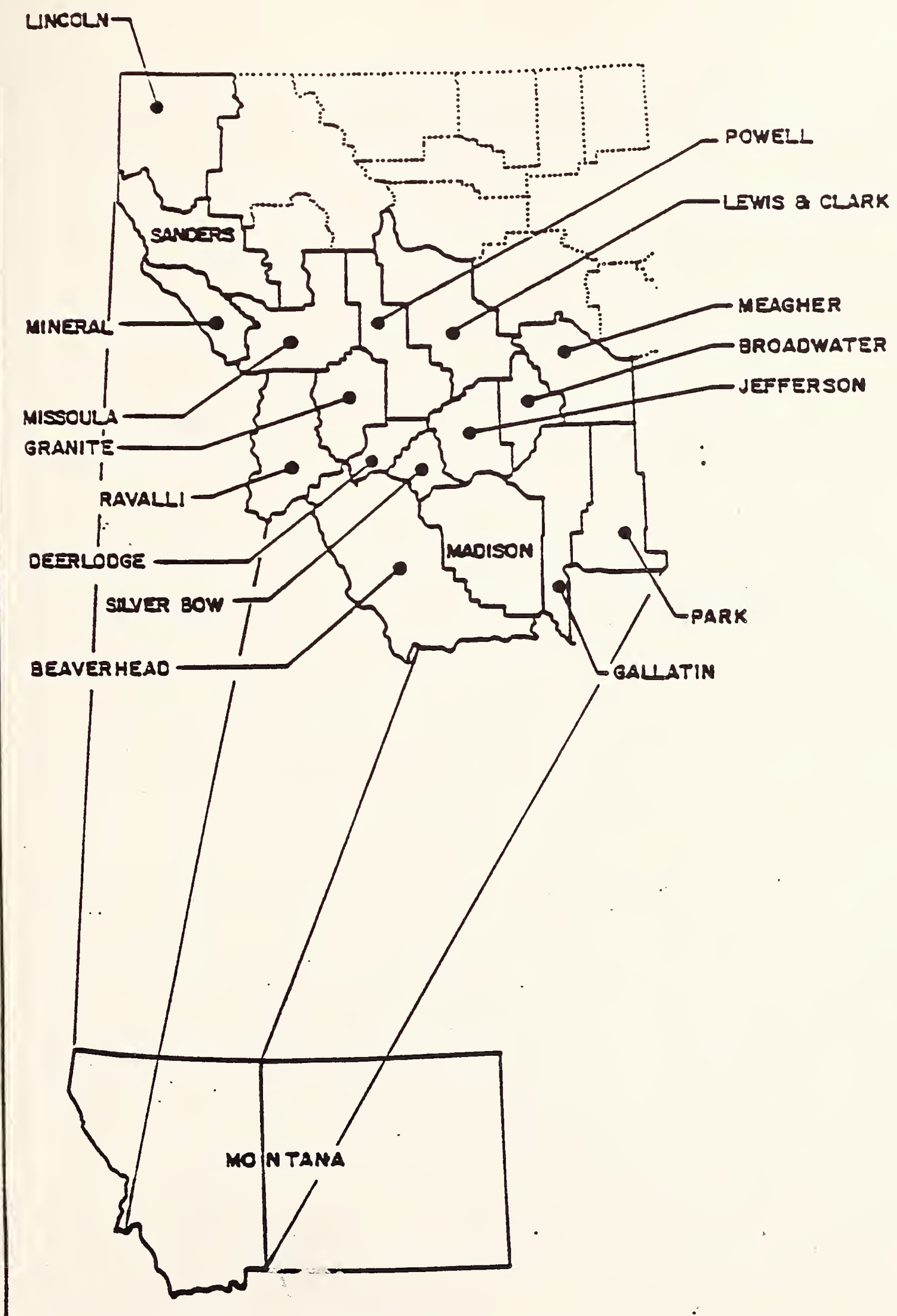

Figure 1. Historic and current areas of placer mine activities in western Montana. 

Estimates of currently active or soon to be active placer mines in the state of Montana vary widely. Montana Department of State Lands (DSL) estimates range from 200-300 sites (Rolfes, DSL, Helena, MT, pers. com. 1990). In contrast, another source reports only 12 active placer mines (McCulloch 1989). The discrepancy between these numbers can be attributed to differences in the definition of an active placer mine, the inclusion of placer mining hobbyists, active permits listed in DSL files, and currently active mines documented by site inspection. Because of the difficulties experienced in maintaining active permit files, including documenting active claims in the field and office, neither estimate may reflect the total number of active claims. This situation, when combined with the number of inactive claims that are in various stages of development, has produced considerable concern for placer mine reclamation in the state.

Increasing environmental awareness in the public sector, combined with agency mandates derived from federal and state laws including the National Environmental Policy Act (NEPA) (42 U.S.C. 4371, et seq.), the Montana Environmental Policy Act (MEPA). (Title 75, Chapter 1, MCA), Federal Clean Water Act and the Montana Water Quality Act have recently focused attention on the issues surrounding mine reclamation in general, and on some level, placer mine redamation. However, lack of information on placer mining activities in the state has restricted formulation of new policy directions or re-evaluation of current conditions. .

\subsection{STATE AND FEDERAL OVERSIGHT}

\subsubsection{Montana Department Of State Lands}

The Montana Department of State Lands is responsible for administrating placer mine activity on all lands except those administered by Native Americans. This work includes permitting and monitoring exploration and mining activities. Reclamation bonds are held for all operations that are not exempted by the Small Miner Exclusion Statement (SMES). This exclusion addresses mine operating requirements when proposed activity involves surface disturbances under 5 acres and excavation of less than 36,500 tons per year. Authority was granted to DSL by the 1989 legislature (82-4305(5), MCA) to hold reclamation bonds on new placer and dredge SMES, up to a maximum of $\$ 5,000$. DSI administers approximately 1,000 SMES (approximately one-third are vi cer mines) and 100 operating permits (Strazdas, Montana Departmenit of State Lands, Helena, MT, pers. com. 1991).

Unlike the permit process for mines outside of the SMES scope, which require the submission of a mining plan of operation and reclamation plans, miners operating under an SMES need not, though they are encouraged to, file a mining operation and reclamation plan. Small operators who file operating plans, which outline some proposed reclamation procedures, may 
be eligible for bonding less than the maximum allowable reclamation bond. Reclamation criteria for bonding less than the allowable amount are spelled out under the State Of Montana Placer, Dredge and Cyanide Rules (Appendix 3; revised rules in final review at time of report). Under the SMES, this maximum amount is $\$ 5,000$ (Montana Metal Mine Reclamation Act, 82-4305(3), MCA), which translates to $\$ 1,000$ per acre of surface disturbance for mine reclamation. In contrast, mines outside of SMES scope are required to provide DSL a preliminary environmental review and a mining and reclamation plan. They also are subject to higher bonding requirements on a per unit basis. The preliminary environmental.review information is then used for preparation of an Environmental Assessment, as required by MEPA and NEPA.

Under the new Placer, Dredge and Cyaride rules, the small miner in a new location (after July 1989) is obliged to reestablish functioning stream channels where channels have been disturbed, including the reconstruction of pools, meanders and comparable grade to the pre-mining condition. The state's interpretation of "pre-mining condition" is further defined in Rules and Regulations Governing the Montana Metal Mine Reclamation Act (26.4.106, ARM; see Appendix 4), which state that the land disturbed by development must be reclaimed to a condition and use status at least equivalent to the condition prior to mining. This condition is interpreted by DSL to mean the condition prior to any mining, whether recent or historic (Strazdas, Montana Department of State Lands, Helena, MT, pers. com. 1991). However, language in 82-4-301, MCA, indicates that complete restoration to original conditions may not always be possible.

\subsubsection{United States Forest Service}

The United States Forest Service (USFS) is empowered to regulate placer mines sited on National Forest lands of Montana through federal legislation including the Locatable Mineral Regulations (36 CFR 228 Sub-part A; see Appendix 5). Reclamation planning is generally required within a Plan of Operations (separate from but often similar to those required by DSL) if mechanized equipment is used. Information within these Plan(s) of Operations is used by the USFS in assuring compliance with federal law through NEPA, and to set bonding for reclamation (36 CFR 228.13). The USFS holds a number of reclamation bonds on small mining claims, because prior to the amended authority given to DSL, bonds were not held by the state. On mines becoming active after July of 1989, the USFS and DSL jointly caluulate reclamation bonding requirements and act in concert to release these bonds after joint inspection of the reclaimed site. Details of USFS and DSL interaction in these situations is outlined in a Memorandum of Understanding (MOU) dated December 11, 1989 (Appendix 6). Although either agency can hold bonds, only the USFS can hold bonds in excess of $\$ 5,000$. 
Regarding the reclamation of stream environments, 36 CFR 228.8 details protection requirements for water quality, fish and wildlife habitat, scenic values and general reclamation inclusive of the rehabilitation of fisheries, where "practicable." "Practicable" is undefined in the rules.

\subsubsection{Bureau Of Land Management}

The Bureau of Land Management (BLM) also administers public lands in Montana where placer activity occurs, and is required by federal law to ensure that miners perform "reasonable reclamation of surface disturbances . . . regardless of the level of operation" (43 CFR 3809.1-1; also see Appendix 7, BLM - Montana State Office Handbook H-3809-1, Chapter 7). A Memorandum of Understanding (MOU) dated May 1, 1981, between the BLM and DSL, outlines inter-agency permit review and administration of mines in operation prior to passage of 43 CFR 3809. However, for mines under 5 acres coming into operation after the passage of 43 CFR 3809, no MOU could be located from either DSL or BLM. As with mine operations on USFS lands, placer miners on BLM land are under the current bonding requirements as administered by DSL. Unlike placer mining on USFS lands, however, the BLM does not require written reclamation plans on mines smaller than 5 acres, though they do require a statement indicating the operator intends to reclaim the mine site according to BLM standards (Appendix 7). For proposed mines greater than 5 acres, a written reclamation plan is required along with a plan of operation.

Specific to the stream environment, 43 CFR 3809.2-2 indicates that all mining operations shall be conducted so no "undue degradation" of federal lands occurs, including degradation of water quality, fisheries, wildlife and fish habitat. Unnecessary or undue degradation is defined as limiting surface disturbances to what would occur normally as the result of a prudent operator in usual, customary, and proficient operations of similar character (3809.0-6). Reclamation requirements include the rehabilitation of fisheries and wildlife habitat (3809.1-4).

\subsubsection{County Conservation Districts}

Local cnur y Conservation Districts also have a regulatory role relating to some flacur mine activity in Montana. The Districts, with technical support provided by the Soil Conservation Service (SCS), are charged with regulating compliance with Montana's Natural Streambed and Land Preservation Act (310 Permit Program). This program regulates any activity that physically alters or modifies the bed or banks of a stream, including temporary diversions and final stream reclamation. In conjunction with a representative of Montana Department of Fish, Wildlife and Parks (FWP) and a local landowner, a District Supervisor can make recommendations to 
district board of supervisors which require a mine operator to comply with certain standards regarding stream manipulation. Issues of compliance with permit stipulations are handled by district county attorneys. These standards are designed to minimize erosion and sedimentation, maintain water quality and stream integrity, protect viable fisheries habitat, and prevent damage to adjacent property. As a public service, the Montana Association of Conservation Districts has a pamphlet available which details the various permits other than and including the 310 which may be necessary for stream related manipulations.

Conservation Districts also may require and hold stream reclamation bonds under authority granted by Montana's Natural Streambed and Land Preservation Act. To do so, individual Conservation Districts must first amend their Model Rules and Minimum Standards, provided by the Montana Department of Natural Resources and Conservation (DNRC). At the time of this report, such amendments have only been completed by Conservation Districts in Jefferson, Broadwater, Ruby Valley, Beaverhead, Missoula, North Powell and Meagher counties. There is no ceiling imposed on the amount of the maximum allowable bond. However, a DNRC legal council memorandum dated March 21, 1984 (Appendix 8), suggested that bonds be "conditioned upon the proper reclamation of the stream bed and (emphasis added) land involved in the project and conformance with any conditions in the 310 Permit."

\subsubsection{Montana Department Of Health And Environmental Services}

The Montana Department of Health and Environmental Sciences, Water Quality Bureau (DHES-WQB), also has some oversight on placer mine operations relevant to water quality. They administer the Montana Pollutant Discharge Elimination System (MPDES) permit program under authority of Section 75-5-101 et seq., MCA, ARM 16.20.901 et seq. and ARM 16.20.601 et seq. The MPDES program establishes effluent limitations for settling pond discharges and specifies best management practices (BMPs) for placer mining operations. Compliance monitoring periods usually include periods of mining, though an MPDES permit may be required for certain stream reclamation procedures.

The DHES-WQB also ensures compliance with Montana Water Quality Standards (WQS), under authority specified in ARM 16.20.6 and 16.20.7. Water quality stancards identify beneficial uses and specify the quality criteria necessary to protect those uses. Compliance includes obtaining DHES-WQB authorizations (i.e., 3[a] authorizations) for short-term exceedance of instream turbidity standards. In addition, the DHES-WQB is charged with enforcing the Montana Water Quality Act, MCA Title 75, Chapter 5, which specifies that wastes should not be placed where they can cause pollution of state waters. The DHES-WQB has prepared a Statewide Non-Point Source Pollution 
Management Plan which specifies Best Management Plans (BMP's) for placer mining and educational activities to assist in implementing BMP's. Although this management effort is in its initial stages, the DHES-WQB maintains a staff specialist to work as liaison with DSL on mining water quality issues.

\subsubsection{United States Environmental Protection Agency}

The U.S. Environmental Protection Agency (EPA) administers several federal environmental laws including the Federal Clean Water Act (CWA). Section 402 of the CWA provides for a permitting program regulating pollutant discharges to waters of the United States. This National Pollutant Discharge Elimination System (NPDES), is delegated in Montana to the DHES-WQB, and is operated by DHES-WQB as the MPDES program. National effluent guidelines for gold placer mines have been published by the EPA (see Appendix 9). Section 303 of the CWA provides for EPA oversight and approval of State Water Quality Standards. Montana placer mining activities need to comply with Montana WQS. Montana WQS are reviewed every three years for national consistency by the EPA.

Section 404 of the CWA provides for a permitting program to regulate discharges of dredged or fill material into the waters of the United States. The U.S. Army Corps of Engineers (COE) administers the dredge and fill or 404 permit program, and the EPA has published environmental criteria used by the COE for permit review. The EPA also comments to the COE on individual 404 permits, and has dual enforcement authority with the COE for unauthorized discharges. Placer mines may need to obtain 404 permits or authorizations if discharges of dredged or fill material are proposed to be placed in waters of the United States. Section 319 of the CWA provides for states to prepare programs to manage non-point sources of pollution, and EPA funds are provided to the DHES-WQB for this purpose. The WQB proposes educational efforts to address non-point source pollution associated with placer mining. Finally, under NEPA, the EPA reviews and comments on environmental impact documents prepared for major mining activities on federal land.

\subsubsection{Montana Bureau Of Mines And Geology}

The Montana Bureau of Mines and Geology has one full-time staff field agent, who is actively involved with placer activity from mine entry to closure. Where requested, this agent attempts. to facilitate placer miner's interactions with the various regulatory and resource agencies, and provides technical support in the field, including the generation of viable mining and reclamation plans. 



\subsection{PLANNING FOR STREAM RECLAMATION}

Though formal submission of a viable mining and reclamation plan of operations is not necessary on some lands and mines falling under the SMES, planning mine operations is an integral component of stream reclamation planning. Planning for reclamation prior to the commencement of mining is critical to the success of stream and general reclamation endeavors. This statement is true whether the proposed mine is less than one acre or tens of acres in size, and is especially so when alterations to flowing waters are anticipated. Of course, the larger the proposed mine and consequent stream and surface disturbance, the greater the need for effective planning.

It is worth reiterating that the goal of reclamation, as outlined in this handbook, is to promote and accelerate the natural succession of aquatic and related terrestrial environments affected by placer mining activities. Though reclamation of the stream environment receives the greatest attention herein, it is essential for those performing stream reclamation to understand that successful reclamation is often contingent upon planning for stabilization of the surrounding uplands, valley bottoms, and floodplains. Indeed, many water quality problems related to placer mining which come to the attention of state and federal regulators are directly related to deposition of sediment in the aquatic environment resulting from erosion in upland areas. This deposition includes the mobilization of sediments from ephemeral channels during run-off or during precipitation events. Farsighted miners recognize potential sources of erosion and sediment, and plan ahead for their stabilization.

The technical aspects of generating a workable and reasonable placer mining reclamation plan are addressed in following sections. However, there are several other elements of reclamation planning which also need to be considered. With respect to aquatic environments, the most important element concerns the definition of desirable or appropriate stream reclamation. In light of the ambiguity inherent in many of the regulatory rules relating to stream reclamation as discussed in Section 3.2, it is the authors' opinion that the standards for stream reclamation at a given site should be defined by the reclamation plan submitted for that site. Further, the generation of a reclamation plan should be the product of interaction between all bodies of oversight and the mine operator. Using this approach, unambiguous and specific reclamation focus areas, techniques, and goals, are identified prior to mine entry, and therefore serve as the benchmark for measuring reclamation success.

Another important element of reclamation planning concerns the ability of a mine operator or bond holder to actually implement the reclamation plan. In 
some cases, reclamation needs are juxtaposed with reclamation finances, operator efficiency, and available equipment. Formulating and implementing reclamation plans can be accomplished with adequate resource agency expertise and supervision. In fact, if solicited, many agencies must assist with reclamation plans. However, agencies don't always have the number of personnel required to address diverse concerns, such as watershed function, hydraulics, geomorphology, geology, botany and the limitations of heavy equipment. Few individuals possess all the expertise needed to generate a workable and effective mining operation and reclamation plan. More commonly, the combined resources of the miner and various regulatory and management agencies are required.

In the sections that follow, a step-by-step approach to reclamation planning and implementation is presented. The steps are intended to restore a placer mined drainage to a condition acceptable to. reclamation professionals. Because each mine site is unique, applicable elements may be excerpted by the resource agency or miner to fulfill particular reclamation needs. 


\subsection{PRE-MINING DATA NECESSARY FOR EFFECTIVE STREAM RECLAMATION}

\subsection{INTRODUCTION}

For the purposes of this report, the recovery of productive aquatic resources is assumed to be the principal goal and standard for reclamation. Although the scope of information recommended for effective reclamation is broad, it cannot reasonably encompass all the factors relevant to watershed function. Consequently, the foundation for data collection is provided by wellestablished principles. For example, reclamation plans must reflect the concept that the surface expression of water is related to overall drainage morphology and stability, to the seasonal water-table and to the vegetative communities they support. In other words, natural processes are the ultimate independent variable in reclamation work.

In this section, an effort has been made to outline only the most timely, costeffective and practical data required. Each aspect required for any reclamation plan is delineated by an italicized header. Information under other headers is provided to establish the framework for more intensive reclamation projects.

\subsection{ASSESSMENT OF CHANNEL AND FLOODPLAIN CONDITION FOR PRIOR DISTURBANCE}

Disturbance, in this context, refers to previous mining activity where little or no reclamation was undertaken. Differentiating previously disturbed sites from undisturbed sites is important prior to new mining entry, because strategies for reclamation planning and implementation will differ accordingly. An evaluation of prior disturbance is also essential for all placer mining reclamation plans.

Information gathered in this context is used to formally establish "prior conditions." This assessment is used to define the need to improve an existing and environmentally unsound condition or to document pristine conditions which reclamation activities will attempt to re-establish. Clarification prior to mining entry provides an unambiguous means of setting reclamation goals.

\subsubsection{Recognition Of Undisturbed Sites}

Recognizing the characteristics of an undisturbed site is relatively straightforward, because pristine conditions are widely recognized on an intuitive level. For practical purposes, the final identification of an undisturbed channel is subjectively based, as there are no accepted quantitative criteria in 
this area (but see Leopold and Marchand 1968; Leopold 1969). This subjectivity need not complicate or de-value the assessment of site conditions, as long as observations are made jointly by resource agency personnel and the miner.

Key indicators of undisturbed sites include: 1) natural appearance with wellvegetated stream banks; 2) well-established riparian vegetation, from forbes and shrubs to a layered canopy; 3) floodplain elevations in vertical and horizontal equilibrium with seasonal high flows (channels in equilibrium with their flow regime normally carry the annual flood within their banks); 4) well-sorted, rounded bed material; and 5) the sequential occurrence of major bedforms (see Keller 1972).

\subsubsection{Recognition Of Disturbed Sites}

Physical evidence of historic mining entry is often obvious because reclamation seldom occurred. Common channel indicators include unusually straight reaches separated by braided reaches and severely incised streams. Because placer mining activities often included re-routing or diverting streams from one side of the valley to another, the presence of abandoned and historic channels is also common. Oddly sorted, unsorted, or inappropriately sized bed material provides additional evidence of unreclaimed placering; for example, the presence of fractured bedrock in low gradient stream areas, or large volumes of small, easily transported material in high gradient stream areas.

Many historically placered drainages also reflect discontinuous expressions of surface water. Excavation of overburden and placer deposits disrupts aquifers, increases the porosity and permeability of valley sediments and causes streams to "sub" or lose surface expression. Porosity refers to the percentage of pore space in a given mixture, and is a function of the uniformity of particle sizes and shapes, and the degree of particle packing. The more loosely packed and random the mixture, the greater the pore space. A mixture composed of a narrow range of material, such as coarse gravel, is more porous than a mixture composed of a wide range of material. In theory, porosity is independent of size, but because of the influence of packing and particle orientation, fine grained sediments are usually more porous than coarse grained sediments.

Permeability refers to the ease of fluid flow throw the material, and urilike porosity, is strongly influenced by particle size. For example, coarse gravels have large openings between particles, affording easy fluid passage. As particles become smaller, the pores also become smaller, increasing the resistance to fluid flow. Furthermore, mixtures tend to be less permeable than uniform sediments, because the finer particles occupy the voids between the larger particles. 
Many placered drainages currently classified as dry or intermittent probably had perennial streams flowing in them prior to disturbance. Abandoned trenches or settling ponds that intercept sub-surface flow, and thereby contain standing water year-round, are clear indicators of this condition. Other obvious indicators of prior placer mining entry at a site include the presence of dredge spoil piles, stacks of hand-sorted rock adjacent to channels from historic sluice operations, and abandoned mining equipment.

Drainages that were hydraulically mined often have vertical scarp faces on valley walls or valley floors separated from hillslopes by steeply excavated headwalls. The abrupt changes in topography created by this procedure are associated with striking changes in localized stream behavior (James 1990). The most common evidence in western Montana includes the occurrence of knickpoints (distinct changes in channel profile) and localized erosion and deposition and concomitant changes in channel pattern (avulsions, braiding, incision, etc.). Where placer mine reclamation included some surficial grading of spoils, valley topography often appears unusually flat or geometric.

Given enough time, channels gradually adjust to disturbed conditions ( $Y u$ and Wolman 1987). Not surprisingly, western Montana drainages that were placer mined over 130 years ago have begun to develop a more natural appearance. Certain shrubs and trees, most notably willow, cottonwood, alder and a few pines, favor disturbed ground and can exhibit rapid growth. Consequently, there are many sites in transition between initial disturbance and some form of recovery. These transitional sites are usually dealt with on a case-by-case basis, but clues can be found through simple vegetative and floodplain detective work (Wolman and Eiler 1955; Sigafoos 1964). For example, while undisturbed drainages exhibit diverse vegetative communities, transitional drainages tend to be characterized by an overabundance of a few plant species.

\subsection{METHODS OF DATA COLLECTION FOR UNDISTURBED SITES}

\subsubsection{Introduction}

There may be a tendency among some miners to overlook various aspects of data collection because of the time and resources required, and to exchange experience for proper planning. The creativ. of adequate reclamation plans is largely based on the quantification of ground conditions. While much of the following data must be collected, some may already exist and can be obtained from resource agencies.

An underlying assumption of this report is that placer mine activities will involve the relocation, diversion, and eventual reclamation of a flowing stream. These activities have often been conducted with little forethought or 
knowledge of river behavior. Rivers are complex open systems responding to a host of geologic, geomorphic and climatic inputs (Chorley 1962). Consequently, reclamation may require years of natural adjustments and overall site regeneration before initial goals are realized. Therefore, it is unwise to short-cut data collection efforts needed to facilitate the reclamation process.

\subsubsection{Basic Background Research Needs}

\subsubsection{PLAN MAP OF STTE}

Maps are highly effective at presenting and transferring information, and can provide a clear focus for the reclamation planning document. As such, an accurate plan map of the proposed mine site is absolutely necessary. The scale of this map should be large enough to permit identification of individual features, such as proposed spoil and topsoil storage areas, access roads and settling pond locations. This plan map is best derived from an aerial photo with a scale of 1:6,000 or better, so that enlargements with a ground scale of 1 inch equal to 100 feet can be produced. Many agencies have aerial photos which can be enlarged to appropriate scales. For sites without aerial coverage, the services of professional aerial photographers, which are located in major Montana cities, may be required. Oblique aerial photos are not suitable because distortion prevents accurate measurements.

At smaller mine sites, an aerial photograph may not be necessary for the development of a plan map. Alternatives to the above include plane table surveys, level transits, and compass and tape traverses. In fact, the level of detail obtainable from these mapping procedures can often exceed that of aerial based plan maps. Selective use of these techniques with aerial based maps can result in maps with excellent topographic detail.

\subsubsection{HYDROLOGIC INFORMATION}

Collection of basic hydrologic information is another critical element of placer mine reclamation. Effective planning and implementation depends on obtaining some idea of the actual or potential. streamflow in a drainage. Because many drainages are ungaged, i.e., no discharge records are kept, it is often necessary to estimate the flow regime for a given stream. If a stream is gaged, this information will be available from local resource agency offices including the USFS, BLM, SCS and the U.S. Geological Survey (USGS).

Before formal estimations of potential discharges are compiled, it is worthwhile to compile qualitative discharge information. This can be accomplished by a combination of ground reconnaissance and interaction with those intimately familiar with the area, such as local residents and other miners. Attempts should be made to gather information on both the 
magnitude, seasonality, and frequency of observed discharges. On the ground, cursory surveys of flood debris, noting location near or in channel, and the debris elevation, can provide valuable clues to a basin's discharge regime.

Where stream flow records are unavailable, it is necessary to estimate the flows which might occur. In engineering, an estimate of large floods, such as the 100-year flood event or the Probable Maximum Flood, is often required (Linsley et al., 1982). However, because floods of these magnitudes are generally catastrophic to existing channel morphology (Costa 1974; Lisle 1981), planning for events of this size is unrealistic. Instead, discharge events with return intervals of one, two, five, ten and twenty-five years are most useful for diversions or final channel reconstruction.

Several relatively simple methods yield acceptable results for the estimation of potential discharges. In fact, other methods that require extensive data collection do not guarantee better predictive capability. In addition, runoff simulation models, which typically attempt to establish a relationship between rainfall frequency and runoff, can be difficult to use (c.f. SCS 1972). Similarly, overly simplistic techniques can deliver questionable estimates. An example of such a basic method is the Rational Runoff Method (Dunne and Leopold 1978), which attempts to relate storm runoff to rainfall intensity frequencies, basin area, and a somewhat arbitrary runoff coefficient.

A preferred method for potential discharge estimation, based upon relatively simple statistical methods, concerns the use of regionally based regression equations. These equations require only simple data and calculations and are generally competent. Information required for the use of these equations includes drainage basin area, mean annual precipitation, and sometimes a geographic correction factor. These equations have been developed for all geographic regions of Montana by the USGS, and are presented in readily useable form (Omang et al. 1983). Alternatively, regression equations for estimation of peak discharges in Montana have also been developed which rely solely upon bankfull channel widths (Parrett et al. 1987).

\subsubsection{GENERAL CHANNEL AND BIOLOGICAL INFORMATION}

Many resource agencies already have general information on file for a number of drair.ages. This data base includes evaluaitions of general channel stability, occasisiai discharge measurements, norspoint sources of pollution, and habitat surveys. If the proposed mine site is on public property, or once was public property (such as recently patented mining claims), the agency(s) involved with their administration should be consulted regarding available stream information. 
Reclamation planning may entail the protection or enhancement of critical or important wildlife habitat in or related to the aquatic environment. Most local resource agencies will have wildlife resource specialists who can highlight the need for any special reclamation needs and concerns. Beyond the local land management agency, FWP is also a good source for information relating to fisheries, waterfowl, small mammals, and big game.

\subsubsection{Field Data}

The collection of specific data is often overlooked in reclamation plans, particularly those involving small mine sites. The failure to approach small mine sites with the same rigorous planning often required for large mine sites is ultimately short-sighted, as a series of poorly reclaimed small mines in a basin can be more disruptive to the watershed than one poorly reclaimed large mine site. Though some of the following techniques seem involved, many do not approach the technical rigidity necessary for normal scientific study of stream environments.

\subsubsection{DETERMINATION OF VALLEY SLOPE AND CHANNEL GRADE}

Determination of valley slope and channel grade is necessary for all reclamation plans. For a proposed mine site of a few acres or more, average channel grade can be determined by running a longitudinal level circuit. This work also should establish elevations at a minimum interval of 200 feet or at major grade breaks. Endpoints should be a minimum of 100 feet above and below the mine area boundaries. Although less detailed, valley slope also can be determined from the contours on 7.5 minute series topographic maps. For eventual channel reconstruction, this calculated slope serves as a guideline for rough site grading and establishes a benchmark for channel grade. For smaller mine sites, determining valley slope from topographic maps is not practical or desired. It is therefore necessary to make this determination in the field with a hand-held level or tripod mounted level and leveling rod. In both cases, determination of discrete slope segments and the plotting of a longitudinal profile is preferable to a single estimate.

\subsubsection{EVALUATION OF CHANNEL PLANFORM}

\subsection{Typical Channel Patterns In Montana}

Channel patterns describe the two-din enwional expression a water course has etched on the landscape. These patterns are a function of fluvial processes acting upon the local geology and topography, and can be classified into three basic categories: sinuous, meandering and braided (Wolman and Leopold 1957). 
Channels flowing through narrow, mountainous valleys tend to exhibit slightly sinuous to sinuous patterns. These patterns are associated with moderate to high gradient valleys and by the presence of strong geomorphic controls, such as numerous bedrock outcrops and proximal valley walls. Erosive energy is primarily focused on the bed, with little tendency for lateral erosion or significant channel migration.

More sinuous and meandering patterns are sometimes noted within mountain valleys or valley segments dominated by broad expanses of alluvial deposits. In these areas, geologic controls have created an increase in valley width, which in turn, have functioned as sediment storage areas or depositional zones. These streams flow on lesser slopes, distribute energy more evenly over bed and banks and commonly migrate laterally.

Braided patterns, which are characterized by numerous small streams divided by discontinuous sand and gravel bars, are generally less typical of placer environments in Montana. Where present, this pattern tends to result from sediment loads that are too large to be carried in a single channel.

\subsection{Measurement Of Planform Elements}

\section{Sinuosity}

Measurement of channel sinuosity is most important in areas where sinuous or meandering patterns exist, because it relates to the determination of channel gradient. Shortening or lengthening the channel in a given area during reclamation will affect the sediment transport regime and alter the channel's rate of energy expenditure.

Sinuosity is measured by taking the ratio of stream length to straight-line valley length, or within the context of placer mining, the ratio of stream length to the length of the mine claim, measured in a down-valley direction (Figure 2a). While a sinuosity index of 1.0 describes a perfectly straight channel, values in the range of 4 or 5 describe tortuously meandering channels. In most mountain stream environments in Montana, meander indexes fall in the range of 1.1 to 2.0. Figure $2 \mathrm{~b}$ depicts channel planviews and corresponding sinuosity indexes for channel forms most likely encountered in mountain environments. At mine sites where large sections of stream will be disturbed, channel sinuosity should be measured in discrete reaches, representative of different valley slopes, widths, and overall topography. It is suggested that these reaches be at least 20 bankfull channel widths in length (Platts et al. 1983). In areas where only short sections of stream will be disturbed, a single sinuosity index may be appropriate. 



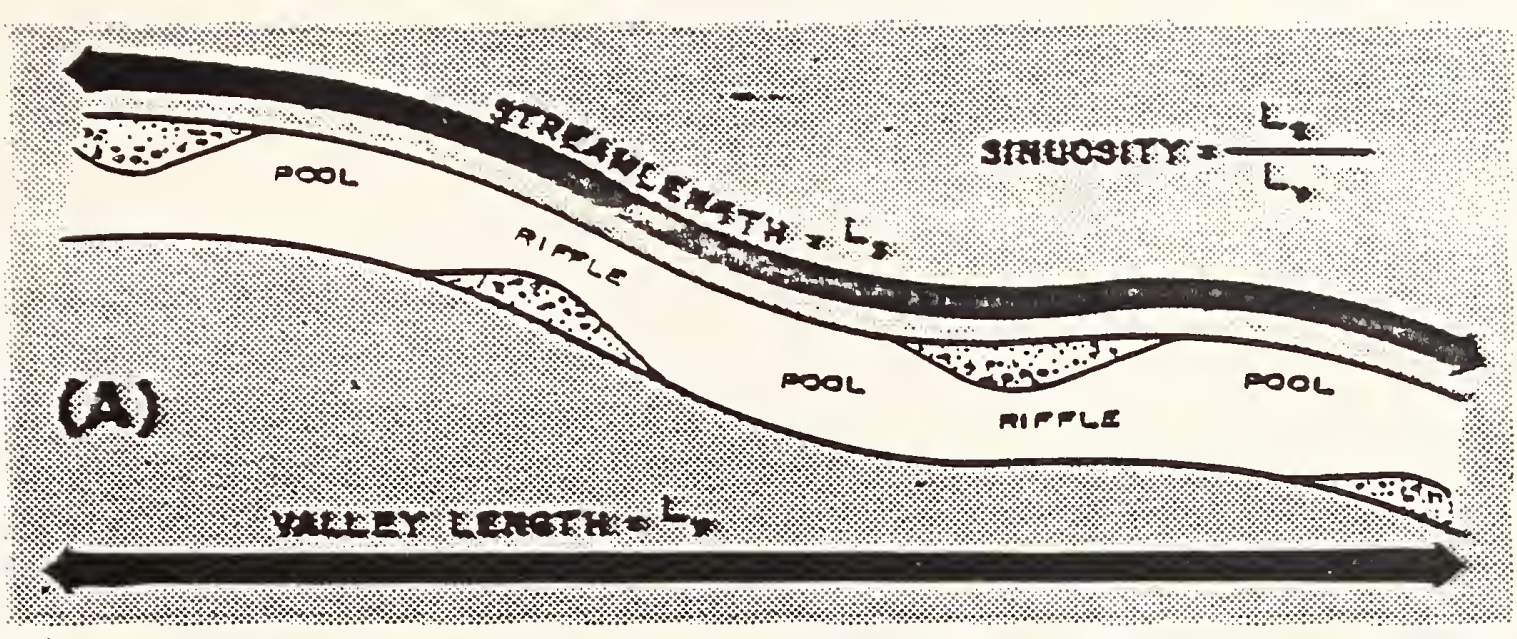

(B)

SINUOSITY 1.05

SINUOSITY 1.10

$$
\text { : }
$$

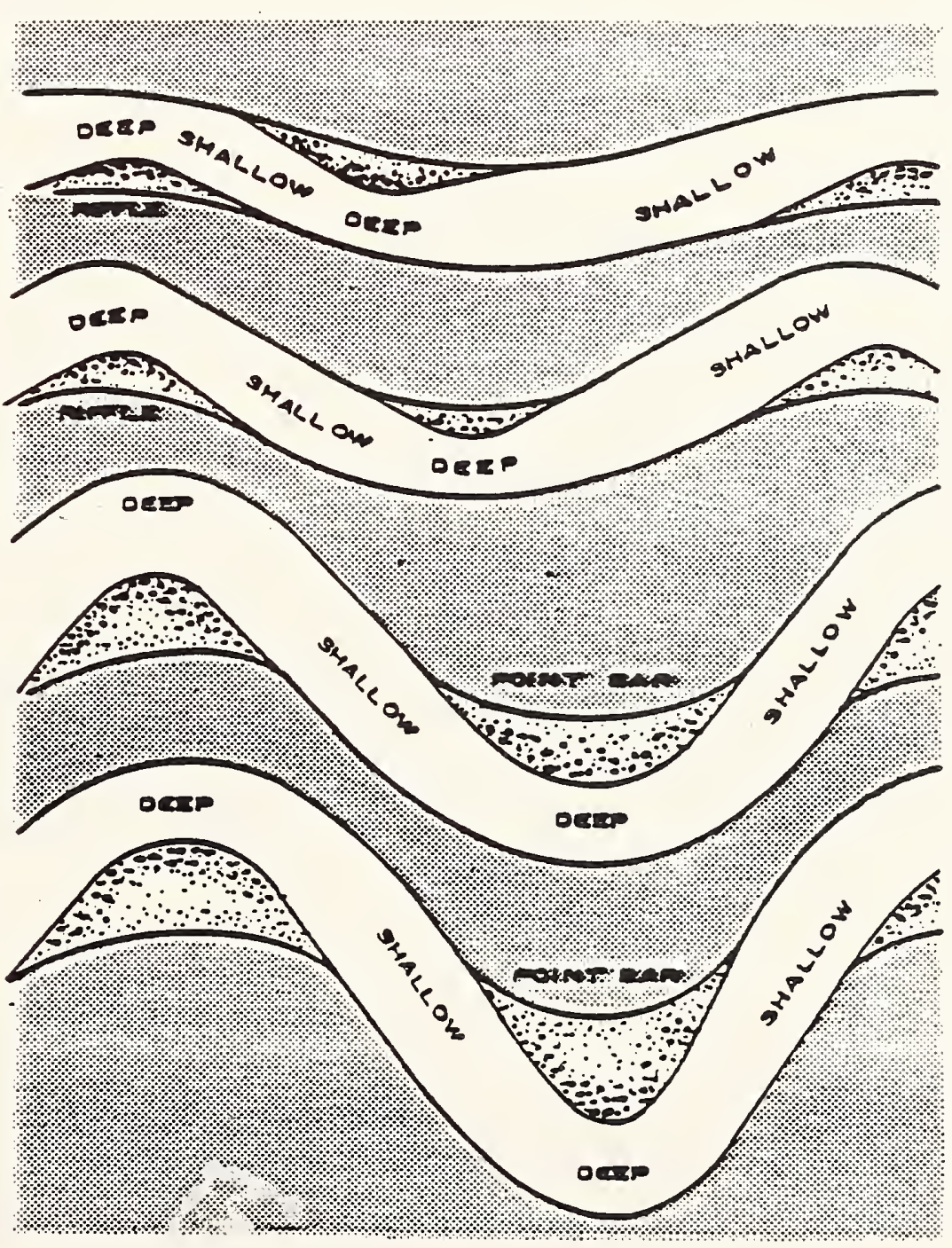

Figure 2. (a) Calculation of stream sinuosity and (b) channel planview illustration tor a range of sinuosity indexes most frequently encountered in mountain stream environments (modified from from Dunne and Leopold 1978). 

There are several qualitative and quantitative methods to describe the rounded curves and often repetitive and uniform shapes of channel bends within a given stream reach. These bends are often referred to as meanders. By convention, a stream is said to meander when its sinuosity index exceeds 1.5 (Knighton 1984), though this reference point is somewhat arbitrary, as over a given reach a channel may vary from almost straight to very looping (Dunne and Leopold 1978). Qualitatively, meanders may appear irregular, regular, confined, or tortuous (Figure 3), and in an area where meandering occurs, this qualification should be made in the field. Where meandering does not occur, quantification of sinuosity is not critical. Methods to quantify meander form include field measurement of radius of curvature, meander amplitude, meander wavelength, meander arc length, and meander width. For practical purposes, only measurement of meander wave length, amplitude, and meander arc length will be discussed here.

In representative reaches, meander wavelength, which is the straight-line distance between the apex of adjacent bends (Figure 4), should be measured at several locations within the reach. For future stream reconstruction, these values will indicate acceptable ranges of bend spacing. For each meander wavelength, the amplitude should be recorded by measuring the straight-line perpendicular distance from the apex of the outside bend to the inside apex of the next point of inflection (Figure 4). Finally, the meander arc length (Figure 4), defined as the channel distance between two points of inflection, should be measured on the ground by walking a measuring tape around a specific meander and recording the total length. For planning purposes, it is not necessary to measure every meander arc length. As in the case of sinuosity measurements, data need only to be collected in representative reaches. In conjunction with the information on meander wavelength, the latter two measurements help define general guidelines for meander reconstruction.

\subsection{Valley Cross-Section}

In mine areas where hillslopes will be worked, it is also important to document existing topographic features, such as valley width. This work normally involves surveying valley cross-sections, documenting significant breaks in slope such as those on hillslopes, floodplain terraces, old meander scars, channel banks and channel bottoms (see below for channel ge urn..t-y considerations). The number of cross-sections necessary for charactcrization of valley topography varies with the size of the site and significant changes in valley width. 



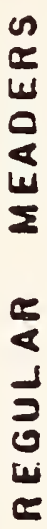

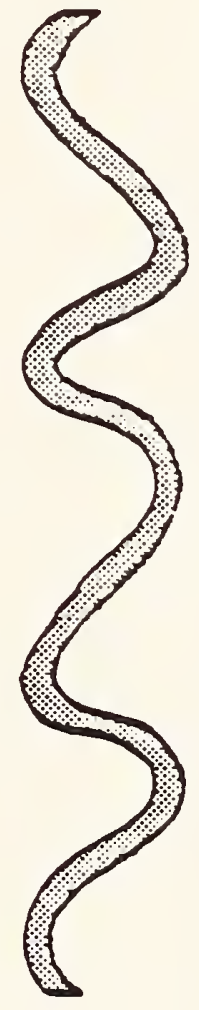

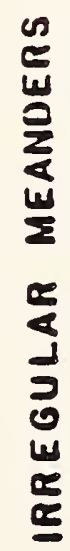

2
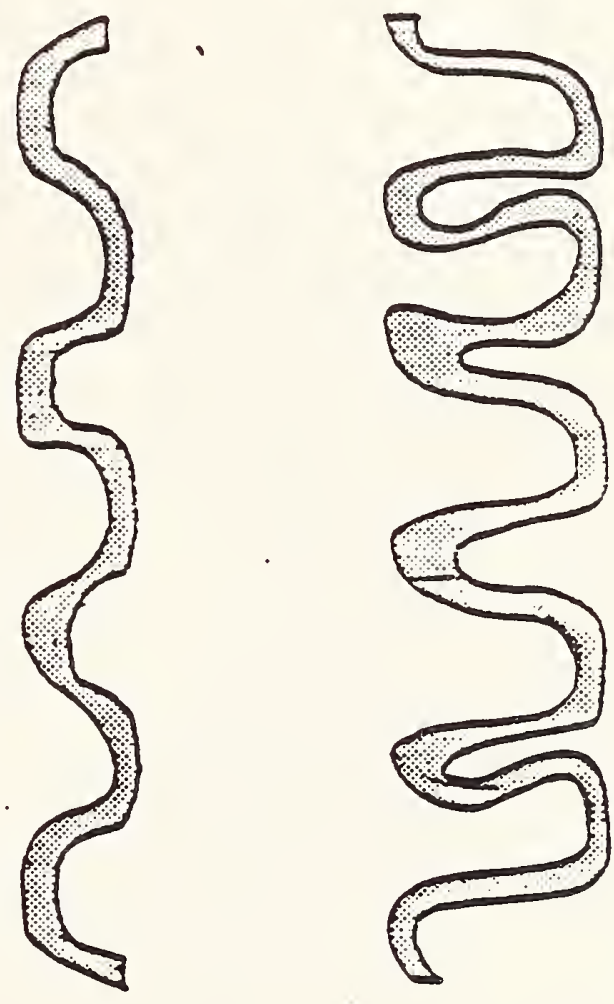

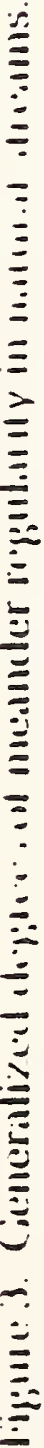

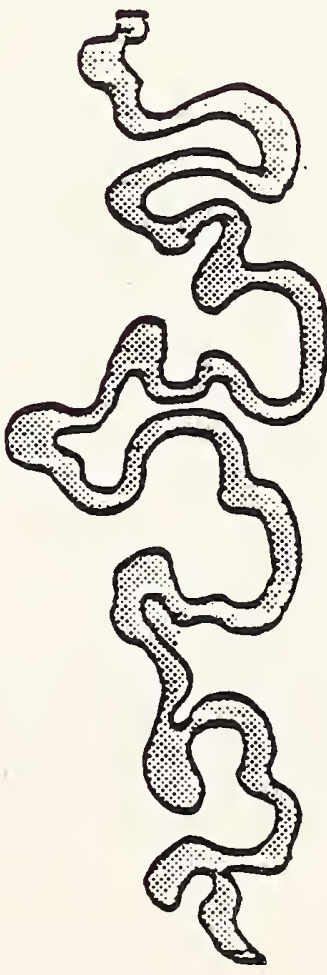




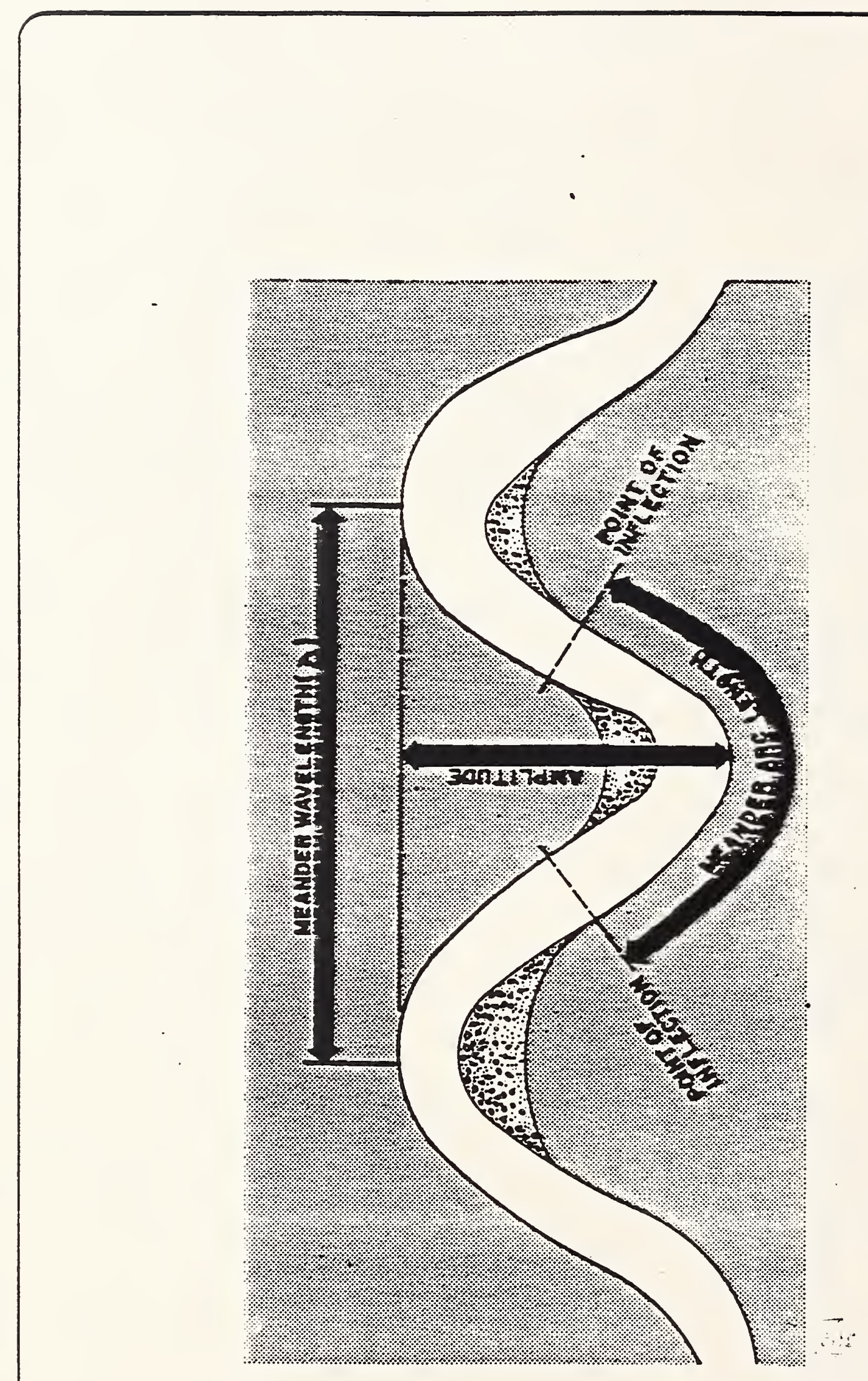

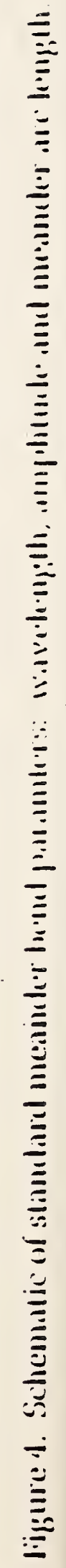




\subsection{Channel Geometry}

Channel geometry refers to the physical shape of the bankfull channel and is most simply defined by channel cross-sections and longitudinal descriptions of channel forms such as pools and riffles. Channel geometry is a function of fluvial processes and reflects the capacity of the existing channel to carry flood flows. Measurement is essential for all stream reconstruction activities because it facilitates eventual channel reconstruction designs.

In the representative reaches defined above, a number of channel crosssections should be measured because natural channel dimensions can vary widely, even in a given reach. Selection of channel locations with representative cross-sections is based on observed geomorphic trends. For example, the deepest part of a sinuous reach follows concave banks, maximum depth is found at the point of greatest curvature, bars develop on the convex bend and the greatest width of these bars is downstream of the point of greatest curvature (Gregory and Walling 1973). Additionally, bed elevations rise and fall in a systematic manner, giving rise to recognizable pool-riffle sequences (Dunne and Leopold 1978). These features are shown in Figure 5.

\section{Measurement -Methods}

In a given reach, representative channel cross-sections should be measured in both riffles and pools. Because the size of the stream and area of disturbance will vary from site to site, there is no definitive minimum number of crosssections necessary for reclamation planning. The number and location of appropriate measurements must be subjectively determined in the field based on natural stream variability. The measurement techniques for either pool or riffle cross-sections are the same (Platts et al. 1987).

Riffles are defined as areas of relatively fast, shallow water flowing over convex beds of comparatively steep gradient (Figure 5). Because riffles are high energy environments, silts and sands are seldom visible. Pools are defined as areas of greater water depth and lower velocity flowing over concave beds of low gradient (Figure 5). These areas are often characterized by the presence of finer bed mbstrates. For practical purposes, these delineations are best made during r,eriod; of low flow when bed features become more prominent.

Once a representative site as been located, the point where water can overflow each bank should be visually determined. Between these two endpoints, a tape (ideally a steel tape under tension, though a cloth tape stretched to eliminate sag is serviceable) should be stretched across the channel. Starting at the left bank (by convention, relative to an observer facing downstream), 


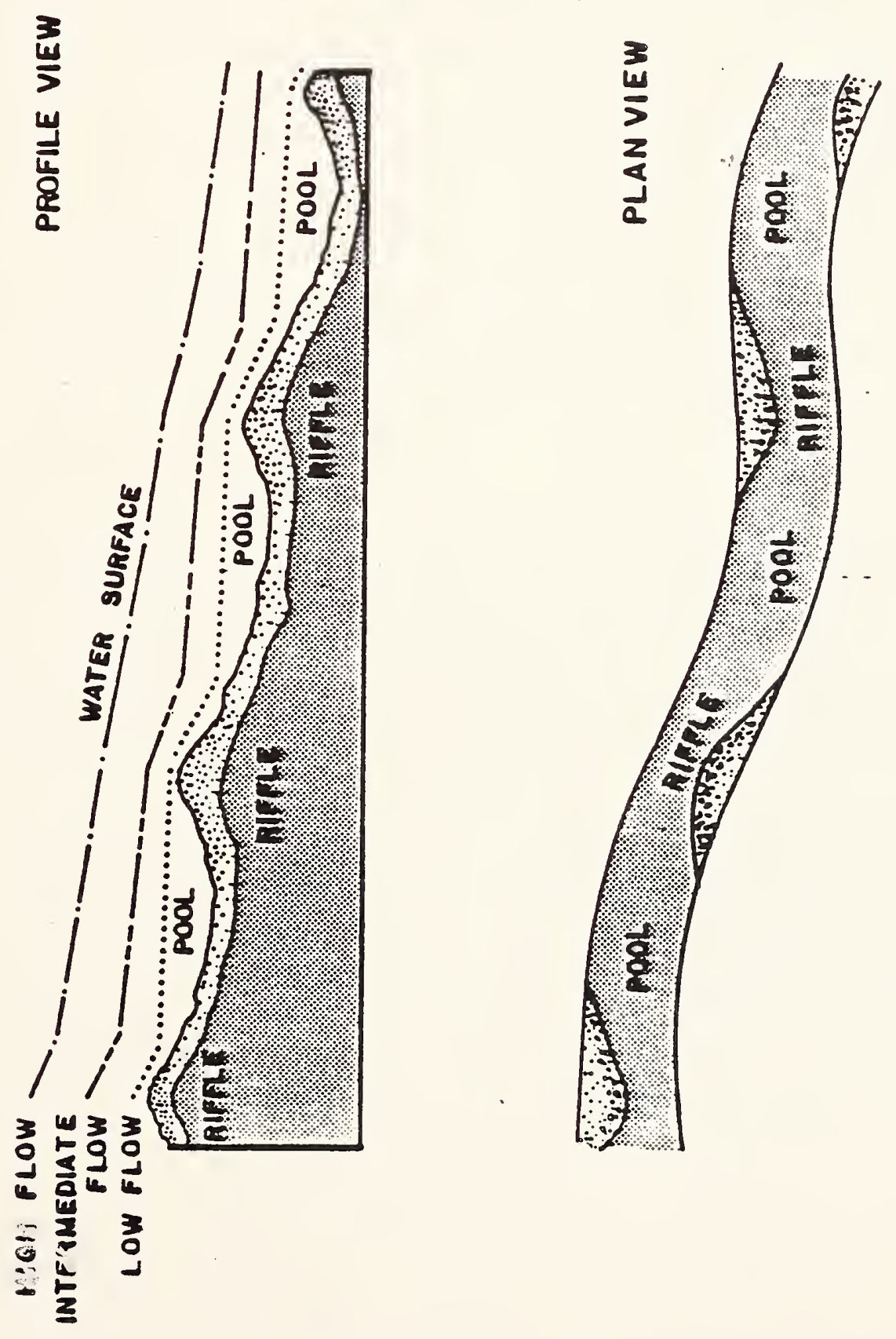

the perpendicular distance between the tape and the channel bed is measured at increments appropriate to the channel width and recorded. For this measurement, a survey rod is held perpendicular to the tape and the depth recorded by a downstream observer. While this less sophisticated approach is acceptable, these recordings are best taken as part of a level survey using a engineers level and rod.

In small streams, a minimum of six measurements should be taken, exclusive of the endpoints where channel depth equals zero. These points should establish the top of banks, edge of water and maximum depth of channel (Figure 6). For larger streams, the number of points necessary to establish breaks in cross-sectional channel elevation should be recorded.

The large variation inherent in pools often necessitates up to three crosssectional measurements at a single location. These measurements should be taken at the entrance to the pool, through the deepest part of the pool, and at the pool exit or tail-out (Figure 7). In contrast, riffles exhibit less variation and may therefore require less intensive measurement.

\section{Pool-Riffle Sequences}

Establishing baseline information on the spacing of pools and riffles is important to reclamation planning because these features are closely related to sediment transport regimes, channel stability and aquatic habitat. Delineation of pool-riffle sequences in the field can be complicated by the fact that on most natural streams, no sudden breaks are apparent between these two features (Platts et al. 1983).

To estimate pool-riffle spacing, or sequences, evaluations should be made in the representative stream reaches. Starting at the bottom of a given reach designated with a linear distance of $0+00$ feet (by convention, stream stationing starts downstream and progresses upwards). The distance of each pool and riffle is then recorded. For example, the first riffle may extend from $0+00$ to $0+55$, while the first pool extends from $0+65$ to $0+75$. Completing measurements to the head of the reach enables calculation of average or representative pool-riffle spacing by simple arithmetic.

\subsection{Survey Of Channel Substrate}

\section{Purpose}

The primary function of channel substrate surveys is to document the composition of the bed and banks for eventual replacement in the reconstructed stream channel. Existing substrate composition is a function of the erosive forces and local geology and influences sediment transport rates and overall channel stability. In reclamation, it is inappropriate to exchange 



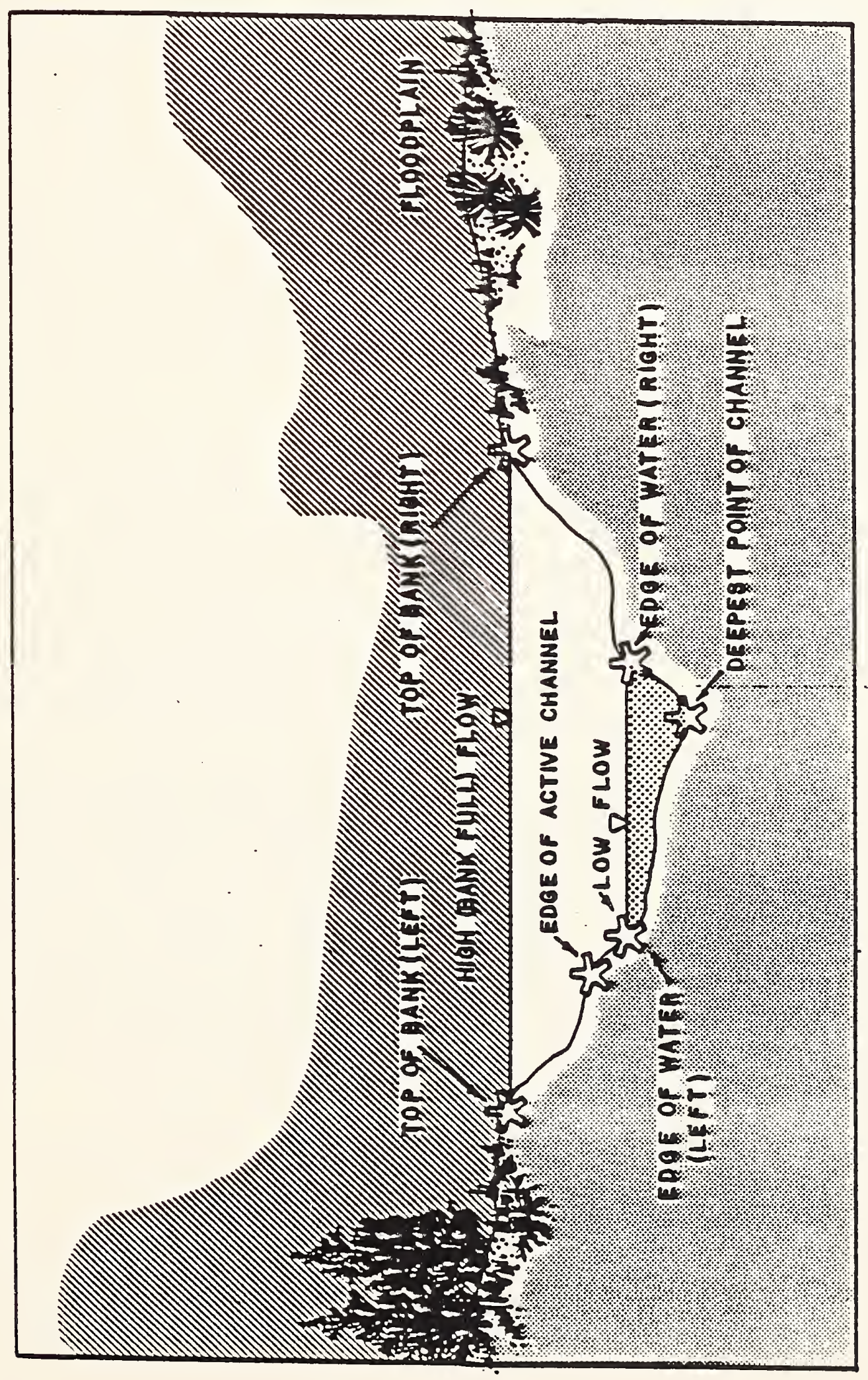



small material for large material. As might be expected, such action can produce extensive erosion, subsequent channel incision and downstream changes in channel pattern associated with sedimentation. Exchanging large material for small material, although not always as dangerous, can reduce local rates of sediment transport, prevent the encroachment of vegetation and natural recovery. In some cases, placing unusually large material on the streambed can initiate bank erosion, lateral migration and cause changes in channel pattern.

In natural gravel bed rivers, the substrate sometimes consists of a relatively coarse, erosion resistant layer over a mixture of smaller sediments (Beschta and Platts 1986). The formation of this so-called armor layer is complex, but is attributed to differential entrainment of bed material (Andrews and Erman 1986). Over time, the smaller and more readily transported sediments are removed, leaving a predominantly coarser fraction on the bed surface as an armor layer.

Bank composition also plays a role in reclamation. A traditional approach to channel reconstruction involves bed and bank stabilization with rock riprap. Though resistant to erosion, these channels rarely possess adequate habitat value and are aesthetically urappealing. The purpose of a bank survey, then, is to identify natural bank material for eventual reconstruction. It is important to recognize that bank erosion is a natural function and that excessive bank stabilization may cause undesirable changes in channel behavior well beyond the project reach.

In many forested stream environments, large organic debris (LOD), consisting mainly of whole or partial tree boles, branches, and rootwads, is common in the stream channel. Extensive research has indicated that this material plays a significant role in channel morphology, sediment and nutrient storage and transport, and aquatic habitat (Keller and Swanson 1979; Swanson and Lienkaemper 1978). For this reason, if a stream within a potential mine site has a significant LOD component, it is important to note its distribution and size during a survey of channel substrate. For the purposes of this handbook, LOD is defined as trees and branches with lengths equal to or greater than one half the average stream width and greater than 8 inches in diameter.

\section{Methodology}

Visual surveys of channel substrate, bank composition an' LUD distribution are generally sufficient for pre-mining data collection. A tabular survey form is easily developed and allows recording of each substrate size category's percentage present in a given area. This survey is accomplished by walking discrete reaches of the stream, estimating the percentage of each category of substrate present, or in the case of LOD, the length, diameter and distribution along the reach length. Although there are accepted size classification 
procedures (Wentworth 1922), the following scheme (Table 1) is offered with reclamation activities in mind. It is suggested that the surveyed reaches fall within previously identified representative reaches and that individual reaches not exceed 200 feet in length. Recording distribution of LOD follows the same format as that with pool-riffle spacing, with the additional component of LOD piece size recorded.

\begin{tabular}{|c|c|}
\hline Channel bed substrate type & Size range \\
\hline $\begin{array}{l}\text { Fines } \\
\text { Gravels } \\
\text { Small cobble } \\
\text { Large cobble } \\
\text { Large rock and boulders }\end{array}$ & $\begin{array}{l}<0.25 \text { inches } \\
0.25-3.0 \text { inches } \\
3.0-6.0 \text { inches } \\
6.0-12 \text { inches } \\
12+\text { inches }\end{array}$ \\
\hline Channel bank substrate type & Elements to record \\
\hline $\begin{array}{l}\text { Fines/soil } \\
\text { Vegetation } \\
\text { Large organic debris (LOD) } \\
\text { Cobble and rocks } \\
\text { Bedrock }\end{array}$ & $\begin{array}{l}\text { Percent composition of: sitts, clays, sand, } \\
\text { gravel, organics } \\
\text { Species, vigor, distribution, areal coverage } \\
\text { Length, width, distribution } \\
\text { Size, frequency, percent composition } \\
\text { Percent composition }\end{array}$ \\
\hline
\end{tabular}

\subsection{Survey Of Active Floodplain And Riparian Area}

Floodplains serve many functions, including storage of sediments and nutrients. Most, but not all natural streams have active floodplains. Stream environments less likely to have well-defined floodplains and associated terraces include bedrock-controlled mountain streams or other valley forms which act to constrain lateral channel migration. Floodplains are created by both vertical and lateral accretion (Wolman and Leopold 1957). Regardless of the specific mechanism, floodplain development is dependent upon the redistribution of sediments carried in the main channel.

The riparian zone is defined as the vegetatively unique area within the active floodplain adjacent to the active channel. Floodplains and riparian zones interact synergisic $\neg 1$ y, as riparian vegetation helps retard overbank flows, encouraging the dipusition of suspended sediments. In turn, many riparian plant species, such as cottonwoods and willows, have adapted their ecology to exploit these sediments. Once established, riparian vegetation plays an important role in both wildlife habitat and channel stability.

Inactive floodplains are commonly recognized as terraces, which are topographically higher than the active channel. These terraces, which may or may not be present on both sides of the valley, are commonly associated with 
placer deposits. Recognition of these different terrace elevations is useful for reconstruction of the valley flat.

Inactive or abandoned stream channels are often present in the floodplain. During overbank flows, these channels may become active and significantly contribute to the conductance of flood waters in a non-erosive matter. Where present, these channels should be identified, and their characteristics recorded. The reconstructed floodplain should incorporate these features.

\section{Floodplain Measurement Methodology}

Where floodplains and associated terraces can be identified, floodplain width relative to both sides of the channel should be measured. This simple procedure entails linear ground measurements of the horizontal distance from each bank to the floodplain terrace (Figure 8). Again, these measurements should be made in the aforementioned representative reaches. The number of measurements is subjective, but should represent the range of widths at the site.

Terrace elevation is a function of flow regime, and should be replicated during reclamation. Ideally, measurements should be made with a survey level and stadia rod at the same location where floodplain width was determined (Figure 8). In absence of a level, a hand-held level or clinometer can be used in conjunction with a measuring rod. Visual estimation of terrace heights is not desirable, but may suffice in some situations.

\section{Riparian Area Vegetatioe Documentation}

Because of the complexity of riparian soils and vegetation communities, and the large-scale disturbance associated with placer mining, complete restoration may not be possible. However, it is important to document the pre-disturbance conditions in riparian areas so effective re-vegetation strategies can be pursued. With this in mind, the most rudimentary riparian area survey should document the following categories.

\section{Streamside Cover}

An important function of riparian vegetation is to provide overhead cover and thermal shading to the stream environment. In each representative reach, rough evaluations can he completed by estimating the coverage contributed by various plants (see Platts et al. 1987). The species listed in each group in Table 2 are not intended to serve as a complete inventory checklist, but as an illustrative guide. 



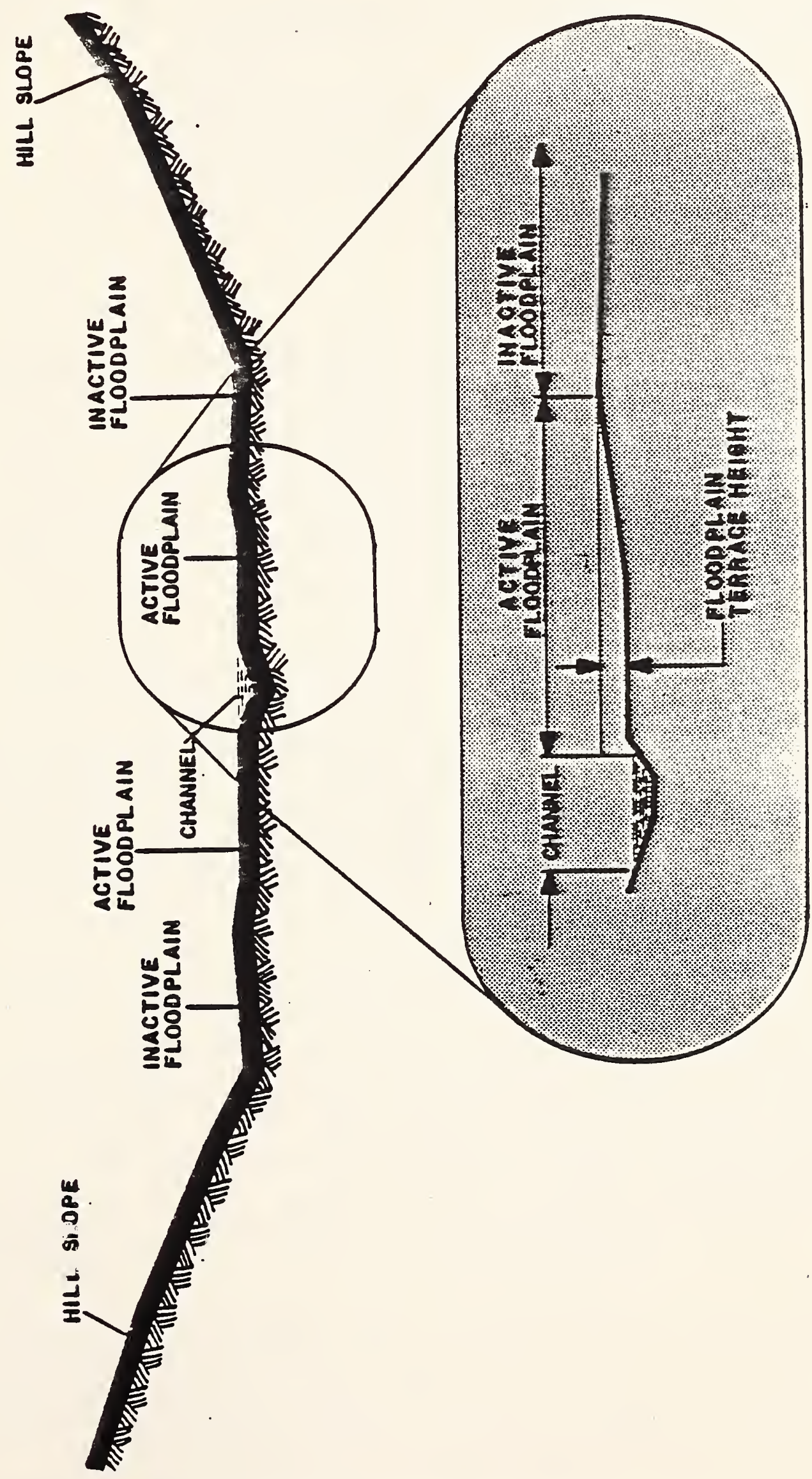

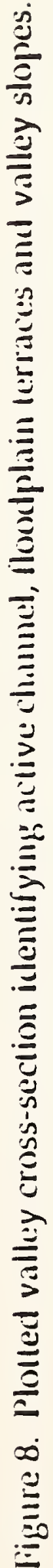



Table 2. Example determination of plant types found in a riparian setting and associated cover provided.

\begin{tabular}{llr}
\hline Plant type & \multicolumn{1}{c}{ Common plants } & Percent cover \\
\hline No vegetation & bare ground & $5 \%$ \\
Grasses & wheatgrass, wildrye, reedgrass, bromes, fescues & $12 \%$ \\
Forbes & yarrow, fireweed, clover, cinquefoil, cowparsnip & $7 \%$ \\
Shrubs & willows, sage, choke cherry, rose & $20 \%$ \\
Trees & cottonwoods, alders, conifers aspen & $56 \%$ \\
\hline
\end{tabular}

\section{Species Present}

To aid in the choice of plantings for reclamation, a species list of existing vegetation should be developed. Although complete inventories may not be possible or desirable, the most common species should be recorded. The Montana Riparian Association, located in the School of Forestry at the University of Montana, publishes classification guides for many riparian areas in western Montana. These publications can be useful for documentation of the riparian community types associated with a particular site.

\section{Distance From The Stream}

In many riparian areas, lateral vegetative stratification is evident (Figure 9). For example, willow communities may dominate the streamside vegetation, while shrubs and tree species dominate the floodplain. These stratifications develop over time in response to changing site conditions and natural disturbances, such as flooding. Where evident, stratification also should be surveyed.

\subsubsection{EVALLATION OF FISHERIES AND WILDLIFE}

Most pristine stream environments are associated with an abundant faunal assemblage. Many wildlife species directly or indirectly depend upon riparian habitat at some point in their life-cycle for forage, cover, resting, reproduction, or migration. In addition, most natural streams in western Montana support fisheries, and there is increasing concern for the deleterious effects of placer mining (Phillips and Humphrey 1987). For these reasons, at the minimum, a cursory evaluation of fish and wildlife resources is required.

Most land management agencies in the state have baseline information on fish and wildlife normally available upon request. Similarly, FWP maintains information on most drainages in the state. However, if no baseline data exists, it may be necessary to conduct cursory surveys to obtain this information. Local FWP representatives should be able to direct the 


reclamation planner should specific fish and wildlife baseline data needs be required. For fisheries, these may include estimates of fish populations and species diversity, as well as surveys of the macroinvertebrate populations. For wildlife, data needs may include identification of range habitat for big game and the size of populations using the habitat.

\subsection{METHODS OF DATA COLLECTION FOR DISTURBED SITES}

\subsubsection{Introduction}

As indicated earlier in this handbook, most drainages in western Montana with known placer deposits have been subjected to mining on several occasions over a period of many years. In. most cases, these entries dramatically altered the drainages, and little or no stream or upland reclamation was attempted. Therefore, the most common situation encountered in placered drainages is one where local topography, hydrology and vegetation have been substantially altered from pristine conditions.

Planning for reclamation in previously disturbed sites entails several challenges not encountered when mining entry occurs in pristine conditions. For example, stream channels in many disturbed sites rarely possess a stable geometry, planform, grade or habitat type. As a result, baseline information is of limited use for reclamation planning. Instead, effective reclamation designs rely on combining basic drainage information with theoretical considerations to arrive at an informed judgement. Despite the difficulties posed in these areas, there are many opportunities to improve the condition of existing streams and floodplains. In some cases, mining and subsequent reclamation may have a beneficial impact on previously degraded environments.

\subsubsection{Methodology}

The most fundamental approach to reclamation design in disturbed sites is to identify natural stream reaches outside of the project area. If these reaches exist, then reclamation design can be based on these representative reaches, in the same manner as described for undisturbed mine sites. Selected representative reaches should reflect a similar valley type, grade, presence of geomorphic controls and flow regime as the site targeted for mining and reclamation. For example, if the proposed mine is located in " narrow canyon, it is unlikely that an undisturbed upstream reach flowi vig inorough a wider alluvial valley would be appropriate for reclamation design.

In areas where a significant degree of natural recovery has occurred after historical mining entry, one may be able to gather valuable stream reclamation design information from the most recovered proximal reach. Though not as valuable a source of information as a nearby undisturbed 
reach, a recovered reach will generally reflect a channel form which reflects the flow regimes it has experienced since being mined, e.g. the recovered reach's channel geometry may reflect dimensions in quasi-equilibrium with the discharge regime. At the minimum, measurements of channel geometry in these areas should be compared with designs generated with theoretical parameters (see Section 6.3.3.4.2).

If a representative reach can't be identified, data collection prior to mining entry is mostly limited to the determination of existing grade, valley configuration and overall hydrologic regime. Unlike the determination of grade in undisturbed sites, the valley and channel grade information gathered in disturbed sites may not reflect the final reclamation grade. This information is collected to document existing conditions, some of which may need to be altered to create a stable channel environment. Grade alteration may involve re-distributing existing dredge piles and mine workings according to reclamation design specifications; or alternatively, an unfavorable existing grade may require specialized channel designs to promote channel stability.

The site's hydrologic regime can be characterized through stream gage information or regional regression equations. With a flood frequency distribution, estimates of peak discharges and runoff events help in the selection of a suitable channel geometry. In addition, the widths of discrete average valley reaches should be measured to help design active and inactive floodplain terraces.

Where extensive working of valley deposits has resulted in large quantities of tailings, it is useful to estimate the quantity of this material. The location of this material should be identified on a plan map because complete site reclamation can involve their dispersal through grading or hauling. It is also useful to describe the material within these worked tailings storage sites. For example, some dredge piles may consist largely of over-sized and parent material (bedrock), while other piles may consist of finer workings. Similarly, abandoned settling ponds or slurry pits should be identified and their material quantities estimated. These determinations should be emphasized because reclamation activities may involve the mixing, disposal and use of different sized materials. 


\subsection{UTILIZING FIELD DATA TO DEVELOP A RECLAMATION PLAN}

\subsection{INTRODUCTION}

Throughout all stages of reclamation planning, it is important that miners work closely with various state and federal agencies. This is particularly true when reclamation plans are committed to paper. This step often requires certain technical abilities, such as the design of stable channels, which may not be within the miner's realm of expertise. Most agencies can be of assistance in these areas by drawing upon the experience of numerous professionals. Additionally, reclamation designs often require many hours of work. Communication with resource agencies can reduce objections to submitted reclamation designs, as well as expedite permitting and bonding.

Well-researched and designed reclamation plans may not be required in Montana when the proposed mine site involves less than 5 acres of ground disturbance. However, committing a plan to paper for mines of all sizes is important, as the creation of such a plan demonstrates both forethought and the commitment of the miner to reclaim the site. Further, documenting reclamation plans on paper allows for an unambiguous definition of what constitutes proper reclamation for a given site, thereby setting site-specific reclamation standards. If changes occur in ground conditions or the planned sequence of mining activities, it may become necessary to modify reclamation plans. By documenting these changes as they occur, an accurate record of reclamation progress is generated, which is useful for demonstration of good faith, flexibility on the part of the monitoring agencies, and for actions taken to release reclamation bonds.

The following sections detail the methods for creation of a reclamation plan based on the data requirements in the previous section. They describe the different steps necessary to create such a plan in both disturbed and undisturbed sites. The central planning and design tool used in both approaches is a detailed plan map of the proposed mine site.

\subsection{RECLAMATION DESIGN FOR UNDISTURBED SITES}

\subsubsection{Base Planning Maps}

Base maps should be developed from che aerial photo or field surveys obtained earlier in the reclamation planning process. The level of detail of these maps will in part depend on the scope of proposed disturbance and degree of proposed manipulation of the stream environment. Typically, drawings are produced on 36" $\times 24$ " mylar sheets by direct overlay of enlarged aerial photos. Mylars are then used to produce blue-line copies. These maps 
should be a principal feature of the final reclamation plan, and are usually accompanied by explanatory text. Therefore, it is important to produce clean, legible, scaled, and accurate plan drawings. All maps should show claim boundaries, adjacent land jurisdiction, a north-south orientation, and a linear scale. Separate maps may portray different stages of mining or reclamation.

An initial map should portray existing ground conditions, including channel planform, channel slopes, floodplains, and generalized vegetative conditions (Figure 10). This map will serve as a benchmark for succeeding reclamation activities; actual channel reclamation will then attempt to re-construct the pristine conditions encountered before the commencement of mining. This map may be supported by photographs of the undisturbed site, with photo points and photo orientation noted on the plan map. Photographs are useful for both the establishment of initial conditions and for monitoring reclamation success.

\subsubsection{Designation Of Mining Panels}

An important aspect of reclamation design is to ensure implementation feasibility during normal placer mine operations. One method of linking reclamation design plans with ground conditions is to sub-divide the entire claim site into distinct panels or cells. One panel may represent several different mining sets. All or some of the panels may be mined in a given season. Their shape, location, or size is often dictated by the type of machinery used for mining and the local geology.

Typically, panels will be mined at different times or will have different uses in the mine operation. For example, a valley-bottom claim of five acres may be broken into three separate panels, numbered one through three. The delineation of panels may reflect different valley or channel conditions or identify the most promising claim areas relative to the least promising as determined by exploration activities. Panels can also help prioritize the sequence of mine opening. In this scenario, Panel One may represent proposed mining for the first year, Panel Two the following year, and Panel Three the final year of operation, if the claim continues to be profitable. Regardless of the criteria for selecting panels, their identification on the ground, and representation on the plan map (Figure 11), will aid in reclamation design and implementation.

Once panels have been identified, the sequence of parel disturbance should be identified to establish an estimated time-frame for mine operations. As the mining operation progresses, reclamation success can be evaluated panel by panel. 


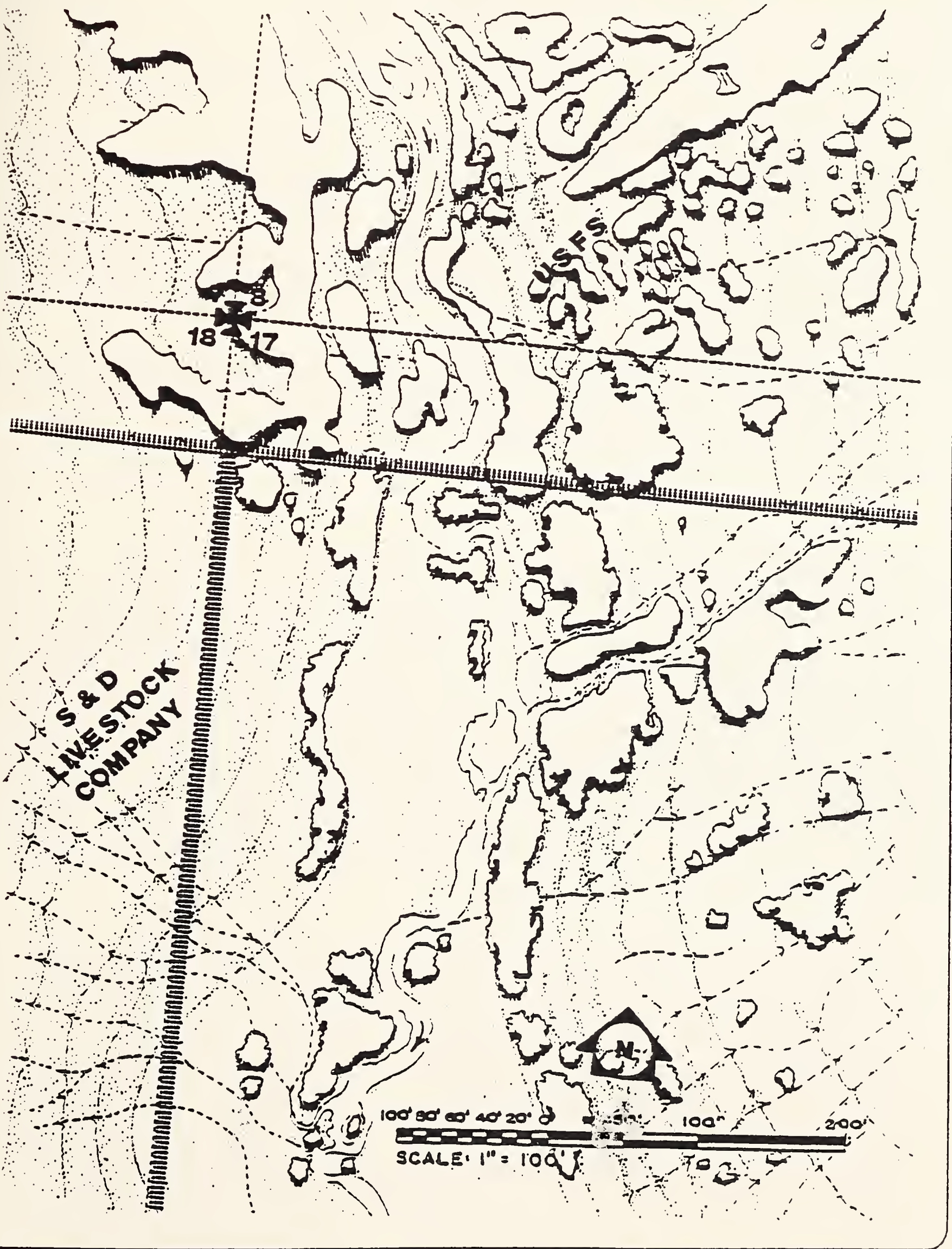

Figure 10. Initial plan map identifying surface ground conditions and property ownership. 



\subsubsection{Incorporating Field Data Into Reclamation Plan Map}

\subsubsection{LOCATING STREAMI CHANNEL ON PLAN MAP}

Because the reclaimed stream will closely resemble the original. stream, the undisturbed channel should be accurately drawn onto the base map. This task is most easily accomplished by enlarging an aerial photo to the appropriate scale, and then tracing the channel onto a base map overlay. Alternatively, the existing channel can be surveyed, and the survey information transferred onto the plan map. On small claims, the channel may be sketched onto the plan map, then field checked by a walking survey.

At this stage in reclamation design, an attempt is made to ensure the recreation of the existing channel, as this channel best represents natural conditions. Consequently, the representative reaches should be indicated on the plan map. Within these reaches, detailed information such as meander characteristics and cross-section measurements should be delineated (Figure 12).

Because placer mining activity substantially alters local topography, it is unrealistic to assume the original channel can be reconstructed in every detail. Changes in ground conditions, such as local valley grade, will likely necessitate design alterations after surficial grading is completed. For example, during reconstruction, the elevation of a given reach may inadvertently be constructed above the grade necessary to match a lower reach. In these cases, some element must be adjusted, such as sinuosity or meander arc length, or a drop-structure built to provide a stable transition. These construction techniques are evaluated in greater detail in a following section. However, the reclamation map at this stage should still reflect the ideal channel planform elements discussed previously.

\subsubsection{VALLEY SLOPE}

Valley slope should also be represented on the map, with the original valley slope presented as the target slope for the reclaimed site. One common method for this type of presentation is to plot the longitudinal valley profile adjacent to the plan view of the mine site. In this way, the longitudinal profile is readily referenced relative to the designated mine panels, original -tream channel location, and representative reaches (Figure 12). Reach numbers and the length of each reach can be plotted on the horizontal axis of the longitudinal profile. This format provides a concise method for crossreferencing grade and slope information with mine site and channel information. 



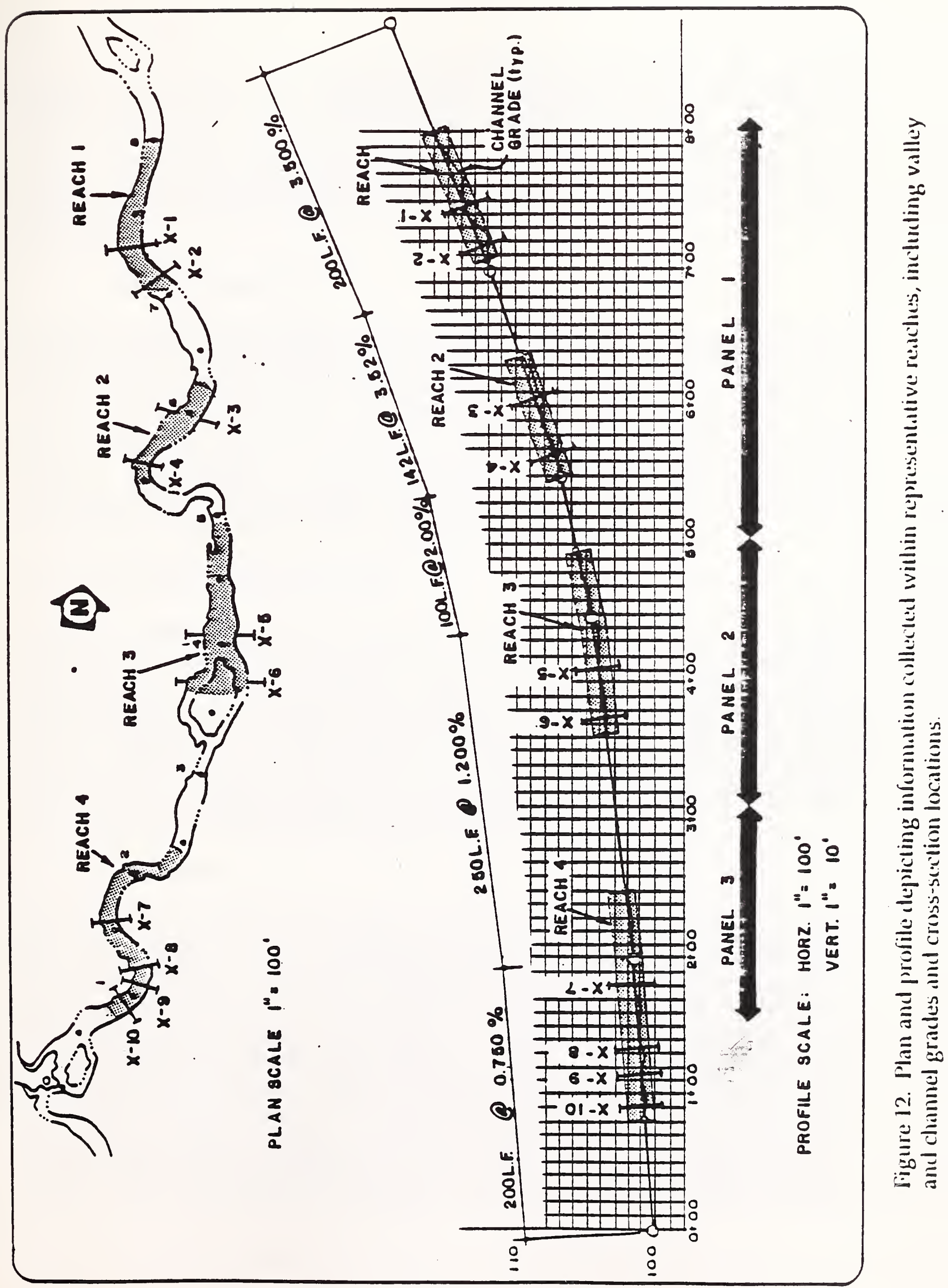





\subsubsection{CHANNEL GRADE}

Where channel grade was recorded (representative reaches or entire channel length) during initial data collection, this information should be plotted on the same plan map with the longitudinal profile of the valley (Figure 12). These values serve as planning targets, and can be adjusted during actual reclamation. Information presented in this format allows for quick reference between channel and valley slope, and their spatial relationship to the entire mine site.

\subsubsection{CHANNEL GEOMETRY}

Existing channel cross-sections should also be plotted. The reconstructed channel will, with slight alterations made necessary by site conditions, have similar channel cross-sections. These cross-sections may be plotted on a separate design sheet, with an indication of the reach and location within that reach where the data was collected. It is particularly important that each channel cross-section is identified with the channel grade where the information was collected (Figure 13). On the base map, these cross-section locations should have been previously identified (Figure 11).

\subsubsection{CHANNEL SUBSTRATE DESIGN}

Channel design should also include a schematic drawing of the wetted perimeter in cross-section. This drawing should dețail the layers of substrate, and their particle size composition, based on reconstruction needs. Under optimum conditions, reconstructed channels will have the following layers from the bottom up: a base of gravel, a mixture of fine sediment and small gravel to effect a seal, additional gravel to isolate the seal and channel armor (see Figure 14). Where possible, the composition and thickness of the armor layer should be derived from the visual substrate survey.

\subsubsection{VEGETATION}

The generation of viable site specific re-vegetation plans may require input from local resource agency personnel or private consulting organizations. These professionals are most qualified to provided necessary vegetative prescriptions, including the most appropriate methods for weed control, soil amendments and planting techniques. Professional knowledge is mnat useful in identifying species best adapted to the site. For example, a giver sito prescription may include a tiered planting scheme, which focuses on seed mixes with initial attributes of providing immediate ground cover, soil stabilization, and fixation of critical nutrients. The seed mix may also contain native species adapted to the site, with longer germination periods, which may eventually out-compete the other species and promote 


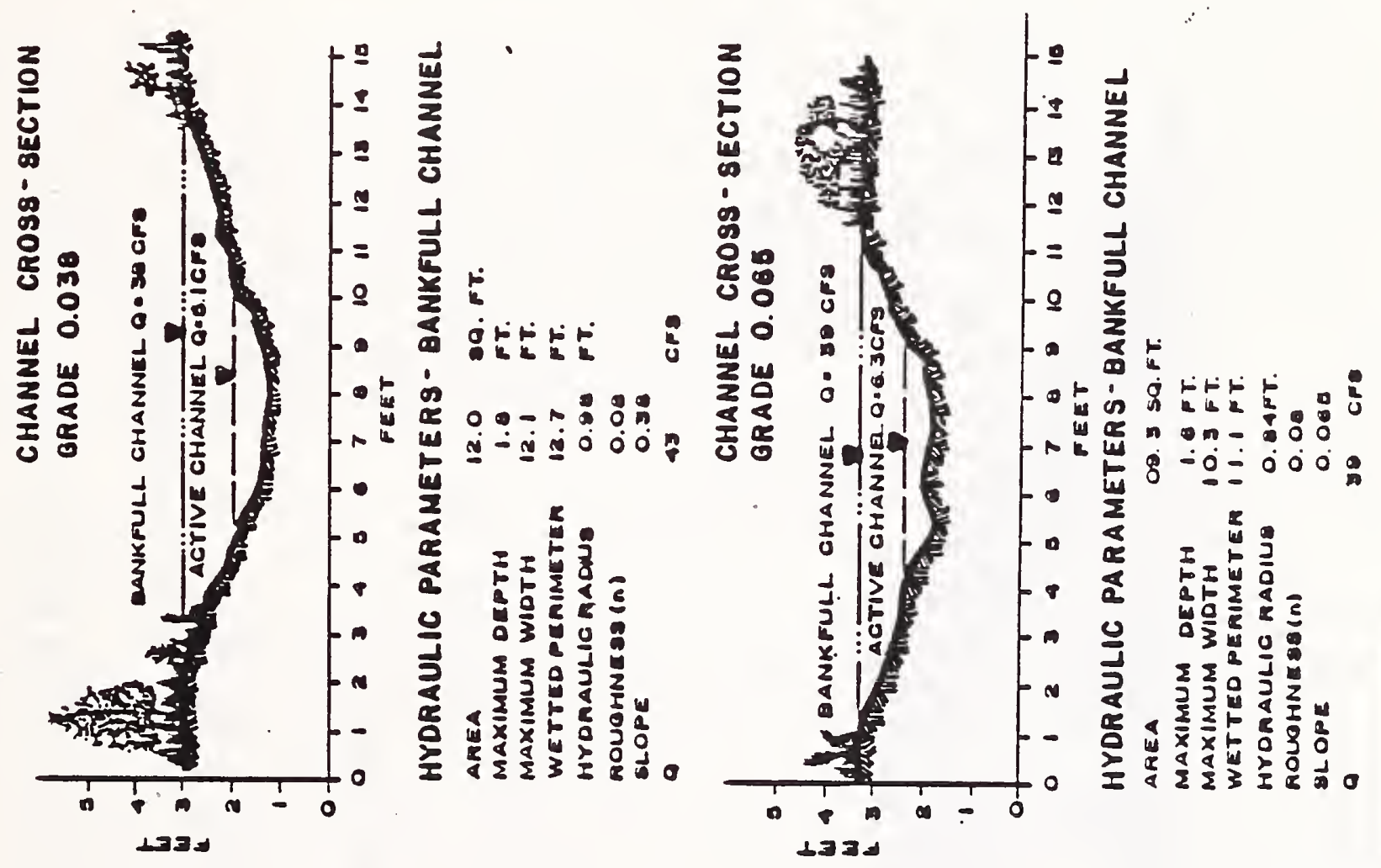

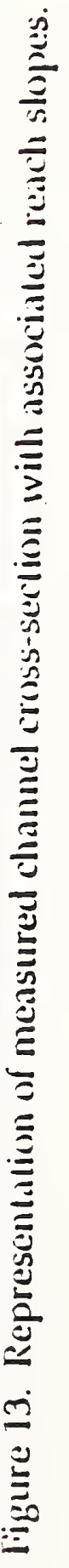




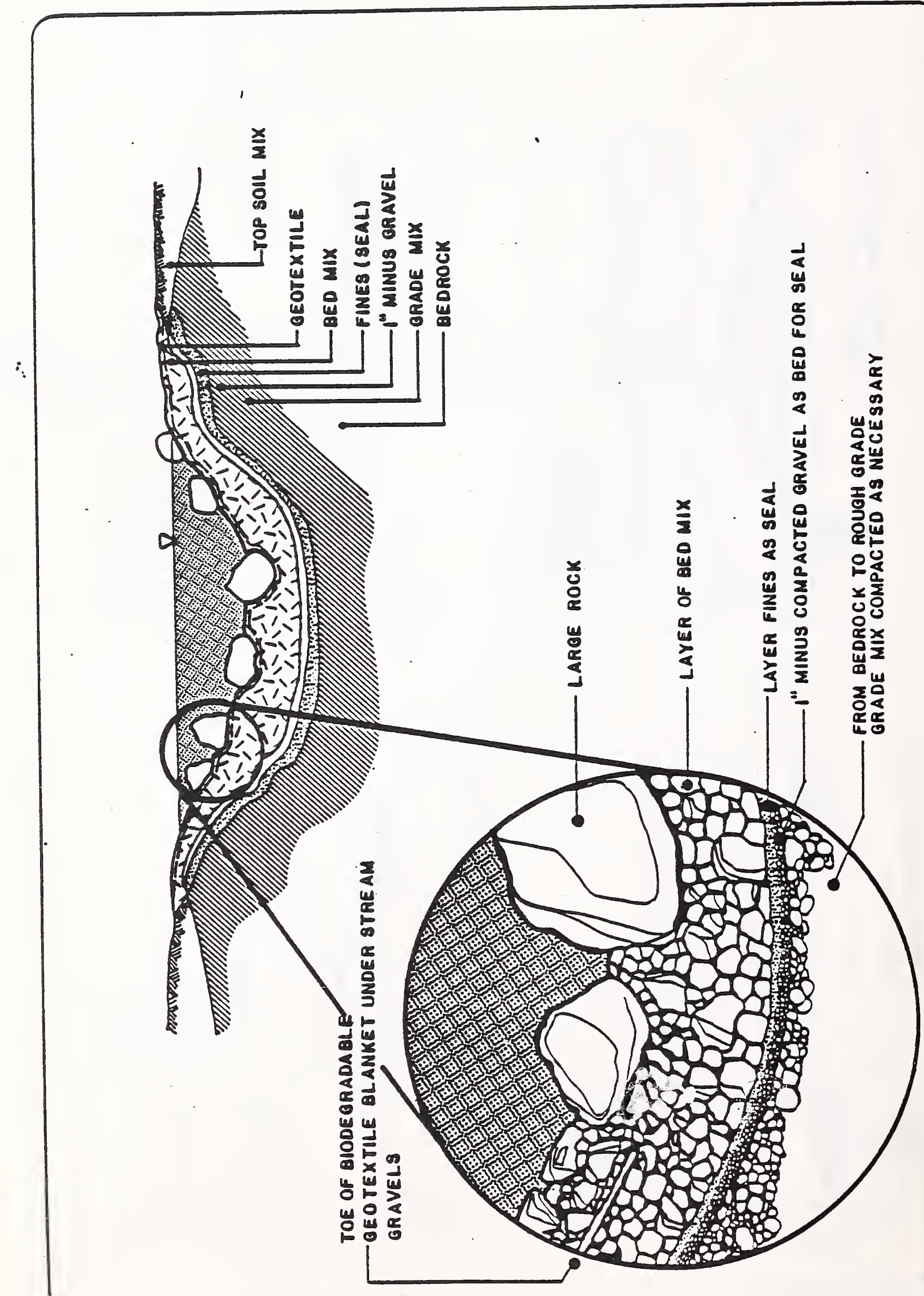


long-term species diversity and recovery of the site. From a stream reclamation perspective, the most immediate concern is to stabilize soil and minimize erosion of upland sediment into the stream channel.

Preliminary data on vegetative composition is used to guide subsequent reclamation plantings. Because of the severe ground disturbance encountered in placer mining activities, it is unlikely that reclamation replantings will exactly match those of the undisturbed site. Vegetative succession and soil development takes many years. The attempt in reclamation planting is to immediately stabilize disturbed ground surfaces, provide a site-similar vegetative substrate to facilitate the development of riparian and upland vegetative diversity, and to enhance the aesthetic and biological condition of the recovering site.

Based upon the initial vegetative survey, a re-vegetation plan should be generated, and presented on a separate design sheet, with appropriate supplemental text. This information should include types of species to be planted, seed mixes, seeding and planting densities, noxious weed control strategies, follow-up planting schedules, definitions of revegetation success and monitoring plan, prescribed soil amendments if needed, and the location of the various vegetative treatments. For example, riparian areas may be delineated on a plan map, with a prescribed willow stem planting density and riparian seed mix. In floodplain areas, specific planting groups of shrubs and trees may be indicated, reflecting appropriate distances between planting clusters, species composition and the prescribed seed mix and seeding density in intervening spaces.

\subsection{RECLAMATION DESIGN OF PREVIOUSLY DISTURBED SITES}

Entering a previously disturbed placer mine site for further mining and reclamation presents the operator with a variety of challenges and opportunities not found in pristine areas. Challenges include: designing a stable channel when historic material handling, hauling and working has created material imbalances along a valley length; the absence of topsoil; unstable valley walls; and the presence of a poorly defined channel. The hydrology of these sites is often difficult to assess because of variable surface water expression, the presence of numerous diversions and standing water in unreclaimed trenches and settling ponds. Indeed, consolidating surface water into one channel may present the largest challenge to re-creating a viable stream. However, the oppo tunities to improve the existing conditions at such sites are usually large. At the minimum, a stable channel can be constructed and efforts made to start the site on the road to natural recovery. 


\subsubsection{Assessment Of Site Potential}

Previously placered mine sites will present the operator with a wide range of ground conditions, ranging from seriously disrupted valley and stream channel forms to sites which have been partially or wholly reclaimed. Realistic goals for reclamation, based on the requirements and potentials of each site, should guide reclamation design. Close communication with personnel from appropriate state and federal agencies, including a number of site reviews, can help establish these goals. For example, in a seriously degraded site where channel erosion or unstable settling ponds pose actual or potential problems for water quality, reclamation goals should focus on stabilizing the watershed and constructing a stable channel. In a less disturbed site where the stream channel is relatively stable, soil development is apparent and vegetation is recovering, opportunities may exist to restore biologic productivity and aesthetic appeal. In all instances, a thorough review of the opportunities to either enhance the aquatic resources or stabilize the local watershed should occur.

In the assessment of site potential, some thought should be given to the enhancement of certain existing ground conditions to provide quality terrestrial or aquatic habitat. For example, the site may have one or several unreclaimed settling ponds, which through time, have evolved into either wet-meadow or wetland habitat. Because of historical loss of these habitats and their intrinsic biological value, a decision may be made to enhance or extend their expression.

\subsubsection{Base Plan Map}

As detailed in the previous section for the development of a reclamation plan for undisturbed sites, a base plan map for the mine site should be made. This map will identify the claim boundaries and the different mining panels, and serve as the central planning tool for reclamation design.

\subsubsection{Incorporating Data Into Reclamation Plan Map}

\subsubsection{DESIGNING AVERAGE VALLEY GRADE}

Using data on the existing valley slope, a longitudinal profile should be plotted to identify reaches of differing grade. This existing grade may or may not represent a stable condition for the site. From this longitudinal valley profile, an average grade for the site also should be determined. This task is accomplished by drawing a straight line between upstream and downstream endpoints of the profile; this new slope is calculated by dividing the vertical change in elevation by the longitudinal distance. The average grade can then serve as the target grade for the reclaimed site. Barring extensive hauling and 
redistribution of material, both within the mine site and beyond, this grade may also provide the most practical working value.

It is also helpful to plot the existing grade for some distance upstream and downstream of the mine site, since both ends of the valley grade must tie-in to these grades. If an undisturbed representative valley section was previously identified upstream or downstream of the disturbed site, the average valley grade for the undisturbed section may be used as the target grade for the reclaimed site. Grade in the undisturbed section should be plotted against the existing grade of the mine site. This visual representation will identify areas within the site which are either above or below the target grade, and therefore identify areas where material re-distribution may be needed or desirable. Using simple mathematics, an estimate of cubic yards required to meet grade within the mine site can then be made. With this information, the feasibility of material redistribution can be considered jointly with the agency setting bonding requirements. Where material redistribution is not feasible, local adjustments to the finished target valley grade should be made, considering the implications of constructing a stable channel at the newly defined grade.

\subsubsection{DESIGNING CHANNEL GRADE}

In most instances, the designed average channel grade will be equivalent to the valley grade. However, because valley stope is based on linear measurement, and channel slope is the product of non-linear channel length and change in elevation, there may be few distinct channel reaches with uniform grade. In fact, a "stair-stepping" channel grade is often indicative of a channel with developed pool-riffle sequences. Ground conditions which exist after the final site grading may dictate site- or reach-specific deviations from the average valley grade. The need to change grade to match unanticipated ground conditions will become. apparent during channel construction activities, and rectified at that time. Where possible, several channel grades should be identified for the proposed new channel, which fall slightly below and above the average channel grade. This information will then be used in the formulation of appropriate channel geometry for the site.

\subsubsection{LOCATION OF RECLAIMED CHANNEL}

In many placered sites in Montana, the existing channel location is an aberration of mining disturbances, and may not represent the best location for the newly constructed stream. Designing the new stream location is a function of site limitations, including valley width, the presence of large quantities of dredged mine workings, depth to bedrock, valley slope, and opportunism. Opportunism includes designing the new stream location in historically abandoned, yet still intact side-channels, meanders or sections of actual stream channel. For example, it was not uncommon during historic 
placer mining operations to divert the live stream from one side of the valley to the other without ever directing the stream back to its original channel. Such abandoned channels may provide the best location for the new channel, and require little more than re-diversion and general site grading to greatly improve the existing aquatic and watershed conditions.

Committing the planned channel location to paper entails a combination of ground reconnaissance and incorporation of either previously collected information on channel sinuosity and planform from representative sections, or intuitive design, founded on basic geomorphic, hydrologic, and fluvial principles. Where representative site data is available, and while in the field, a general channel location should be sketched onto the base map. Rough design in the field is important. so that the proposed channel accurately reflects the lay-of-the-land, including the presence of subtle slope breaks, geomorphic controls such as bedrock outcrops, and valley width. The design also should be refined by incorporating sinuosity and planform information from the representative reaches.

Where representative reaches aren't available, geomorphic characteristics of the drainage can be used as a guide for channel location and plan. As discussed previously, most placered sites in western Montana are located in generally high gradient, narrow valleys. The proximity of the valley walls at these sites may dramatically-limit the options for channel location and planform. In wider valley sections, the designer has more freedom. For example, the stream may be located so that it flows near existing, undisturbed vegetation. In addition, if the valley gradient is moderate, a meandering channel may be located so it shifts from one side of the valley to the other at a shallow angle between the stream axis and the valley axis (Rundquist et al. 1986).

Experience dictates that in addition to valley width, valley slope has a controlling influence over channel sinuosity. In particular, the threshold slope is nominally set at $1.5 \%$, a figure that also compares well with standard hydraulic practice (Chow 1959). Thus, where design slope exceeds $1.5 \%$, target sinuosity should range between 1.1 and 1.5. If the design slope is $1.5 \%$ or less, more sinuous channels are possible, with manifest meandering possible on slopes below $1 \%$.

Localized areas of the finished valley grade may be greater than prescribed in the reclamation plan. Where planned stieam channels meander more strongly than prescribed by the valley gradient, some measures may be required to reduce erosion potential. In particular, floods may cut through constructed meander bends and develop a more incised, linear channel. In these cases, channel grade and other backwater profile flow controls, such as labyrinth weirs or cascades, can be incorporated to enhance channel stability. Another option available during these situations is to locally decrease the 
sinuosity index. Construction techniques designed to incorporate channel grade control into the reconstructed channel will be outlined in greater depth in a succeeding section (see Section 7.3.7 and 7.3.8).

\subsubsection{DESIGNING CHANNEL GEOMETRY}

Typical natural channel designs rely heavily on hydraulic engineering criteria and geomorphic parameters, such as critical bed and bank shear stresses, considerations of bedload transport, and "equilibrium" valley slopes (Rundquist et al. 1986; Jackson and Van Haveren 1984). Much of this work utilizes empirical equations bounded by local geologic conditions and research. Although there is disagreement concerning the appropriate use of these relations, they continue to demonstrate their utility (c.f. Dury 1973; Williams 1986). The reader is referred to Graf (1971), U.S. Army Corps of Engineers (1970), Bray (1982), and Hedman and Osterkamp (1982) for design approaches not covered in this report.

Temporary stream diversions, designed to safely transport a live stream around the mine site, also need to be considered by the miner in some instances. Technical design of these channels follows many of the same guidelines and steps outlined in this handbook for the construction of natural channels. However, because the focus here is on the construction of permanent channels designed to support aquatic fauna, the mine planner needs to consult other literature for adequate and cost-effective design for diversion channels (for example, see Simons, $\mathrm{Li}$ and Associates 1982).

\subsection{Representative Reach Information Available}

If channel cross-section information was gathered from a representative reach, it should serve as the guide for the construction of the new channel, with some slight modifications. For example, bank configurations in undisturbed reaches may result from cohesive bank substrates reinforced by bank vegetation. The resulting angle of repose of these banks may be greater than can be achieved in designed channels constructed in less cohesive alluvium. Therefore, where bank vegetation in a representative reach is deemed an important factor in bank stability (Salminen 1990), the designed bank slopes should reflect lesser angles. Depending on the cohesiveness of the proposed bank materials, design bank slopes should range between 1.5:1 to $3: 1$, as these are generally less than the angle of repose and are more easily revegetated. As the channel adjusts over time and vegetation encroaches, the banks will evolve into a more natural configuration.

Measured cross-sections in representative reaches also should represent a stable channel configuration capable of conducting the flow regime of the basin. These cross-sections, modified to account for cross-section evolution (above), should be plotted on a design sheet, noting the channel grade and 
channel location (such as pool, riffle, or run) at the point of measurement. For design purposes, channels can be portrayed as modified trapezoids or irregular polygons, bearing in mind that the constructed channel will be finished with rounded contours. The number of cross-sections required is variable, but should facilitate matching the targeted valley and channel slope with values outside the project area, and reflect the overall prevailing goal of creating a diverse channel with quality aquatic habitat.

\subsection{Representatioe Reach Information Unavailable}

If representative reaches cannot be found, i.e., all applicable sections of the drainage are disturbed, cross-sections must rely on the anticipated flow regime of the basin. If gaging data are available, flood frequencies should be consulted or generated for the site (see Dunne and Leopold 1978). Where this information is unavailable, flood recurrence values should be generated using methods described earlier.

Geomorphic research (Wolman and Leopold 1957; Hey 1982) has shown that many channels carry a bankfull flood once every two years, and that these flows are important in defining channel shape (Wolman and Miller 1960). For the purpose of channel design, this discharge is designated as the design discharge. However, some professionals prefer to design channels based on the flow event expected once every five years; this point is a matter of preference, and should be determined site-specifically. However, if there are questions regarding the site-specific adequacy of the flood frequency estimates, it is wise to choose a conservative design discharge.

The Manning equation is the most common method for designing channels (Mott 1979; Dunne and Leopold 1978). One form of the Manning equation is presented here.

$$
\mathrm{Q}=\left(1.49 \mathrm{R}^{2 / 3} \mathrm{~S}^{1 / 2}\right)(1 / n)(\mathrm{A})^{\circ}
$$

where $Q=$ discharge $\left(f t^{3} / \mathrm{s}\right)$

$R=$ hydraulic radius (ft) and $R=A / W P$, (the ratio of wetted perimeter [WP] to cross-sectional area [A] of flowing water)

$\mathrm{S}=$ slope of the water surface (or channel grade)(ft/ft)

$n=$ the dimensionless Manning resistance coefficient

Because this equation is sensitive to the value of the " $n$ " coefficient, it is easy to under-design or over-design a channel. Consequently, references have been developed to assist in assigning an " $n$ " value. These references are based on actual calculations of " $n$ " from known discharge and cross-sectional data (Barnes 1967; Dunne and Leopold 1978; and Jarrett 1985). Because most constructed channels in mountain environments will have a high degree of 
bed armor and channel roughness, " $n$ " values will probably range between 0.05 and 0.08. In any event, use of the equation is an iterative processes, and different " $n$ " values should be tried until an acceptable discharge is determined.

For the Manning equation described here, both discharge (Q) and slope (S) are known and " $n$ " selected. Hydraulic radius (R). and cross-sectional area (A) must then be manipulated to create a suitable geometry for a particular site. It is evident that different channel shapes can have the same hydraulic radius and cross-sectional area, e.g., a trapezoidal channel vs. a semi-circular or square channel. Consequently, the real test of this approach is to arrive at an inherently stable channel geometry that also provides quality in-stream habitat for fish. In this work, there is no better help available than that provided by the real world. In this respect, selected empirical equations, which describe relationships between various channel parameters, can be consulted to guide the creation of an appropriate channel cross-section.

Relationships between discharge and measurable channel parameters have centered upon bankfull flows, which tend to have a recurrence interval between 1-2 years (Dury 1973; Pickup 1976). Numerous empirical relations, based on data from streams and rivers around the world, have been developed and are reported in the form:

$$
\begin{aligned}
& \mathrm{w}=\mathrm{aQb} \\
& \mathrm{d}=\mathrm{CQ}
\end{aligned} \text { and, }
$$

where $\quad w=$ width

$\mathrm{d}=$ depth

$Q=$ discharge

(a) and (c) are empirical coefficients

$(b)$ and $(f)$ are statistically derived exponents

Determining bankfull channel width is the first step in the inductive design of channels using the Manning equation. For Montana, Parrett et al. (1984) have developed equations which relate the two year peak flow event $\left(Q_{2}\right)$ to bankfull width. However, it should be emphasized that in cases where the $Q_{2}$ event was estimated, this procedure can at best, only provide a theoretical bankfull width. Osterkamp and Hedeman (1977) also have developed equations for estimating appropriate channs! widths in high gradient natural streams based on the mean annual discharge of several Montana and western U.S. streams. Where a mean annual flow can be estimated, it is worthwhile to compare the Osterkamp and Hedeman (1977) channel width values with those of Parrett et al (1984). 
Once bankfull width has been derived, the next step is to derive a maximum depth, or thalweg, which is the distance from the top of the banks to the lowest point in the channel. Unfortunately, empirical equations concerning depth have not been developed specifically for Montana. As such, more universal equations have to be used. For the purposes of this report, a design depth can be obtained using the equation developed by Williams (1986), as follows:

$$
D=0.12 W^{0.69}
$$

where $D=$ bankfull mean depth (m)

$W=$ bankfull channel width (m)

Note that this equation is in metric form and was derived from logtransformed data. In this case, $W$ is calculated from above.

Alternatively to, or in conjunction with the above, the literature also reports (Bray, 1982) empirical equations relating design discharges to bankfull width and depth which were developed in gravel-bed rivers. Using such equations, various trial widths and depths can be calculated. In most cases, the range between the differently calculated parameters will not be great. For iterative design purposes, a width or depth value falling between the calculated range may be appropriate.

It should be noted that estimates of bankfull width and depth are intended as design guidelines, and not as absolute values applied to all channel crosssections. That said, the channel designer needs only to fit, through trial and error calculation with the Manning equation, a cross-section to the design discharge. For example, the first trial cross-section, when divided into its component parts of hydraulic radius $(R)$ and area (A), may produce a channel which cannot convey the design discharge. With this knowledge, a second cross-section is designed, using the width and depth identified above as a rough guide, but with a larger area, and perhaps a greater $R$ value. When this cross-section is divided into its component parts and inserted into the Manning equation, the design discharge may be slightly higher than necessary. The appropriate channel cross-section may then be taken as the intermediate value.

An added dimension to this iterz tive process is to investigate conveyance of a given cross-section with varjing " $n$ " values. For example, a channel described as having a cobble bottom and smooth sides may have an " $n$ " of 0.040 , while the same channel with bank vegetation may have an " $n$ " of 0.055 . Because it is better to over-design than under-design a channel, " $n$ " should be chosen conservatively. In addition, individual cross-sections can be divided into segments, with individual " $n$ " values assigned to each segment. This procedure enables greater precision, particularly for complex asymmetrical 
cross-sections, and is described in detail by Chow (1959). This design process can be simplified by either using computer programs for both programmable calculators and micro-computers. Most computer-based graphics programs easily calculate areas for non-symmetrical polygons and perimeters, facilitating rapid iterations.

Guidelines for cross-sectional channel shapes are difficult to identify, because of the range of variation in natural channels. However, a modified trapezoid shape may be appropriate for riffle and run sections (Figure 15), as these forms have the greatest likelihood of evolving into more natural configurations over time. Pool cross-sections vary with their location in the channel, bends versus inflections, but some commonly encountered pool cross-sections are provided for reference (Figure 15). From this illustration, it is clear that pools are generally asymmetric, i.e., they have shallow slip-off slopes on the inner bank and near vertical banks on the outer bank. Pools also tend to be about $25 \%$ less wide than riffles. At the conclusion of calculations, design sheets should detail various parameters, such as wetted perimeter, average depth, and bankfull width for different of design slopes.

\subsubsection{DESIGNING CHANNEL SUBSTRATE (REVISED)}

Once the channel has been sized, the next task is to design the materials comprising the wetted perimeter. As stated previously, the new stream bed may be comprised of four individual layers. Starting from the bottom, these layers include a gravel base, a mixture of fine sediment and gravel to effect a seal, a gravel mixture to isolate the seal and protect it from scour, and a surficial armor layer to provide bed stability.

In ideal situations, the thickness and composition of the gravel base and the seal is determined by estimating the porosity and permeability of the available material (see Freeze and Cherry, 1979). The results are then related to the ground pressures generated by the heavy equipment used in construction (Caterpillar, 1990). To determine the thickness and composition of the gravel mixture used to isolate the seal, both porosity and permeability and the crosssectional area of the mixture should be determined. The characteristics of this layer are important because they affect the degree of subsurface flow. Thus, in highly porous and permeable materials, the thickness of the isolating mixture should not exceed $10 \%$ of the area of the channel above the armor layer. Otherwise, excess subsurface flow will affect the biologic productivity of the reconstructed stream. In non-porous and non-permeable ratisizl, the crosssectional area of the isolating layer becomes less critical, and becomes more of a material management concern. 


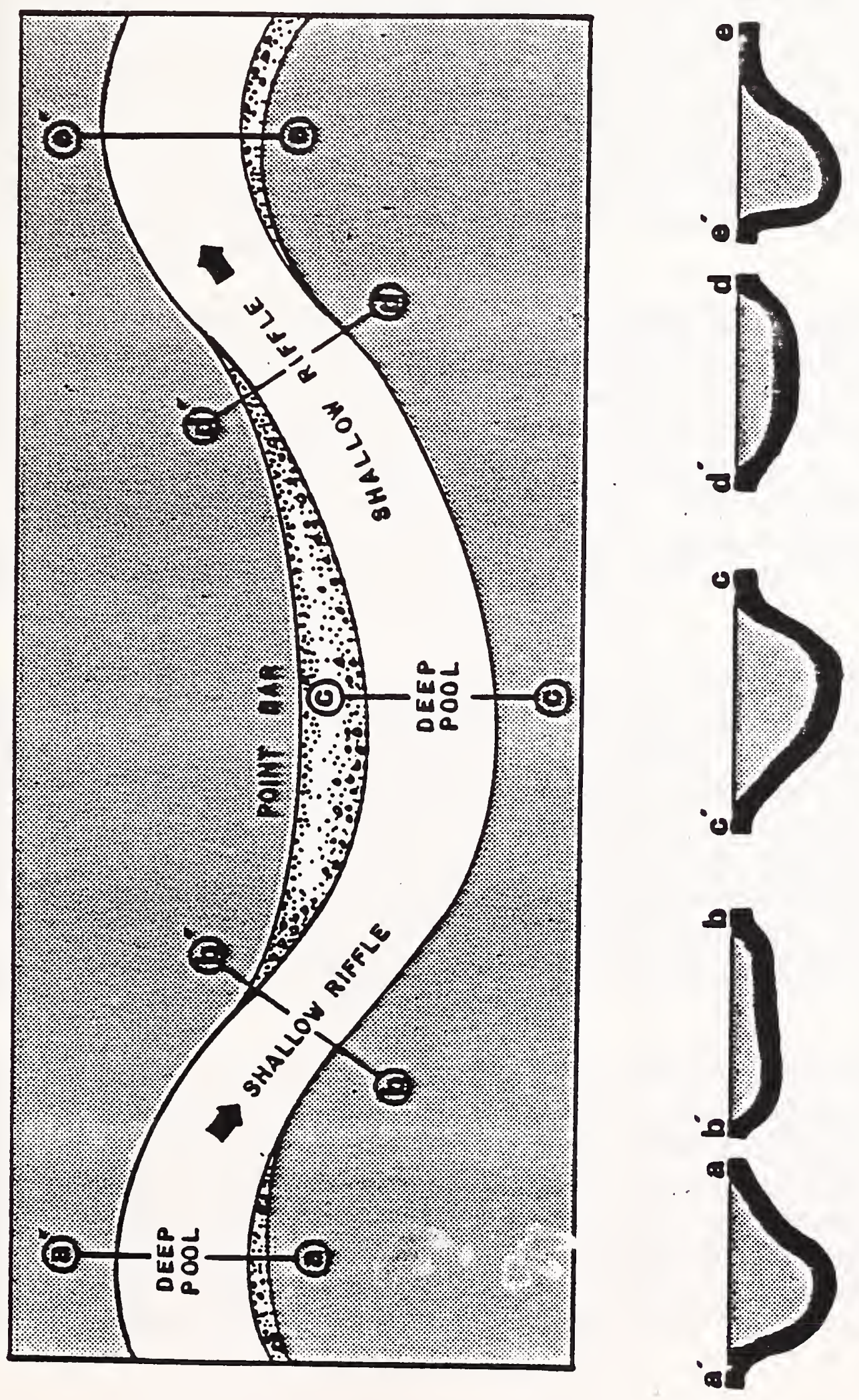

In practice, difficult construction conditions, local geologic constraints or lack of suitable material may preclude the construction of individual base, seal and isolating layers. In these cases, silts, sands and small gravels should be combined, applied in small lifts, and then compacted to create a single, subsurface layer. If constructed properly, this heterogeneous mixture will perform as well as individual layers. For guidelines in mixing materials, the reader is referred to texts on groundwater flow (for example, UOP, Inc., 1982). As a general rule, however, gravel content in these mixtures should be limited to $30 \%$ to maximize surface flow. With higher gravel concentrations, porosity and permeability vary widely due to the unpredictable way in which larger particles orient and compact. For this reason, the gravel content of a combined layer should never exceed $65 \%$.

While other layers may sometimes be combined into a mixture, the armor layer should always be constructed as a separate unit. Although somewhat dependent on material availability, the design discharge and the degree of channel stability sought, the composition of this layer should be carefully considered. Placered environments are susceptible to drainage basin instability and increased sediment production. The character of the armor layer merits attention because it plays a large role in determining stream stability. For example, if the stream bed is unstable, bedforms can develop and produce undesirable or unexpected erosion.

Bed stability can be provided by creating a balance between the size of material within the channel and the forces generated by the flow. In gravel-bed rivers that are in equilibrium with their drainage basins, disruption of the armor layer and bedload transport occurs as bankfull discharge is approached. In these natural streams, the range of particle sizes in motion may be large, but the actual rate of bedload transport is usually small (Andrews and Erman, 1986). In contrast, the short-term design goal for reconstructed streams is to have little particle motion during the design discharge. In this way, the channel is less likely to be overwhelmed by hillslope processes as the drainage basin recovers from mining activity.

Although many relationships have been developed to estimate the size of material required to resist bed motion, the most viable approach is to calculate shear stress (Carling, 1983; Carson, 1987; Wiberg and Smith, 1987; Ikeda, and Parker, 1989). Many studies have demonstrated that disruption of the armor layer and bedload transport are closely correlated with the shear stress in excess of a : amount necessary to initiate motion (see Einstein; 1950; Parker, 1978). in this respect, a practical procedure for calculating this socalled excess, or critical shear stress, is provided by Andrews (1983, 1984). In 
brief, the technique compares the shear stress generated by the design discharge to the shear stress required to dislodge the median size material in the armor layer. In this analysis, as long as the force generated by the flow is less than that required to move the median particle in the armor layer, the channel is likely to be stable. In other words, for the channel to be stable, the calculated value for shear stress generated by the design discharge $(T)$ must be less than the calculated value of shear stress required to move the median particle in the armor layer ( $\left.T_{C}\right)$.

The shear stress generated by the design discharge can be calculated as:

$$
\mathrm{T}=\mathrm{DS} /(\because \mathrm{s} / \because w-1) \mathrm{d} 50 \text {, }
$$

where $D$ is the mean depth at the design discharge in meters

$S$ is the water surface slope,

¥s is the specific weight of sediment,

$\because w$ is the specific weight of water, and

d50 is the median diameter of material in the armor layer in meters, as measured by sieve analysis.

The shear stress required to move the median particle in the armor layer is equal to:

$$
\mathrm{Tc}=0.0834\left(\mathrm{~d}_{50} / \mathrm{D}_{50}\right)^{-0.872},
$$

where D50 is the median diameter of the subsurface material directly below the armor layer, in meters; again, as measured by sieve analysis.

This relation accounts for the relative protrusion of individual grains in the armor layer as well as the friction among armor and subsurface particles. The equation holds as long as the ratio of $d 50 / D 50$ falls between 0.3 and 4.2 . When this ratio exceeds 4.2 , the force required to dislodge the median particle size in the armor layer can be taken as a constant value of 0.020 . The equation has not been tested for values less than 0.3 .

For reference, a comparative shear stress diagram for gravel-bed rivers is shown as Figure 16, and the following computational example is provided. If we know the design discharge will have a depth of 0.5 meters and a slope of 0.0075 , the shear stress gerierated by this flow will be equal to: 


$$
\mathrm{T}=0.5 \times 0.0075 /(¥ \mathrm{~s} / ¥ w-1) \mathrm{d} 50 \text {, }
$$

By convention, the specific weight of sediment is taken to be equivalent to that of quartz, which has a value of 2.65. The specific weight of water is always equivalent to 1.00 . Thus, if the median particle size of material in the armor layer is 0.065 meters, we have:

$$
\begin{aligned}
& \mathrm{T}=0.5 \times 0.0075 /((2.65 / 1.0)-1.0) \times 0.065, \\
& \mathrm{~T}=0.5 \times 0.0075 /(1.65) \times 0.065, \text { or } \\
& \mathrm{T}=0.03
\end{aligned}
$$

If the subsurface material has a median particle size of 0.045 meters, the critical shear stress can be calculated as:

$$
\begin{aligned}
& T_{C}=0.0834(0.065 / 0.045)^{-0.872,} \\
& T_{C}=0.0834(1.44)^{-0.872, \text { or }} \\
& T_{C}=0.06
\end{aligned}
$$

In this case, the shear stress generated by the design discharge is far less than that required to move the median particle in the armor layer, and therefore, the bed should be stable. To protect the subsurface material from scour during the design discharge, the thickness of the armor layer should range from a minimum of 1.5 times the depth of the median stone size or 12 inches, whichever is greater (United States Army Corp of Engineers 1970; Whiting et. al., 1988). For a number of reasons, it is both expected and desirable that the armor layer consist of a variety of stone sizes (for example, see Brayshaw, 1985).

When specifications for the armor layer have been completed, a final check on the over-all stability of the design channel can be made by following the procedure developed by Lane (1953). In cases where the designer would like further verification, other techniques are available (for example, see Chang, 1985 and Wang and Shen, 1985). As a final note, in areas where an adequate armor layer cannot be constructed to due to limited material availability, substrate will have to be imported or grade-control riffles/structures built at appropriate intervals (see Chow, 1959). 


\subsubsection{DESIGNING FLOODPLAINS}

\subsection{Representative Reach Information Available}

Active and inactive floodplain terraces may or may not be appropriate for a site, depending upon the local valley morphology and hydrologic regime. Most natural streams have at least a poorly developed active floodplain, where most riparian vegetation is located (refer to Figure 8, Section 5) In general, if active and inactive floodplains and associated terraces are present in the representative reaches, appropriate terraces should be included on the plan map. They should reflect the local valley sinuosity and be variable in width, using the measured variability as a guide. Generally, as valleys constrict and gradient steepens, floodplains narrow. Conversely, gradients decrease where valleys widen. Whatever the case, designed floodplains should display some variability in width, on both sides of the channel, for habitat and aesthetic diversity. Active floodplain elevations should be determined by the representative reaches, and designed to slope up to inactive terraces at moderate slopes, such as 50:1 or less. The transition between the active and inactive floodplain should generally contoured at slopes of 3:1 or greater. 



\subsection{Representative Reach Information Unavailable}

When designing floodplains with no local morphologic guidelines, it is extremely important that the designer recall that by definition, floodplains are expected to receive and contain periodic overbank flows. As such, the combined flow capacity of the active channel and floodplain should be able to pass, at the minimum, the flood with an expected fifty year recurrence interval without substantial erosion. Where inactive floodplains are incorporated into reclamation designs, total floodplain capacity should approach that expected from floods with recurrence intervals of seventy-five to one hundred years. The designer should determine floodplain flow capacities in the same manner as channel geometry design (Manning equation), by calculating the dimensions necessary to pass a discharge within the channel and on the floodplain. Using two different " $n$ " coefficients, one for the channel and one for the floodplain, is a commonly accepted procedure.

If ground information is unavailable concerning appropriate floodplain width and height, the reclamation designer must rely on loose guidelines and knowledge of the proposed mine site. A properly designed floodplain should serve three functions: 1) dissipate flood flow energy and 2) provide depositional areas for suspended and other fine sediments and 3) provide a medium for local aquifer recharge during overbank flows. Floodplain terraces may also be desirable in narrower valleys if valley wall stability is a concern. For example, where mining activities have resulted in steep, unstable headwalls or hillsides in close proximity to the planned stream location, a structural toe may be necessary to stabilize the hillside. This terrace may also function to capture and store material eroded off the hillslope, keeping this loose, easily entrained material out of the stream environment during normal flows. This terrace may become active during high flows if surrounding elevations permit.

An active floodplain should be incorporated in any reclaimed valley segment. The width of this floodplain will be dependent on the local hydrologic regime and geologic constraints. For example, in narrow gulch placers, valley walls may constrain active floodplain widths to tens of feet or less, with no opportunity to incorporate an inactive floodplain. In wider alluvial valley segments, active floodplain widths may be up to hundreds of feet wide. As a rule of thumb, an inactive floodplain terrace should be designed it vider valleys if the valley width is at least 15 times the active channel widin.

In natural active floodplains, riparian vegetation is often established from the edge of the active channel to the inactive floodplain terrace or valley toes at elevations equal to or slightly greater than the bankfull elevation. Riparian vegetation in these areas is keyed into the local water table, which is often dependent upon fluctuations of water surface elevations in the channel. 
Mature active floodplains are generally flat or slope slightly upwards towards the inactive floodplain. Therefore, active floodplains should be designed to be mostly flat within tens of feet of the bankfull channel edge, and then slope gently upwards as one moves further away from the channel. The prescribed slope up towards either the inactive floodplain or valley toe should be between $20: 1$ to $50: 1$. The elevation of the active floodplain at the transition point to the valley hillslope toe or inactive floodplain terrace should vary from 0.5 to 0.6 times the bankfull depth (Rundquist et al. 1986). Therefore, the distance of the inactive floodplain terrace from the active channel is a function of: 1) the cross-valley slope of the active floodplain, 2) the total width of the valley segment, and 3) the desired discharge capacity of the floodplain and channel.

\subsubsection{VEGETATIVE PLAN}

Revegetation design and planning in areas that have been repeatedly disturbed through placer mining is especially challenging. Often there is a limited quantity of topsoil available for reclamation. Soils are important for their moisture retention capabilities and cation exchange capacities. In disturbed areas, there may be few naturally regenerating plants to provide seed stock. Though it is ultimately desirable to.re-establish a diverse plant community in the reclaimed mine site, the primary concern in these areas is to establish ground cover to inhibit soil erosion, fix nutrients, and begin the development of organic content in the soils.

An inventory should be made of the site to quantify or estimate the topsoil availability and location. During stripping operations, these areas should be given special attention for removal and stockpiling. Plans should be made to salvage as much organic matter on the site as possible, including slash, branches, shrubs, leaf-litter, and small woody debris. Organic matter should be blended with what topsoil is available. Stockpile siting should be such that the material does not need to be moved more often than the initial stripping and final drifting, and should be located away from the active channel. These stockpile sites should be indicated in the mining plan.

In severely disturbed sites where topsoil is scarce, treatment with certain soil amendments may be necessary during reclamation. These amendments may accelerate humus layer development, improve moisture retention and act as fertilizers. Plans also may be needed to inhibit the invasion of noxious weeds it the site. Because revegetation is such a critical aspect of site reclamation, the services of professionals from the private sector, or resource agency personnel, may be required.

Where possible, reclamation plantings should attempt to incorporate plant species that are adapted to the site, including such factors as growing season requirements, elevation, annual moisture regime, and valley aspects. 
However, some non-native species may be necessary for specific purposes, such as soil stabilization, development and nitrogen fixation.

Reclamation revegetation plans need to specifically address riparian zone regeneration schemes in addition to plans for upland revegetation. The rapid establishment of riparian vegetation is critical to the success of active floodplain and channel reclamation. Failure to properly account for riparian zone regeneration may result in a near or complete failure of many of the other reclamation activities. Good candidate species for riparian zone reclamation include those species which can exploit the disturbed ground conditions following channel and floodplain construction. Where possible, opportunistic planting schemes including transplanting "islands" of nearby and undisturbed vegetation should be considered. For example, using a loader or backhoe, whole willow clumps can often be transplanted to reconstructed floodplains with a high degree of success, providing immediate benefits to wildlife and riparian zone function. Island or vegetation cluster planting can be a particularly effective revegetation technique when managed concurrently with mining and reclamation activities. For example, if mining is proceeding slowly upstream, an operator stripping topsoil and vegetation ahead of the active cut can utilize this vegetation and soil for reclamation activities in the most recently reclaimed downstream cut. There are likely many other examples of opportunistic riparian zone revegetation schemes such as this one available to the observant reclamation planner.

\subsubsection{DESIGNING AROUND SITE ANOMALIES}

During reclamation design in disturbed sites, problems may arise when unexpected ground conditions are encountered; some of these anomalies are related to relicts of past mining activity. These problems include the presence of unreclaimed trenches, settling ponds, large dredge piles and the existence of channel diversions. Because the intent of reclamation is to enhance the final condition of the site relative to conditions at mine closure, these anomalies must be addressed in some fashion. It is therefore important for the miner and the regulatory agency to clearly identify both the opportunities to work with or around such obstacles, and to address obstacles beyond the scope of expected reclamation activities. Where possible, serious consideration should be given to obtaining funds from other sources to be used specifically for site enhancement beyond the scope of the miner's legal obligation. If such funds are available, agency scureces should direct the miner to them and assist in their acquisition.

Many ground obstacles may necessarily be altered by the most recent mining entry. For example, an operator may feel obliged to move tailings piles in order to mine the site beneath or adjacent to the piles, re-excavate or fill an existing tailings pond, or use an existing stream diversion for mine drainage or operation. Where these activities occur, their subsequent reclamation is 
important. Opportunities also may exist to modify existing ground disturbances to enhance general site conditions. In some reclaimed placer mine sites, it is not uncommon to find old settling ponds functioning as wetlands. These ponds may be enhanced by relatively simple construction techniques such as re-shaping pond edges, contouring of berms, and selective pond deepening. Vegetative plantings also may benefit these sites by increasing diversity and broadening the forage base for waterfowl and wildlife. However, many old settling ponds are not suitable for the retention of year-round water, due to unstable containment berms, undesirable interception of ground water which would better be expressed as running surface water, or simply being in a poor location.

Where existing ground disturbances are financially or physically beyond the realistic scope of the current mine reclamation activities, it may be necessary to work around the obstacles. For example, solutions may include constructing a new channel around existing obstacles, providing only superficial treatment of unused and relic settling ponds, and constraining the options for selection of valley grades. 


\subsection{INCORPORATION OF RECLAMATION ACTIVITIES WITH MINING OPERATIONS}

\subsection{INTRODUCTION}

The most well thought-out reclamation plans are only as effective as their implementation. Perhaps the most frequent breakdown in the total stream reclamation process occurs once actual mining operations have begun. Though placer activities may commence with the intention of reclaiming the site, several factors can conspire to circumvent final and effective reclamation. These factors may include poor planning, inefficient mine operation, lack of profitability, or eventual disregard for reclamation as a goal. Tenuous exploration work can result in misleading claim information, which dictates profitability and in turn, can affect expenditures of time and effort in reclamation. In some cases, there may be a lack of understanding on the part of the operator that effective reclamation techniques can be practiced concurrent with mining. Consequently, the following sections illustrate ways to integrate reclamation with mining. Other factors affecting the failure to reclaim placer mine sites are addressed in a separate report (Regulatory Considerations Regarding Placer Mine Reclamation Of Stream Environments In Montana).

As evidenced by the state and federal guidelines surrounding mining (see Section 3.2 and appropriate appendixes), total reclamation of disturbances created by placer mining entry should not be considered a secondary activity of mining. Not only are reclamation efforts more effective when they are treated as an integral part of the total mine operation, they are commonly less expensive. This reality is the central reason for conducting reclamation concurrently with excavation, material handling, disposal and final disposition of all mine workings.

The scope of this report focuses on medium to low volume placer mine operations which typically use mobile trommels and/or some form of sluice for the separation of gold from excavated pay gravels. Some type of trommel is the most common placer gold separation plant in Montana, as these units are the most efficient separating gold from clay deposits (McCulloch, Montana Bureau of Mines and Geology, Butte, MT, pers. com. 1991). Mobile operations are the most commonly er.-:untered in western Montana. Their operation differs significantly fror a stationary plants, where material must be first hauled to the separating facility, and then hauled back to the site of excavation. Material handling in these operations usually involves greater sums of capital and depends on processing up to thousands of cubic yards of gravel per day. In contrast, most mobile trommel operations require little more than one piece of heavy equipment to load the trommel and process 
from tens to hundreds of cubic yards of material per day. Despite these differences, however, many of the reclamation concepts discussed here for mobile trommel operations apply equally to stationary plant operations.

Because it can be safely assumed that every placer mining operation will be unique in terms of the physical setting, size of operation, mining and gold separation techniques, and type of equipment used, this handbook cannot provide specific details for concurrent reclamation in every instance. However, it has been noted that every placer operation will have some similarity based on the need to: 1) excavate, transport, and stockpile overburden and low value gravels, 2) excavate and transport pay gravels to the processing system, 3) process the pay gravel to recover gold, 4) manage tailings and 5) reclaim the site (Salisbury and Associates, Inc. 1987). In the following sections, aquatic reclamation principles based on the above similarities will be generally explored.

\subsection{SEQUENCE OF MINING OPERATION}

\subsubsection{Review Of Operation And Redamation Goals}

Following permit acquisition, but before mine start-up, a review of the mining and reclamation plan with the applicable agency personnel should occur. This meeting will reiterate the targeted goals for reclamation at the site, and should include a discussion of attendant monitoring of reclamation success once surface disturbances are created. At this stage, all necessary permits, final adjustments to the sequence of panel excavation and a timetable for various stages of reclamation should be in hand.

\subsubsection{Mobilization And Set-up}

Mobilization and set-up of a placer mine site may include delivery of heavy equipment, road pioneering, timber felling and clearing, and construction of storage and maintenance sheds. During these activities, every effort should be made to limit the area of ground disturbance, particularly near live and planned stream locations. For example, where excavation or material storage is not planned, an exclosure should be delineated to avoid future and unnecessary reclamation of these sites. Heavy equipment traffic over these areas should be avoided, since it can seriously impact the soil and vegetative properties of the area. Buffer zones should be designated alongside all riparian areas to help preserve existing vegetation and protect stream environments from potential sedimentation. Buffer zones are undisturbed areas that maintain the integrity of the adjacent stream channel.

Finally, material storage sites (including topsoil stockpile areas), and settling pond locations should be designated on the ground. These areas should be planned according to the sequence of panel excavation, bearing in mind the 
location of the newly constructed stream channel and floodplain. This element of planning will be addressed further in a following section.

\subsubsection{Stream Relocation}

In Section 6.3.3.4, the need for effective channel diversion design was emphasized. It was noted that the construction of diversion channels is much different than the construction of natural channels. When site conditions and the mine plan dictate that a stream must be relocated, the stream channel is either diverted around the site in a temporary manner, or permanently relocated. The permanently diverted creek may be built in two different phases. The first phase may consist of simple re-routing, through an armored channel of appropriate size, or even routing through pipes. The second phase of construction may involve detailed channel work, such as the addition or removal of substrate, modification to channel pattern and the construction of terraces. This phase is outlined in greater depth later in the handbook. These activities may not be appropriate until an entire mining panel is brought back to the designed target grade. Temporary diversions tend to be associated with construction de-watering, and should therefore be constructed to provide adequate working conditions.

When de-watering a section of live stream that supports a fish population, it is suggested that the water diversion take place slowly over a period of several days. This procedure allows resident fish to respond to decreasing flows by migrating from the site to downstream or upstream areas which still carry adequate flow. Additionally, by slowly diverting water into the temporary diversion channel, the operator has the opportunity to evaluate the adequacy of the diversion channel and correct any immediate problems before experiencing larger flows.

Once a channel is relocated, it is strongly suggested that the channel not be relocated again. Channel manipulation can be time consuming and greatly increase the cost of the mining operation. Further, the likelihood of channel and general site erosion and downstream water quality problems increases with each handling, and re-establishment of stream function is reduced.

\subsubsection{Siting Of Excavations}

Utimately, the siting of excavations for the extraction and processing of goldbeariing gravels should be based on earlier exploration work and local geology. During the reclamation planning and design phases, the designation of distinct mining panels should have been made with this information in hand. Knowledge of the presence and estimated value of the gold deposit within the greater mine site is essential to the smooth operation and reclamation of areas disturbed by mine operations. Mining and subsequent reclamation should take place in only one panel at a time; haphazard 
excavations, and the creation of trenches or cuts in different locations, leads to complications during reclamation. Opening only one panel at a time minimizes ground disturbance, and by operating in this manner, the reclamation bond can be kept to a minimum.

Within any given mining panel may be any number of sets. Sets refer to discrete areas of operation which are usually based on the mining equipment configuration. For example, a set may be bounded by the effective reach of the excavating equipment, such as a dragline or hydraulic excavator, in one setting for washing gravel in a mobile trommel. Because placer pay streaks are often discontinuous over short distances, the development of succeeding sets may be dictated by gold recovery from the preceding set. This may encourage "hop-scotching", or the development of many discontinuous excavations within a given panel. Though the miner is often economically obliged to mine in this manner, when excavation siting, depth, or widths begin to diverge from that anticipated in the pre-mining reclamation plan, the results of these activities need to be balanced with the consequences for reclamation and it's related increase in operating costs and bonds.

\subsubsection{Material Handling}

Proper handling of excavated materials will save the operator great expense when reclaiming the mine site. Depending on the nature of the site, mining configuration and the method of gold separation, the various excavated and processed materials may have different uses in reclamation. As such, the volume of needed reclamation materials should be known, and as the mining operation proceeds, these materials should be stockpiled in the proper location and quantity. Because excavating and processing material is the basic expense of mining, every effort should be made to avoid excessive handling. This can be accomplished by integrating excavation and material storage with the different reclamation prescriptions for the site.

\subsubsection{TOPSOIL AND ORGANICS}

Before the lode bearing trench or cut is opened, topsoil and organic matter such as woody debris, shrubs, and litter in the immediate area should be stripped and stockpiled. Where opportunity allows for the whole salvage of shrubs or islands of vegetation, these should be set aside. As with excavations, stripping should not exceed the amount of ground planned to be actively mined during the current operating season. The exact stockpile location for topsoil and organics will be in part dictated by the quantities onsite. For example, in many previously placered environments, topsoil and organic matter may be very scarce. Where this is the case, the final dispersement of the topsoil will be prioritized for the riparian and floodplain areas. Consequently, the stockpiles should be located within easy drifting distance of these areas. 
Where topsoil and organics are in adequate supply for redistribution over all disturbed ground, the stockpile sites should be located parallel to and far enough away from the excavation to allow room for stockpiles of overburden and low paying gravels between the excavation and the topsoil. Whether working upstream or down, the most easily reclaimed excavations are contiguous cuts rather than scattered excavations.. As the cut grows in length, topsoil ahead of the trench is regularly stripped away from the ground surface and stored in parallel "windrows" out of normal traffic areas. Windrowing material in this manner usually facilitates the most efficient trench or cut backfilling of materials in the preferred order.

\subsubsection{OVERBURDEN AND LOW-PAYING GRAVELS}

Overburden, which consists of the non-paying alluvial, colluvial, and fluvial deposits, also needs to be stockpiled in areas which facilitate the most efficient excavation backfilling, site grading, and channel reconstruction. As with all excavations which will be backfilled, the operator should avoid creating areas of material imbalance, or areas where stockpile volumes exceed that necessary for backfilling and valley grade adjustments. Excavated material quantities are more likely to remain in balance if overburden is stored similarly to topsoil, i.e., in rows adjacent to and between the topsoil and open trench or cut. The exact configuration for stockpiling will be different in every instance, and reflect among other factors, the depth and extent of overburden, availability of storage sites and equipment in use.

\subsubsection{PROCESSED MATERIALS}

Perhaps the most difficult aspect of material handling to generalize relates to the separation of gold from pay-gravels. Depending on what separation method or combination of methods is utilized, such as a trommel, vibrating screen or sluice, processed gravels will be sorted differently. Further, each mining set-up will result in varying levels of material size segregation after processing. For example, in one case a portable trommel operation equipped with a grizzly, oversize conveyor and sluice may be operating in the bottom of a trench. Materials processed by the plant may be mechanically separated, but the different sized materials are not normally stockpiled by size; they are left in the trench where they exited the plant. In another case, a similarly equipped separation plant may be operating away from the cut or trench, resulting in discrete size segregated piles around the plant. In the former case, stockpiling segregated sizes of material for reclamation activities would involve a great deal of additional material handling not necessary in the latter case. Many other scenarios are possible.

Given the diversity of operations possible, two assumptions are made in this section: 1) there is a need for different size classes of material for reclamation 
activities and 2) the processing of pay gravels results in some sort of material segregation. Depending on the mining operation and separation plant configuration, some or all of the following concepts may be applicable. In any case, it is the responsibility of the mine operator to assure the appropriate materials for reclamation activities are gathered. The viability and efficiency of these operations rely greatly on operator initiative and creativity.

In many placer operations, there will be the following material classifications: 1) topsoil and organics 2) overburden consisting of either sorted gravel and cobbles (as in previously processed tails) or a heterogeneous composition of rock, gravels, and fines, 3) "over-sized" rock and boulders, often separated by a screen (grizzly) and generally greater than 14 inches in diameter, 4) cobble and rock less than 14 inches and greater than $1 / 2$ inches in diameter, 5) sluice or trommel tails generally smaller than $1 / 2$ inch, and 6) fines consisting of sand, silt, and clays. Management of material sizes 1 and 2 have been discussed; the other size classes are discussed below.

Fractured parent material or bedrock, if present, is usually the last fraction of overburden excavated from the lode bearing trench, as placer gold is often found in this geologic layer. Much of this material is "over-sized" rock which is separated out by a grizzly fitted at the head of a sluice on the trommel hopper. Depending on whether large rock is available on-site, some of this material may be useful in channel reconstruction as roughness elements (see Section 7.3.7). If these needs have been previously identified, some of this material may be stockpiled in a suitable location. Over-sized material not needed for reclamation should either be stockpiled in windrows on the inside of the previous overburden pile, and closest to the open trench, or in the case of a separation process in a cut or trench, left where processed.

Cobble and rock may or may not be distinctly segregated from smaller gravel and fines depending on the separation process. An example of this type of separation occurs when a plant is equipped with an over-size conveyor. Depending on the substrate, this class of material may be appropriate for channel bed armor, and should therefore be stockpiled in necessary quantities. Stockpiling of this material may be unnecessary if, for example, the composition of the overburden is adequate for channel armor.

Sluice or trommel tails consisting largely of small gravels may be appropriate material for the gravel filter layer in the reclaimed channel. If possible, material of this size should be stockpiled in necessary quantities. The location of these and other stream construction stockpiles should facilitate minimum handling during reclamation activities, and will be different for every site.

Most placer operations located in valley bottoms near active streams will have ponds below the trommel or sluice operation to settle fine material. These fine materials are divided into the general soil categories of clay, silt 
and sand. The volume of recovered fines produced by processing will vary depending on mine configuration. For example, a wash plant operating on a floodplain or outside of a cut may have a settling pond system which concentrates and captures virtually all available fines. A portable wash plant operating in a cut may be separated from its downstream settling pond by a natural french drain. Recovery and concentration of fines in this example is diminished, as fines percolate into the interstitial spaces in the french drain, with only the highly mobile "slimes" captured in the settling pond.

Because many placer sites are topsoil limited, particularly those in areas of previous placer mining, recoverable fine substrates may comprise a large fraction of the soil available for revegetation. In addition, this material may constitute the sole source for the construction of an impervious seal for the new channel bottom. Therefore, the material regularly excavated from settling ponds in the course of normal operation may need to be stockpiled for later use. Depending upon the reclamation need, this fine substrate may be stockpiled in different areas. Where fines are in limited supply, their final dispersement should focus on the active channel area and floodplain.

Previously identified channel reconstruction needs also may require the operator to stockpile gravels and rock out of the way of normal mine activity. Depending on the specific mining conditions, the collection and storage of these materials may involve special planning, including storage in an adjacent mining panel which is not yet opened.

\subsubsection{Material Mixing}

The mixing of either excavated overburden, or gravels which were sorted by the trommel or sluice with other substrates, may be necessary for reclamation. Mixing falls into three different categories: 1) backfill materials, 2) topsoil and 3) stream substrate. Because many alluvial valley aquifers are a function of underground material composition, it is important to avoid backfilling trenches and pits with clean gravel and rocks, as these filled areas may then function as subsurface drains. This scenario is most likely when pay-gravel separation is done away from the active cut. When the separation process occurs in a cut or trench, material mixing is accomplished during normal operation. Draining of a valley aquifer may be desirable during mining operations, but is inappropriate for reclamation. Pre-disturbance water table elevations should be preserved, or in some cases elevated, to the extent possible. In this respect, it may be desirable to mix sorted gravels with overburden or with fines from settling ponds before or during backfilling. Some operators have had success breaking-up "French drains" and raising the water table in cuts by constructing a series of slot trenches backfilled with fines prior to seasonal or final reclamation (McCulloch, Montana Bureau of Mines and Geology, Butte, MT, pers. com. 1991). By filling the interstitial spaces between gravels with more hydrophilic material, ground water storage can be 
enhanced. Mixing different size fractions for backfilling is also important near the reconstructed channel, as subsurface drains in these areas can limit surface flow.

In topsoil limited sites, it is often necessary to use small gravels mixed with fines from settling ponds to augment topsoil volume. Without the presence of fines, the regraded valley-bottom soils will have little moisture retention capacity, ultimately limiting the opportunities for plant growth. Mixing may be accomplished by a dozer drifting piles of topsoil (or small gravels) with material excavated from settling ponds during clean-up or pond reclamation. For greatest efficiency, these needs should be addressed when material storage sites are planned.

Substrate requirements for the new channel may also require mixing of different sizes of cobble, gravel and boulders. These needs should be previously identified during the channel design process, as they can often be avoided by utilizing appropriately sized overburden. For example, by using a brush blade on a dozer, coarse rock may be "raked" out of overburden and drifted to a stockpile. The overburden may then have an enhanced percentage of fines. Channel materials may be mixed and stored in a distinct storage area, or mixed at the channel construction area by drifting piles of different substrates.

\subsection{RECLAMATION OF MINING PANEL}

All prescribed reclamation activities, with the possible exception of actual channel construction, should proceed at the pace of mining activity. In other words, as the excavation of overburden and separation of gold from gravel proceeds upstream or downstream, the trench or pit should be concurrently reclaimed. The term "concurrent" may refer to activities in one season, or preferably, on a daily basis. This balance assures that mining activities do not exceed reclamation activities, and upon seasonal shutdown or mine abandonment, most site reclamation has already occurred.

\subsubsection{Bringing The Mining Panel To Rough Grade}

Achieving rough grade in a mining panel should not be difficult if mining activities are nonducted with material balance in mind. Much of this grading should have be $n$ done during site operations, with areas of material imbalances identified and rectified. For example, during backfill operations, an excess or deficiency of backfill may be noted. This could be due to swell associated with excavation or over- or under-stockpiling. Excess material can be used for topographic contouring, while deficlencies indicate the need to obtain more fill. Regardless, once an excavation's pay streak has been exhausted, the cut should be backfilled as described above. Because excavated 
materials were stockpiled or returned to within easy drifting distance of the excavation, this objective should be readily accomplished.

Once the excavated site has been filled, all disturbed areas should be graded to the target valley slope. For most purposes, a tracked bulldozer is necessary. This task may include grading excavated materials left over from trench backfilling and opportunistic material redistribution, as when grading a previously disturbed area with large dredge piles. Where possible, overburden and spoils should be graded to match the local valley topography. For example, backfill slopes should be blended into existing valley hillslopes and non-geometric undulations incorporated or contoured into the longitudinal valley profile. It should be realized that excavated material generally has a lower bulk density than undisturbed ground, resulting in a net increase in excavated material volume. A skilled operator can "hide" large quantities of excess material through contour grading.

To facilitate channel construction, a swale along the alignment of the proposed channel can be graded into the active floodplain (see Section 7.3.3). Consultation of the base reclamation planning map can be used to stake the approximate plan form on the ground and ascertain the proper elevation. The depth and width of the swale should approximate the final channel dimensions. Over-sizing the swale should be avoided, as material may have to be brought back in to meet channel elevation requirements. This step in grading should be closely monitored with surveying techniques.

To efficiently create floodplain terraces during grading, the rough floodplain terrace shape should be delineated with cut or fill stakes to bring the terrace to the designed elevation. In most cases, simple dozer work should then be sufficient. Excess material from cut backfilling can usually be distributed in the inactive floodplain. In unusual cases, material redistribution may be necessary, and require hauling material by truck or scraper over short distances.

An important consideration in flood plain grading is the relation of the groundform relative to the surrounding upland drainages. For example, where ephemeral drainages emerge from the valley slopes onto the floodplain, it is important to extend these channels across the floodplain to the new channel. The planform of these ephemeral tributaries should be slightly sinuous, and capable of conducting the anticipater discharges for the area. For scaling purposes, these ephemeral swale si ses should be based on the observed upslope channel dimensions. These swales can also serve to route floodwaters during overbank flows.

Final rough contouring of the active floodplain usually entails final dispersement of "left-over" piles of overburden. In areas with wide active floodplains, contouring can include the creation of shallow connected 
depressions, which serve the dual purpose of creating diverse microclimates for the establishment of vegetation and act as high water drainages and sediment catchments.

\subsubsection{Channel Construction}

Channel construction is perhaps the most technical aspect of placer mine reclamation in the stream environment. The design and construction of naturally appearing, hydraulically sound and biologically functional channels requires dedication to detail and skilled equipment operation. Because many operators do not have training or experience in channel construction, it is highly desirable to coordinate channel construction activities with trained resource professionals, such as agency hydrologists, consulting specialists or others with an understanding of river mechanics. Given the difficulty of effecting the behavior of natural channels, it is essential that function be stressed over channel form. In other words, the ability to withstand runoff is more important than concern for vegetative plantings. However, this fact does not predude the operator from striving for a channel that is aesthetically appealing.

\subsubsection{Channel Excavation}

If a swale following the new channel course was not incorporated with the floodplain grading activities, it should be part of this construction phase. Using the reclamation base map, the proposed channel location should be staked on the ground. At this time, certain planform elements of the designed channel may be altered to accommodate unanticipated ground conditions. For example, an abrupt and unplanned change in slope, made necessary by the grading operation, may require a slightly sinuous. reach with a steeper gradient than initially planned. All channel location stakes should indicate the depth of cut or fill necessary for construction of the channel at the designed grade. Reference should be made to designs so that the channel excavation is sufficient to accommodate backfilling with gravel, fines and bed armor, while maintaining the designed channel geometry.

A tracked excavator is the most versatile piece of equipment for this channel excavation, as they can simultaneously excavate the channel and load out material for transfer to a fill site. Under no circumstances should the material excavated from the permanent channel be left along side the channel as a berm. Berms are unnatural, inhibit floodplain function during large discharges and can thereby deleteriously affect channel behavior. If it is necessary to temporarily buffer the new channel from potential overland flow sedimentation from ongoing mine operations, silt fences, hay bales or brush wattling should be considered. 
During channel excavation, the initial expression of pool-riffle sequences should be formed. Pools can be excavated below grade, while riffles will be finished by backfilling with channel substrate to variable depths. Pool-riffle spacing should be based upon information gained from the originally undisturbed stream, representative reaches, or when this information is unavailable, by design. A geomorphic truism indicates that, in stable streams, pool-riffle sequences tend to occur once every five to seven channel widths. In other words, where no other guide is available, pools should be spaced approximately every five to seven channel widths apart. Because this suggestion is generic, site conditions will dictate modifications in pool spacing. For example, in many high gradient mountain streams, cascades, riffles, and runs are the predominant channel forms, with few well defined pools. Instead, pools are typically small and associated with roughness elements such as large woody debris or boulders. In these high energy environments it is difficult to generalize bedform spacing; therefore, it can be based on hydraulic considerations and frequencies reported in the literature (Grant et al. 1990).

Channels with identical cross-sectional areas but different slopes have different hydraulic capacities. The design cross-sections for different reach slopes should be used for a general guide in creating all channel geometry. However, some variation in cross-section shape throughout a reach, while still providing the necessary channel capacity, is desirable in order to provide for biological and aesthetic diversity. If multiple cross-sections were recorded to define meander bends, this data can be used as a suitable reference. Ultimately, the reconstructed stream should have the appearance and function of a natural channel.

\subsubsection{Backfilling Channel With Substrate}

Once the channel has been formed and the excavated material removed or blended into nearby topography, backfilling the channel with the prescribed layers of substrate can begin. Using previously stockpiled materials, the channel should first be backfilled with a gravel base layer consisting of 1 inch minus gravel. This layer serves as the foundation for the bed seal layer, which is constructed with fines. This seal of silts and clays should should then be placed cover the entire wetted perimeter. It should be compacted to a minimum depth of a few inches. Applied properly, this base and seal will prevent excessive seepage loss th the aquifer. Half of the channel armor material, referred to as bed mix in th: design specifications, should then be placed on top of the seal. The rewiaining bed mix is applied after placement of woody debris, erosion fabric and roughness elements as described below. 


\subsubsection{Woody Debris Placements}

The incorporation of salvaged woody debris provides roughness and fish habitat. Although this material can be placed opportunistically, most locations should be pre-planned and indicated on the ground with the channel orientation stakes. Figure 17 illustrates some generic placements in reconstructed channels. When placing woody debris, it is important not to excavate through or damage the bed seal layer. It is important to place woody debris materials during this phase of construction, so that final application of bed and bank armor can be used for reinforcement if necessary.

\subsubsection{Placing Erosion Blanket For Bank Protection}

Because most new channels in placer mined sites are excavated in unconsolidated spoils, the exposed channel banks will not be as resistant to erosion as desired. Traditional bank stabilization techniques include covering the wetted perimeter with a blanket of rock rip-rap. However, use of this material actually inhibits the establishment of desirable bank vegetation. As an alternative, a variety of biodegradable and non-biodegradable geotextile fabrics can be used. Biodegradable erosion blankets, typically composed of coconut, filament and straw, temporarily protect banks from scour and provide a germinating medium for seed and saplings. Non-biodegradable erosion fabrics should only be used on a temporary basis in areas of extreme vulnerability to erosion and scouring. Following channel stabilization, nonbiodegradable fabrics should be replaced with biodegradable fabrics. Nonbiodegradable fabrics are often useful for temporary diversion channels.

Prior to placement of erosion fabric, the banks should be compacted, topsoil placed on the immediate banks, raked smooth and seeded with the mix prescribed in the re-vegetation plan. The erosion blanket should be placed so that coverage extends from mean low water elevation to at least 0.5 feet above bankfull elevation. While the blanket is secured to the banks with metal staples and a top key-trench, the toe is secured with gravel supplied by the second half of the bed mix. In areas where additional bank protection is needed, the procedure begins with layering non-biodegradable fabric over prepared soil, followed by two layers of biodegradable fabric.

\section{7.j.7 Placing Rock Roughness Elements In Riffles}

In relatively high gradient reaches, boulders can be used as roughness elements to help dissipate flow energy. Scaled to the anticipated flows, and proportioned to the channel size, each boulder is normally buried to at least one-third of its height into the channel substrate. Boulders also may be integrated to create a labyrinth weir that acts to stabilize grade and enhance habitat. Figure 18 provides a generalized view of these rock placements. Where additional bank protection is required, large rocks may be appropriate. 


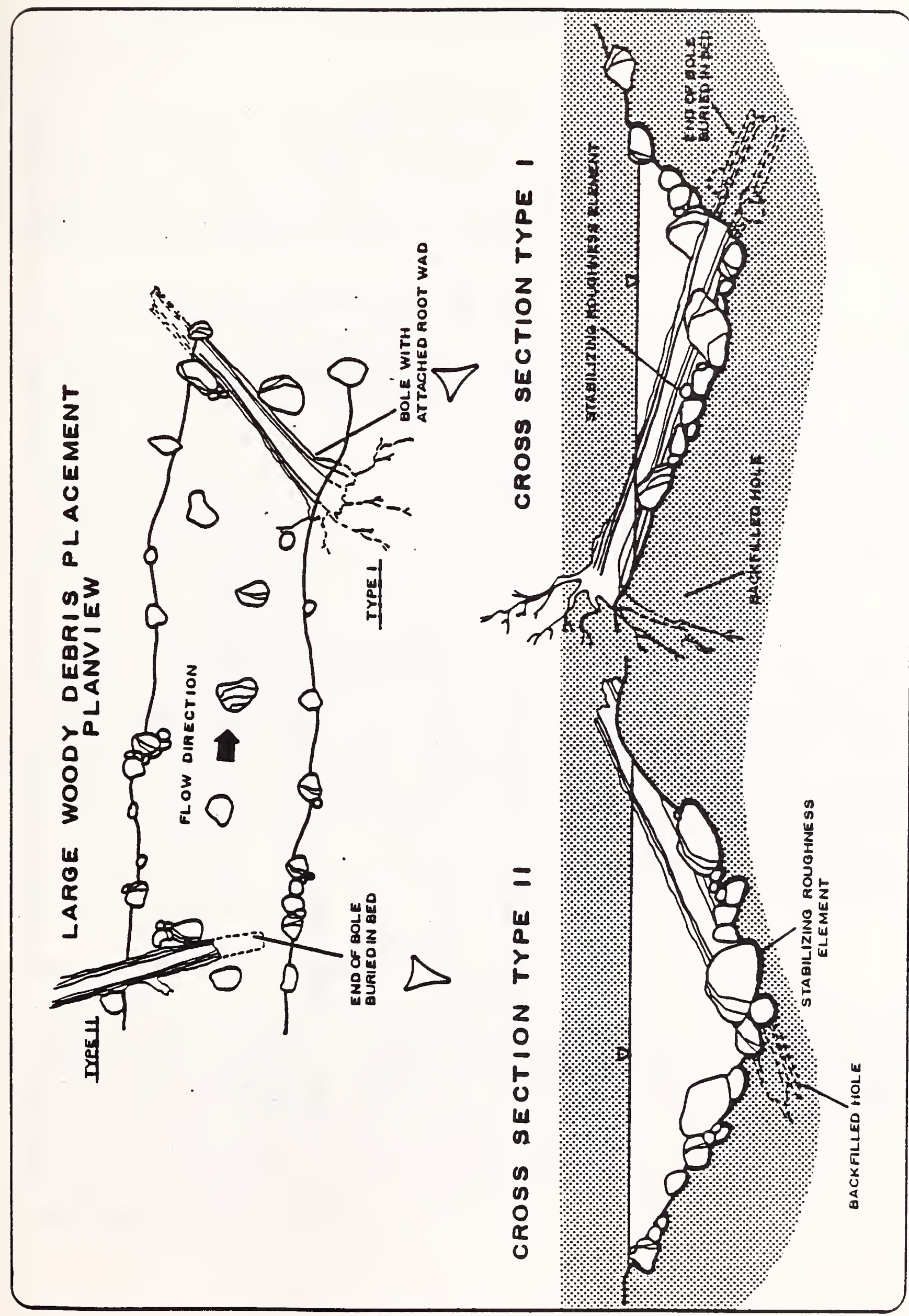

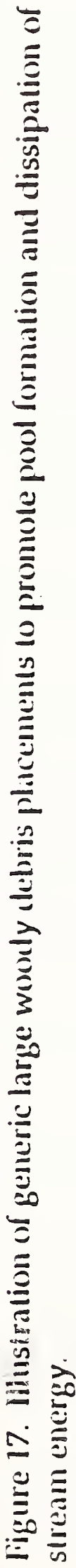



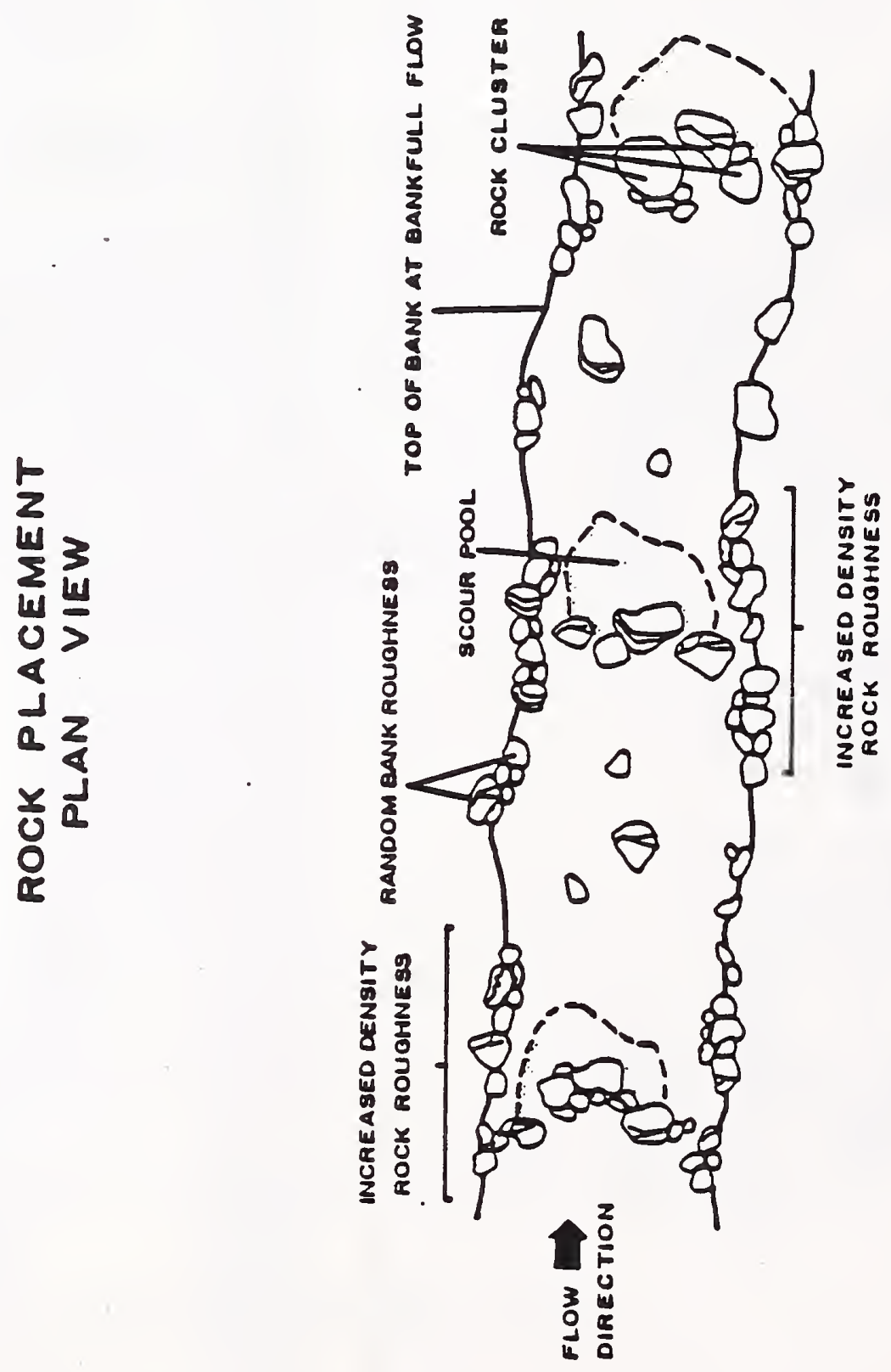
In low gradient reaches, however, the inclusion of large rocks is usually inappropriate.

Riffle sections should have a higher density of large roughness elements than runs. Although the delineation of where a run begins and a riffle ends is subjective, they are visually distinctive. Riffles commonly have convex bedforms, fast flowing water, rough water surface and also may have small standing waves or hydraulic jumps. In contrast, runs are reminiscent of long shallow glides, with less roughness and fairly calm water surface.

\subsubsection{Maintaining Designed Channel Grade}

Channel construction requires that grade be continually checked during construction. This monitoring helps avoid unplanned adjustments to the channel which may require extensive re-working of long reaches. For example, it is very difficult to make adjustments when the channel is constructed considerably below grade, particularly where reaches with two different gradients meet. Minor grade adjustments can be made by increasing the depth of substrate backfill, but greater grade adjustments may require so much backfill that channel capacity is affected. It is easiest to adjust transitions which are super-elevated relative to the next downstream reach.

In most channel reconstruction projects, unanticipated ground conditions or construction techniques will lead to situations where grade is higher than designed. This frequently occurs at valley slope breaks, where two reaches of different grade meet. Where this discontinuity occurs, a transitional segment should be built to counter potential headcutting at the knickpoint. The principal construction objective in these areas is to create a well armored cascade, or energy drop, which dissipates channel energy through a controlled change in channel elevation. Despite grade monitoring, variability is a part of channel construction. Consequently, final grade adjustments, if necessary, can be accomplished with boulder placements, submerged weirs or simple changes to riffle elevations.

\subsubsection{Channel Bank Revegetation With Willow Plantings}

After all stream construction activities are completed, the stored or mixed topsoil should be drifted over the final grade. Topsoil is spread last to misimize potential loss and compaction by heavy equipment during channel construction. Care should be exercised to achieve even topsoil depths over the graded site. Where topsoil is limited, the new riparian area should receive priority treatment. Re-establishing vegetation in the riparian area, to enhance watershed stability, is generally of greater concern than reestablishing vegetation on terraces. 
Although seeding prior to the placement of the erosion blanket is an important aspect of re-vegetation, the use of willow plantings provides the most cost-efficient means of stabilizing banks. For greatest success, willow cuttings should be collected locally during periods of plant dormancy, such as early spring or late fall. However, willow cuttings collected during all periods of the growing season have been successfully planted in many areas of Montana.

Willow stems should be cut from the terminal ends of new growth in 2 foot lengths between 0.5 and 1.5 inches in diameter. Cuttings will develop greatest concentrations and strongest shoots just below bud scars, so they should be cut within 1 to 4 inches of the distal end of the stem. Cut stems should be tied in bundles and stored in a cool place until planting (Phipps and Kester 1981; Hartman and Kester 1968; Warren-Wren 1972).

Willow stems should be planted in soft material, such as topsoil or loose, unconsolidated gravel, by pushing them in by hand or pounding with a two pound hammer. The planted stems should be angled downstream to prevent debris from dislodging them during high flows. Planting density should be at a minimum of one stem every 1.5 feet, at one or more bank heights. Stems should be oriented right side up and planted with proximal ends at or below the anticipated low water elevation. The stems should be planted with two to three growth buds exposed, usually leaving 2 to 5 inches of stem above ground.

Once planted, the willow stems should begin to set roots and show bud development by the end of the growing season. In addition to providing additional anchoring points on the erosion blanket, root development and growth will begin to stabilize channel bank soil. Upon further maturation, the willows will provide substantial fish and wildlife habitat value. For estimating habitat values for fish, see Binns (1982) and Hamilton and Bergersen (1984).

\subsubsection{Floodplain Rehabilitation}

Final floodplain rehabilitation includes the opportunistic dispersement of large woody debris and over-sized boulders to create microclimate diversity, wildlife habitat, and riparian and floodplain revegetation. Large woody debris and large boulders should be discretely distributed throughout the graded floodplain either in clusters or singly. The shrubby species indicated for planting in the reclamation plan should be installed. During all such activities, heavy equipment traffic should be kept to a minimum to reduce areas of soil compaction. 


\subsubsection{Reclamation Monitoring}

Despite the creation and implementation of a well designed reclamation plan, total site restoration may not occur for many years, or in the case of entry into a pristine valley, perhaps even decades. In brief, the natural processes of soil genesis and evolution of vegetative communities cannot be accelerated by human efforts. Additionally, reclamation activities have no control over natural phenomena, such as extended periods of drought or above average precipitation and flooding. The occurrence of any of these events may impose changes on the reclaimed site which may slow the regeneration process, or even seriously impede original reclamation objectives.

Because of the above realities; reclamation monitoring should occur, and prescriptions made, to adjust site conditions as necessary. Much of this monitoring should be done by the mine operator and may entail little more than season-by-season evaluation of the preceding season's reclamation work. For example, following winter shutdown and subsequent spring runoff, unanticipated channel erosion may occur in certain areas. These problems should not only be promptly addressed, but an evaluation made as to the cause of the problem. This experience should be valuable for the next work season or for other mine sites. The period of monitoring should, at the minimum, include the life of the mine, and where mining entry is relatively short-lived, continue for several years after closure. Necessary site prescriptions may include additional vegetative plantings, control of surface erosion, and adjustments to the new channel. The information gained in long-term monitoring should be used for a guide to evaluate the effectiveness of various reclamation techniques, and used for future reclamation planning at other sites. 



\subsection{COSTS ASSOCIATED WITH PLACER MINING AND RECLAMATION}

\subsection{INTRODUCTION}

This portion of the document provides miners and regulatory personnel with an understanding of costs associated with placer mine reclamation in the stream environment. These costs include those required before any mining actually occurs; that is, costs associated with pre-mining data collection, reclamation planning and permit acquisition. Also addressed are costs incurred once mining has commenced, such as those for site preparation, regrading, annual winterization (interim reclamation), annual maintenance and operation, monitoring, finished reclamation and re-vegetation.

There are numerous costs associated with reclamation and the environmental aspects of placer mining. In the last twenty years or so, many of these expenses were not fully realized by placer miners. In fact, based on the number of abandoned mines and forfeited bonds throughout this period, many operators and investors failed to consider the overall economic feasibility of their mining operations. This document is not intended to address the costs associated with placer mining itself, such as the exploration, mining, and processing of ore. It is assumed. that anyone interested in undertaking placer mining will recognize the financial aspects entailed and will fully evaluate costs and retums. Those unfamiliar with estimating the capital and operating costs of placer mining are referred to the booklet prepared by the U.S. Bureau of Mines (Stebbins 1987). For a thorough discussion of placer mining methods and economic evaluation, miners should refer to more extensive texts (Macdonald 1983).

Despite the fairly detailed cost information available on mining, there is little quantitative data regarding reclamation or general environmental costs. In the past, most emphasis was placed on production costs over reclamation; note that cost estimation manuals (Stebbins 1987) have included reclamation under supplemental operating cost headings such as "Lost Time and General Services," despite the magnitude of costs involved. With an increased perception by the public of the value of land and water resources, laws have been passed requiring more stringent environmental protection and reclamation (such as SMCRA, the Surface Mining Control anr. F . -lamation Act of 1977). As such, the true cost of reclamation should be rfaized by the miner. These costs, however, need not be prohibitive to a successful mining operation, as long as they are recognized early on:

"The additional costs for environmental protection are minimal if the ecological requirements are catered for from the start; they can be very considerable if only tacked on at the end" (Macdonald 1983). 


\subsection{OPERATOR COSTS VERSES CONTRACTOR COSTS}

It is important to recognize the difference between the cost of reclamation undertaken by a mine operator during the mining process and by a bond holder after forfeiture of a bond. An operator who owns and operates his or her own equipment will have relatively low reclamation costs; for example, equipment costs should be limited to fuel and lubrication, maintenance and repair. Conversely, a bond holder undertaking post-mining reclamation will administer contracts with one or more heavy equipment contractors. Equipment costs will be higher because contractors will charge overhead and profit; furthermore, state or federally funded work will require a contractor to pay Montana or Davis-Bacon wage rates. Additionally, administrative costs would likely total 15-20\% of a contract (Pierce, Geologist, USDI Bureau of Mines, Spokane, WA, pers. com. 1991). Therefore, the costs for reclamation by operators may amount to less than half of that for contractors undertaking the same work.

Costs in this document have been gathered from a variety of sources. Many sources did not adequately reflect whether work was undertaken by a miner or a contractor; therefore, they did not indicate if overhead, profit or administrative costs are included. In the text we have attempted to identify qualifying information to allow appropriate comparison. Since we have a limited amount of information on direct operator costs, we have reported most figures as contractor costs. Where available, figures are given for both types of costs. Within this framework, the following sections identify average costs per common unit for placer reclamation in Montana.

\subsection{ESTABLISHING BOND AMOUNTS}

The cost of reclamation has a direct correlation to the bond amount levied by Conservation Districts, DSL and USFS for placer miners, both for areas of disturbance of less than 5 acres (applicable to the SMES) and for larger sites. In the past, reclamation bonds for placer mining in stream environments have been undersized. As evidence, consider that few placer mine sites where bond has been forfeited have been adequately reclaimed by the bond holder. Generally, the bond amount was insufficient to undertake site grading, reconstruction of stream channels and re-vegetation of riparian corridors.

Bond amounts should be sufficient to cover reclamation costs identified in the approved reclamation plan if such reclamation had to be performed by the regulatory agency in the event of forfeiture. The Handbook For Calculation of Reclamation Bond Amounts (1987) identifies four assumptions in cost estimations of performance bond amounts: 
1) bonds are based on the costs of performing reclamation by a thirdparty contractor engaged by the bond holder;

2) performance bonds are based on those conditions that define the point in the planned mining operation that presents the greatest estimated reclamation costs for the permit term;

3) the permit applicant is responsible for providing all reclamation information necessary to validate the reclamation plan and bond amounts, but any other sources in addition to those provided by the applicant should be used to validate costs; and,

4) performance bonds are based on the applicant's adherence to the approved mining and reclamation plans, permit conditions and performance standards.

\subsection{PRE-MINING RECLAMATION DATA COLLECTION AND ANALYSIS COSTS}

From descriptions of the data required to establish a baseline for reclamation (see section Pre-mining Data Necessary for Effective Reclamation), it is apparent that a considerable amount of time is required for data collection and analysis. Some, if not all of the work required, can be undertaken by the miner, possibly with assistance or direction from various resource agency personnel. The miner must realize that the work he or she intends to undertake is time-consuming; while there may be no direct costs to the miner, he or she must be able to allocate the time required.

\subsubsection{Professional Services}

On large-scale and medium-scale placer mining operations, professionals are usually hired to undertake a variety of specific duties according to their expertise. These areas include exploration evaluation, mine feasibility, topographic surveying, soils inventory, reclamation design and supervision, permit acquisition and negotiation, legal counsel, operation management and re-vegetation. Depending on the size of the proposed operation, the capital available, the mine potential and the experience of the miner, some or all of these professionals might work as a team throughout feasibility, design, mine operation and reclamation.

The cost for professional services depends on the type of service and the expertise available. Generally though, professionals charge fees according to time worked, plus any expenses associater with the project 'referred to as time and materials). Hourly rates for tishnical level persunnel generally range from $\$ 25$ to $\$ 40$. Those for professional personnel tend to range from $\$ 50$ to $\$ 75$. Charges for engineering services are at the high end of the range. Legal counsel costs upwards of $\$ 100$ per hour for non-trial time. Expenses usually include mileage (20-30 per mile), per diem ( $\$ 50-70$ per day depending on location), phone calls and any project-related materials. 
Based on hourly rates, surveying costs for conventional topographic information can vary between $\$ 250$ and $\$ 1,500$ per acre (Smit 1988). Costs for simple longitudinal and cross-sectional information are much less than for digitized contour maps taken from scaled aerial photos.

\subsubsection{Aerial Photographs}

Aerial photos are one of the best tools for developing base maps for placer mine planning, mining and reclamation. Professional aerial photographers are able to take clear, accurate photos for relatively low cost. Costs for aerial photos will depend on two factors; the distance of the site from the photographer's base airport, and the surface area to be covered on film. Typically, hourly costs for flying time (pilot, plane and photographer) are $\$ 150$ to $\$ 300$. Actual costs associated with aerial photography depends on the area to be shot, but a 1-mile stream length would cost less than $\$ 1,000$. Contact print enlargements to standard $36 \times 24$ inch sheets are nominal (about $\$ 50$ each).

\subsubsection{Field Measurement Tools}

As described in the section entitled Pre-mining Data Necessary for Effective Reclamation, certain field equipment should be considered essential to collect information. The following survey tools are available from engineering supply firms and forestry supply companies: a 200-foot steel (\$100-400) or fiberglass tape (\$20-60); an engineers or builders level (\$300-600), with a tripod $(\$ 80-160)$ and extendable stadia rod $(\$ 100-200)$. Those capable of using an alidade and plane table can purchase complete systems for around $\$ 2,000$.

\subsection{RECLAMATION DESIGN/PERMIT ACQUISITION COSTS}

Costs associated with preparing reclamation designs and acquiring a mine operating permit can be substantial. For example, the costs for submission of a placer mine permit application for the mining of $1,000,000$ cubic yards of material, including reclamation designs of 38.1 acres and 9,400 feet of Washington Creek (near Avon, MT), were approximately $\$ 130,000$ (Wall, Mining Consultant, Salt Lake City, UT, pers. com. 1990). This mine site has been extensively placered since the turn of the century with little or no reclamation attempted. Most projects of any magnitude will require the services of professionals in the fields of hydrolozy cngineering, fisheries and geology (Richards, Shoshone-Bannock Tribes, Fort ilall, ID, pers. com. 1989).

It is difficult to estimate the costs for reclamation design and permitting if all services were contracted to professionals. This difficulty results from the variation in mine sites, the degree of existing information available and the costs for services. However, some design and permit costs have been reported (Table 3 ). 
Table 3. Design and feasibility costs per lineal foot of stream incurred or estimated for placer mine projects in stream environments. See Table 14 for source details.

\begin{tabular}{|c|c|c|c|}
\hline Item. & Affected Area & Cost/.Unit & Reference Source \\
\hline Consulting design services & unknown & $\$ 0.70 / \mathrm{ft}$ & Lawrence, pers. com. \\
\hline Engineering and biological & 2.5 miles & $\$ 5.40 / f t$ & Richards, pers. com. \\
\hline $\begin{array}{l}\text { All phases of design, depends on } \\
\text { baseline data available(estimated) }\end{array}$ & variable & $\$ 1-10 / \mathrm{ft}$ & Mohr, pers. com. \\
\hline $\begin{array}{l}\text { Legal, administrative \& permitting } \\
\text { (estimated) }\end{array}$ & 1.6 & total project costs & Mohr, pers. com. \\
\hline $\begin{array}{l}\text { Reclamation plans and portions } \\
\text { of operating permit application }\end{array}$ & $9,400 \mathrm{ft}$ & $\$ 1.70 / \mathrm{ft}$ & $\begin{array}{l}\text { Inter-Fluve, Inc. } \\
\text { (Washington } \mathrm{Cr} \text { ) }\end{array}$ \\
\hline
\end{tabular}

\subsection{MINING AND RECLAMATION COSTS}

Since the vast majority of costs in mining and reclamation involve those for heavy equipment, the source of equipment will be reflected in total project costs. If an operator mining one acre intends to undertake all work with a small dozer that he or she owns, then operating costs will be limited to fuel and parts. In larger projects where the work is contracted, the local prevailing rates for equipment and manpower will influence total project costs. In some areas of Montana, the labor pool has a high percentage of unemployment. Similarly, in depressed locations, equipment contractors are operating at less than optimal utilization. In these situations, equipment and labor used in a mine operation will offer relatively competitive rates.

Conversely, if a mine project involves any work funded by a state or federal agency, then specific wage rates apply. With federally funded work, DavisBacon Wages must be paid to the labor force rather than local labor rates. Davis-Bacon labor rates are \$15-18 per hour, whereas local rates may be \$7-9 per hour. Similarly, Davis-Bacon rates for heavy equipment operators, including fringe benefits, are \$31-33 per hour (U.S. Department of Labor 1990). With state funded work, prevailing wage rates and fringe benefits must be paid. State of Montana prevailing wage rates for labor are roughly similar to the federal rates (Moutina Department of Labor and Industry 1990). Thus, if the state must uidertake reclamation on a forfeited bond, heavy equipment costs could be $10 \%$ higher and labor rates could be $100 \%$ higher than if the operator would have contracted the work.

Mine and reclamation costs can be divided into three general cost categories; including: 1) site preparation, 2) rough grading and 3) finish grading and 
reclamation. The following sections address costs associated with this work. Heaoy equipment costs identified in Section 8.6 are those expected if a miner, large or small, does not own and operate his own equipment. Costs for owner-operators (either small family outfits or large corporations) would be somewhat less, depending on whether they owned their equipment outright and whether it was in good operating condition.

\subsubsection{Site Preparation Costs}

Costs for site preparation typically include mobilization of heavy equipment, materials and manpower; clearing and grubbing; road pioneering, and stockpiling of topsoil, large woody debris and boulders. Mobilization costs usually include those for transportation of heavy equipment, expected per diem costs for labor, and certain up-front purchases. These costs will be dependent on the distance to the contractor's base of operations. Mobilization costs for large heavy equipment suitable for placer mining (dozer, loader, scraper and excavator) for distances up to 25 miles may run $\$ 200$ to $\$ 300$ per piece (Smit 1988). In some operations, mobilization costs are estimated as a percentage of the total project; a mobilization cost at $6 \%$ to $7 \%$ of project total has been reported (USDA 1989; ESA, Lafayette, CA, pers. com. 1989)

Road pioneering, site preparation and stockpiling are typically done by large bulldozers, excavators or draglines. Non-usable woody debris is collected in slash piles and burned; material suitable for reclamation is stockpiled. Topsoil is dozed into piles at locations identified in the plan of operation. Similarly, large boulders are collected at stockpile sites.

The hourly costs for heavy equipment will vary depending on the work capacity of different machines. The total cost for site preparation per unit of work (such as per acre cleared and cubic yard of topsoil stockpiled) will similarly vary depending on the number of work units, the machinery used and the efficiency of operation. Given this caveat, costs per work unit are summarized in Table 4.

\subsubsection{Rough Grade Costs}

In any placer mining operation material handling is the single most costly aspect of the project. Thus, mishandling material can be one of the costliest mistakes of a mining operation and can quickly lead to economic failure. A good rule of thumb is that "every load extracted from the ground should have its ultimate destination planned in advance" (Macdonald 1983). Double handling should be avoided because it essentially doubles the cost of moving overburden and ore-bearing material. It should be noted that placer deposits, when extracted from the ground, typically expand 14\% to $18 \%$ (USDI 1987, and Smit 1988) and have been known to swell as much as 30\% (Macdonald 1983). 
The cost of material handling is the main reason reclamation should take place concurrently with mining. Material that is extracted from the ground and passed through a processing plant should be returned to the approximate area of removal as part of a coordinated operation. For example, on a small project where material is pushed to a trommel with a dozer, after separation the spoil should be pushed back before a large pile develops. Similarly, on a large project where trucks haul material to a wash plant, they should return to the source carrying spoil material. High material handling costs are another principle reason reclamation bonds prove largely inadequate when an operator abandons a claim part way through the operation.

Table 4. Cost per acre for site clearing and stockpiling topsoil based on contractor costs (derived from Smit 1991).

\begin{tabular}{lllll}
\hline Item & Labor Cost & Equip. Cost & Total Cost & Total WI \\
& Per Acre & Per Acre & Per Acre & O \& P/Acre \\
\hline
\end{tabular}

Site clearing: felling trees and piling

w/ tractor, level terrain, large tract.

$25 \%$ to $50 \%$ hardwoods:

400 trees/acre

$>600$ trees/acre

$\$ 415$

$\$ 595$

$\$ 1,425$

$\$ 2,050$

$\$ 1,840$

$\$ 2,645$

$\$ 2,200$

$\$ 3,150$

Stripping and stockpiling topsoil w/ 300 HP dozer, conditions:

sandy loam $8^{\prime \prime}$ deep, ideal

sandy loam $8^{\circ}$ deep, adverse

clay soft $8^{\circ}$ deep, ideal

clay hard $8^{\circ}$ deep, adverse

$\$ 87$
$\$ 163$
$\$ 140$
$\$ 247$

$\$ 87$
$\$ 163$
$\$ 140$
$\$ 247$
$\$ 399$

$\$ 722$

$\$ 602$

$\$ 1,056$
$\$ 473$

$\$ 860$

$\$ 710$

$\$ 1,290$

Reprinted by permission of R.S. Means Company, Inc.

For reclamation to occur in large mining operations that use a stationary or semi-stationary trommel, overburden and treated ore-bearing material will need to be returned to the approximate location of their original source (refer to previous section entitled Material Handling). In these cases, initial economic feasibility should account for concurrent material re-distribution; if it must occur after the fact, costs increase dramatically.

As outlined in the section Deoeloping a Reclamation Plan, we have used the term rough grading to include general shaping to bring ground elevations to grade and to form floodplains, terraces, ponds and tretlands. While following design specifications, this work is usually near to grade (within a few tenths of a foot of specifications) because of limitations imposed by the size of the earthmoving equipment. The equipment used to bring the mine site to rough grade will likely be the same on-site equipment used for overburden and placer removal. This equipment may include: hydraulic excavators (with 3 cubic yard buckets), twin engine scrapers, articulated front end loaders 
(with 5 cubic yard or larger buckets), dozers (D8 and larger), draglines and dumptrucks (16-35 cubic yards).

As described in the previous section, one must use caution in quantifying costs due to the variability in controlling factors. These factors include the size and configuration of the mine site, the amount of overburden, the size of stream affected, if any, the equipment used, and the knowledge and skills of the miners. Furthermore, costs for returning a site to rough grade based on surface area cannot be compared from one site to the next without identification of the extent of grading required. For example, where one acre may only require simple grading, another adjacent acre may require moving thousands of cubic yards to bring a valley bottom to grade. Therefore, rough grading costs are reported on a cost per cubic yard according to the type of equipment operating and the conditions encountered (Table 5). In comparison, the U.S. Forest Service in Region 1 reports a cost of $\$ 0.66 / C Y$ for common excavation for road building, regardless of the type of equipment used (USDA 1989). For an evaluation of the application and efficiency of various types of heavy equipment, the miner should consult sources with that emphasis (e.g.; Oberlender 1986, periodicals such as Highway and Heavy Construction, and equipment manufacturers such as Caterpillar®).

Table 5. Approximate contractor cost per cubic yard for bulk excavation of material moved by heavy equipment (derived from Smit 1991).

\begin{tabular}{|c|c|c|c|c|}
\hline Heavy Equipment and Conditions & Labor & Equip. & Total & $\begin{array}{c}\text { Total } \\
w / \text { O\&P }\end{array}$ \\
\hline
\end{tabular}

1.5 CY backhoe, hydraulic, crawler mounter

(100 CY/hr)

excavate common earth

$\$ 0.43 \quad \$ 0.85 \quad \$ 1.28$

$\$ 1.57$

300 HP dozer, 50 feet haul

sand and gravel

common earth

clay

$\begin{array}{llll}\$ 0.13 & \$ 0.45 & \$ 0.58 & \$ 0.70 \\ \$ 0.15 & \$ 0.52 & \$ 0.67 & \$ 0.80 \\ \$ 0.29 & \$ 0.84 & \$ 1.08 & \$ 1.29\end{array}$

21 CY scraper, 1/4 push dozer, 1,500 feet haul sand and gravel common earth

$\$ 0.25$

$\$ 1.58$

$\$ 1.83$

$\$ 2.12$ clay

$\$ 0.29$

$\$ 1.81$

$\$ 2.10$

$\$ 2.42$

$\$ 0.46$

$\$ 2.89$

$\$ 3.35$

$\$ 3.87$

Dragline, $3 / 4 \mathrm{CY}$ (35 CY/hr)

sand and gravel

$\$ 1.21 \$ \$ 1.54$

$\$ 2.75$

$\$ 3.51$

Reprintud by permission of R.S. Means Company. Inc. 
In this report, finished grade is considered to include two features: 1) work required to bring final valley bottom elevations to grade according to the design specifications, and 2) construction of the active stream channel and any permanent ponds or wetlands. Both of these aspects require more detailed work than that undertaken during rough grading. In fact, it is during this stage that on-site reclamation supervision is most important. In order to prevent undue expense, it is recommended that the miner and reclamation supervisor (if different individuals) meet with the appropriate regulatory agency personnel before any final grade work occurs. In this way, any adjustments or on-site alterations can be identified before final grading and stream construction occurs.

Heavy equipment suited for finish grade is typically smaller than that used for rough grading. This smaller equipment may include: hydraulic excavators with 0.75 to 1.75 cubic yard buckets, front end loaders, dozers with adjustable blades (D4 to D6) and 16-20 cubic yard dumptrucks. In practice, heavy equipment used at a mining site is expected to fulfill all work requirements, whether or not it is suited to the application at hand. This tendency is particularly evident on smaller operations. Because most of the finish grade work done by heavy equipment on stream construction is only indirectly related to cubic yards placed, it is best to address costs of equipment relative to time used (Table 6).

Table 6. Average cost per week and month by heavy equipment type, based on contract and rental rates (USDA 1989; Equipment Guidebook Company 1990; Associated Equipment Distributors 1991). These figures do not include operation and maintenance costs (fuel and repairs).

$$
\text { Heavy Equipment }
$$

Cost/Week

Cost/Month

Cat 225 excavator $w /$ thumb $\& 1.25 \mathrm{CY}$ bucket

Cat D7 Dozer

Cat D4H Dozer

Case 580 rubber tired backhoe

Cat 966 Loader, articulated, w/ 5 CY bucket

Cat 950 Loader, articulated, w/ 3.5 CY bucket

Cat 631 scraper, $21 \mathrm{CY}$ twin engine

Dumptruck, $16-20 \mathrm{CY}$

$\begin{array}{rr}\$ 2,650 & \$ 8,000 \\ \$ 2,960 & \$ 8,700 \\ \$ 1,250 & \$ 3,750 \\ \$ 560 & \$ 1,675 \\ \$ 2,400 & \$ 7,200 \\ \$ 2,000 & \$ 6,000 \\ \$ 3,600 & \$ 11,000 \\ \$ 6,500 & \$ 22,000\end{array}$

\subsubsection{STREAMS}

The cost for reconstruction of a stream channel depends largely on the size of the channel and the method of reconstruction. Larger streams are more costly to reconstruct than smaller ones because they have more surface area and they generally require the use of larger bed material to ensure channel stability. Stream sizes can be divided into three. categories based on typical 
stream widths encountered in placer mining in Montana and the characteristics of different sized streams. These width categories, based on barkfull conditions, are: 1) less than 8 feet, 2) 8 to 15 feet and 3) 15 to 25 feet.

The method of stream reconstruction also affects cost. Much of the conventional thought regarding reconstruction of stream channels considers only flow conveyance and channel stability. As such, many post-mining stream channels consist of uniform trapezoidal channels armored with riprap along their entire course (Simons and Li Associates 1989; Soil Conservation Service 1977; U.S. Army Corps of Engineers 1970; Lyle 1987). In contrast, this document assumes that channel reconstruction will closely replicate natural conditions and provide a diversity of trout habitat.

In Montana, information concerning operations under the SMES, including costs, are considered confidential (Rolfes, DSL, Helena, MT, pers. com. 1990). Therefore, little direct information concerning small placer mining bond or reclamation is available. The maximum allowable bond for SMES miners is $\$ 5,000$, regardless of anticipated reclamation costs. Therefore, the $\$ 5,000$ maximum figure cannot be used to estimate the actual costs of reclamation.

Based on information collected from a variety of sources, the average total cost per foot of stream reconstruction is tabulated below (Table 7). As indicated, these figures include total costs for construction as well as total costs for design and construction. All costs are based on the assumption that no major rough grading or other site preparation is necessary.

Table 7. Average total cost on a per foot basis for stream reconstruction associated with placer mining and other major environmental disturbances.

Comments

Not specified, assuming recla-

mation concurrent w/ mining

Construction costs for stream

diversion w/ no account

for natural channe!

Design and construction of

total reclamation, including

that necessary for fish habitat,

including erosion control.

$<8$ feet wide

8-15 feet wide

15-25 feet wide
Total Cost per Foot

$\$ 5-10$

$\$ 20 / f t+(31 c)(c f s) / f t$

Pagel, pers. com.

Reference Source

Rolfes, pers. com.

$\$ 10-15$

$\$ 15-25$

$\$ 25-50$

Inter-Fluve, Inc. Inter-Fiuve, Inc. Inter-Fiuve, Inc.

Erosion control materials are frequently placed along streambanks to provide short-term stability until vegetation becomes established. The specific costs 
for these materials are discussed in the upcoming Revegetation section under Erosion Control Methods.

The materials required for stream reconstruction are usually located within or near the placer mine claim. The settling pond, trommel or sluice sort material to various sizes; much of this material is necessary for channel construction. This material includes fines, gravels, cobbles and boulders, although boulders are less common. If unavailable on-site, boulders may need to be hauled from off-site, and this cost will depend on the location of the source. Costs for rock can range from \$10-\$25 per cubic yard depending on the haul distance. Similarly, if whole trees, root masses and other large organic debris do not exist on-site, they may also need to be located and hauled to the mine area.

\subsubsection{PONDS AND WETLANDS}

In order to construct a pond or wetland in a low gradient area, the site must be brought to finished grade and topsoil and mulch placed in shallow margin areas. Some form of grade control structure (such as a low grade boulder weir within the outflow channel) and overflow spillway (such as a swale) will need to be placed. The amount of finish grading required depends largely on the relative precision of the rough grade work. Placement of topsoil and organic mulch, from on-site stockpiles, can be readily accomplished with a dozer. Finish grade costs for ponds and wetlands of this type can be low as $\$ 2,000 /$ acre and as much as $\$ 10,000 /$ acre or more.

If a pond or wetland is constructed with a berm on the downstream side, an impervious core may be required. The height of the berm will dictate the degree of engineering required to ensure stability. Because of the specific nature of bermed or dammed ponds, costs estimates are not appropriate.

\subsection{REVEGETATION COSTS}

\subsubsection{Introduction}

Revegetation costs for sites disturbed by placer mining vary from moderate to extremely high depending on the intensity of re-vegetation efforts. For example, broadcast and drill seeding is much less expensive than planting containerized, rooted stock and protecting them from animal browse as $t$ desiccation. As part of the reclamation plan, it is important to determi: te we level of re-vegetation required for hillslope and channel stability, shade protection through canopy development, wildlife forage and cover, and aesthetic improvement. These requirements will be dictated partly by site conditions and partly by the degree of reclamation required by the permitting agency. Identification of re-vegetation requirements before any mining occurs is important, as it allows a clear determination of costs. A broad 
approach that addresses grasses, forbes, shrubs, trees and emergent plants (for wetlands) is necessary to ensure a thorough re-vegetation program. These costs can then be integrated in the mine cost feasibility analysis.

The following sub-sections address basic re-vegetation requirements for placer mine reclamation in Montana. These reported costs should be considered minimal, relative to more extensive and appropriate re-vegetation methods. Costs are based on re-vegetation being contracted out to specialists.

\subsubsection{Seed}

Seed is generally applied by one of three methods: broadcast seeding, drill seeding or hydro-seeding. The first two methods are usually applied to relatively flat ground surfaces and are relatively similar in cost. Hydroseeding involves application of fertilizer and an organic tackifier in addition to seed; this method is used on steeper slopes and is more expensive than other techniques (Table 8).

Table 8. Reported costs for various seeding methods. See Table 14 for source details.

\begin{tabular}{lrr}
\hline Method & Cost per Acre & Reference Source \\
\hline Broadcast seed & $\$ 200-300$ & $\begin{array}{c}\text { Stebbins } 1987 \\
\text { Broadcast seed, 80 PLS/square foot }\end{array}$ \\
$\begin{array}{l}\$ 80-350 \\
\text { Broadcast seed }\end{array}$ & $\$ 1,400$ & $\begin{array}{c}\text { Burke, pers. com. } \\
\text { Mohr, pers. com. }\end{array}$ \\
Drill Seed & $\$ 80-100$ & Burke, pers. com. \\
$\begin{array}{l}\text { Hydroseed (estimated) } \\
\text { Hydroseed } \\
\text { Hydroseed }\end{array}$ & $\$ 2,400$ & Mohr, pers. com. \\
& $\$ 1,200-1,600$ & Burke, pers. com. \\
\hline
\end{tabular}

\subsubsection{Shrubs And Trees}

Well-rounded re-vegetation programs need to address re-creating riparian corridors, re-foresting hillslopes and planting intermediate level shrubs where appropriate. As mentioned previously, re-planting of rooted stock can be extensive. An appropriate level of revegetation should be identified in the reclamation plan and agread upon by miner and regulatory personnel prior to mining. Costs for woody plasts should be incorporated into the reclamation plan to allow adequate re-vegetation of these species (Table 9). 
Table 9. Reported costs for planting and protecting rooted stock. See Table 14 for source details.

Method Cost per Acre Reference Source

Woody plants, rooted stock $\$ 600-720$ Burke, pers. com. 500-600/acre

Animal Browse Repellent, chemical

$\$ 50-60$

Burke, pers. com.

\subsubsection{Emergent Vegetation}

Revegetation of emergent vascular plants is generally undertaken by planting tubers during the spring. While tuber stock can often be collected locally from existing wetlands, it is usually more cost-effective to purchase stock from nurseries specializing in wetland vegetation (assiuming that specific species are adapted to conditions of the mine site). With adequate preparation (soil and organic material) of shallow margins in ponds and wetlands (6-18 inches water depth), planting of emergents is relatively inexpensive. Under ideal conditions, a two-person labor crew can plant approximately 0.3 acres of shallow area per hour if tubers are spaced on 1 foot centers. Table 10 lists the per acre cost of some common emergent plants.

Table 10. Approximate costs for planting tubers of emergent species on 1 foot centers under ideal conditions (material costs from Kester's Wild Game Food Nurseries, Inc. 1990). Figures are based on labor costs of less than $0.5 \mathrm{c}$ per square foot.

Plant Species Material CostSF
Total CostSF Total Cost/Acre

Wapato duck potato

(Sagittaria latifolia)

Deep water duck potato

(S. rigida)

116

$11.5 €$

$\$ 5,060$

Hardstem bullnush (Scirpus acutus)

Softstem bullnush (S. validus)

River Rush (S. fluviatilis)

11.56

126

$\$ 5,280$

Rush (Juncus effusus)

19.56

15.56

126

206

$\$ 8,800$

$16 c$

$\$ 7,040$

200

12.56

$\$ 5,500$

Sedge (Carex comosa)

406

$20.5 c$

$\$ 9,020$

Cattail, broadleaf (Typha latifolia)

Cattail, narrowleaf (T. augustifolia)

22.56

$40.5 c$

$\$ 17,820$

$16 \varnothing$

$\begin{array}{r}236 \\ .956 \\ \hline\end{array}$

$\$ 10,120$

$\$ 7,260$

\subsubsection{Erosion Control Methods}

With limited vegetative cover in the first few years following placer reclamation, short-term erosion control methods are commonly used to 
ensure hillslope and streambank stability. In the last few years, these temporary erosion control measures have focused on using biodegradable materials woven into rolls of fabric and held together with UV-sensitive plastic netting. They are applied to potentially unstable ground and held in place by stakes or key-trenches, or both. Fabric materials include coconut filaments, straw, wood cellulose fibers and jute. Some material is designed for hillslopes of limited slope, while others are intended to resist high water velocities and steep slopes. The average 100 foot long, 6-8 foot wide fabric roll is easily installed by a 2-3 person labor crew. Table 11 estimates costs and applications for some of the more common organic erosion control fabrics based on manufacturers specifications and application rates.

These costs will vary depending on site conditions and crew experience. For example, 4,500 square yards of BonTerra ${ }^{\mathrm{TM}}$ Coconut fabric (C2) applied along the Clark Fork River near Warm Springs, Montana, were installed at a bid price of $\$ 3.85 /$ SY, while real costs were likely closer to $\$ 5 /$ SY (Bruce Parker, Schafer and Associates, Bozeman, MT, pers. com. 1990). These actual costs are substantially higher than estimated by the manufacturer (Table 11). The U.S. Forest Service reports costs for Region 1 to be $\$ 1-3 /$ SY depending on the price of material used (USDA 1989).

Table 11. Estimated costs per square yard for installation of various erosion control fabrics under different applications using a three person crew.

\begin{tabular}{|c|c|c|c|}
\hline Material and Application & $\begin{array}{l}\text { Material } \\
\text { CostSY }\end{array}$ & $\begin{array}{l}\text { Installed } \\
\text { CostSY }\end{array}$ & Manufacturer \\
\hline $\begin{array}{l}\text { Coconut fabric (C2) applied along stream banks } \\
\text { Straw fabric (S2) applied to } 3: 1 \text { to } 2: 1 \text { hillslopes }\end{array}$ & $\begin{array}{l}\$ 1.30 \\
\$ 0.74\end{array}$ & $\begin{array}{l}\$ 1.42 \\
\$ 0.86\end{array}$ & $\begin{array}{l}\text { BonTerratm } \\
\text { BonTerratm }\end{array}$ \\
\hline Jute netting applied to $3: 1$ hillsiopes & $\$ 0.93$ & $\$ 1.05$ & Antiwash $₫ / G e o j u t e \circledast$ \\
\hline $\begin{array}{l}\text { Wood fiber applied to hillslopes } \\
\text { Wood fiber applied along stream banks }\end{array}$ & $\begin{array}{l}\$ 0.52 \\
\$ 1.18\end{array}$ & $\begin{array}{l}\$ 0.64 \\
\$ 1.30\end{array}$ & $\begin{array}{l}\text { Curtex Blankets } \\
\text { Curlex Blankets }\end{array}$ \\
\hline
\end{tabular}

\subsection{MONITORING COSTS}

Where mine effluent is discharged into streams, periodic water quality monitoring should be undertaken by the miner to ensure compliance with state water quality standards according to the Montana Pollutant Discharge Elimination System (MPDES). As stated previously (see section entitled State and Federal Oversight), the MPDES is administered through the DHES-WQB. Water from slime settling ponds, sluices, wash plants, trommels and dredges are all examples of potential sources of contaminants.

Sampling costs depend entirely on the number of samples required by a MPDES permit. Small, weekend operations may only require a sample 
upstream and downstream of the mine site taken two days a week. Larger operations may require a number of samples taken daily. Typically, samples are analyzed for turbidity and total suspended solids; costs per sample generally amount $\$ 5$ for each parameter.

Monitoring reclamation success generally requires development of a sitespecific program. Monitoring may include measuring biological response (plants, fisheries or aquatic invertebrates), physical habitat response (channel and floodplain changes, embeddedness of stream gravels, sedimentation, erosion), or a combination of the two. Because current regulations do not require specific monitoring programs, and because costs depend on the specific components of a program, we have not presented costs for this activity.

\subsection{MAINTENANCE AND OPERATION COSTS}

At the end of every mining season, disturbed areas must be stabilized to prevent erosion during winter and spring months. During this period, freeze-thaw cycles and spring runoff are major contributors to hillslope and channel erosion. Winterization efforts typically involve removing road crossings over stream channels, rip-rapping unreclaimed and unstable stream banks and grading floodplain areas to drain toward the channel. Costs for winterization depend on the amount and degree of disturbance, which vary from mine to mine from year to year. Based on the need to undertake some rough grading, floodplain re-configuration would cost $\$ 200-\$ 500 /$ acre. Given that riprap might need to be placed along sections of stream channel, temporary stream stabilization would cost $\$ 5-\$ 20$ per foot depending on the size of the stream and the degree of instability.

Reclamation of severely disturbed sites, such as those resulting from placer operations, usually takes a number of years before conditions reach some state of equilibrium. Poorly implemented reclamation methods, unseasonably high runoff, or drought conditions often reduce reclamation success in the first years, thereby requiring annual maintenance. Even with ideal conditions, maintenance is often necessary to ensure reclamation. There are few sources for costs of annual maintenance of reclaimed stream channels, however Scheeler (Confederated Tribes of Umatilla Indian Res., Pendleton OR, pers. com. 1989) reported $57 \$$ per foot of stream channel for unspecified annual maintenance. Jn ur experience, significant maintenance on channels up to 40 feet in width, which involves intensive earthmoving with a medium-sized tracked excavator, averages $\$ 1.20$ per lineal foot. Miners and bond holders should recognize that some inventory and repair is usually necessary from year to year on larger projects. Where reclamation occurs simultaneously with mining over the life of a mine, periodic maintenance at a cost of $50 \ll$ to $\$ 1$ per foot of stream channel appears reasonable. 
In literature reviews and conversations with resource agency personnel, some figures for placer mine reclamation costs were identified simply as total costs (Table 12). Often, it was not clear whether these costs were limited to the construction phase, or if they also included the design and permit acquisition phases. Cost figures were adjusted to a common unit dencminator to allow comparison; note the wide range in cost per foot of stream channel reconstruction. Despite this variance, these figures should give the miner and regulatory agency personnel an idea of the potential costs associated with stream reclamation.

In an effort to combine all the information collected in this cost section, an attempt was made to estimate probable reclamation costs for 2 placer mines of differing characteristics (Tables 13 and 14). Costs are estimated for both concurrent and post-mining reclamation. Note that the difference in costs reflects operator verses contractor rates, whether equipment mobilization is required, and if administrative charges are included. Regardless, the majority depends on the amount of regrading required. Although these costs are averages based on hypothetical placer operations, they should provide wouldbe miners and regulatory agency personnel an appreciation of probable reclamation costs.

\subsection{SOURCES OF COST INFORMATION}

Since little quantitative cost information exists for placer mining operations in the Northwest, inquiry letters were mailed to federal, tribal, state and private organizations involved with mining. Individuals were requested to contribute any information pertinent to placer mine reclamation costs, based on their experience. They were asked to identify the range in costs involved with stream diversions, relocations, channel construction and associated riparian and floodplain reconstruction. It was also requested that information be reported on a cost per unit basis, e.g., cost per linear distance, cost per cubic yard of material moved, as a total cost relative to area disturbed, or the amount (and derivation thereof) of reclamation bonding required for reclamation activity.

Table 15 lists the names, organizations, addresses and phone numbers of persons responding to the inquiry for information. This table identifies those persons and ory?nizations referred to in this section as sources of information.

In Montana, there are a few public sources where individuals can request information on procedures and costs. These services are primarily designed for the placer miner and for persons interested in undertaking placer mining. The Montana Bureau of Mines and Geology runs the Aid to Small Mines 
Program, presently coordinated by Robin McCulloch, Mining Engineer and Staff Field Agent. The Bureau's address is: Montana College of Mineral Science and Technology, Butte, MT 59701, phone 406-496-4171.

Table 12. Total costs for a variety of placer mine reclamation projects in the Pacific Northwest. See Table 14 for source details.

Type of Reclamation

Regrade, erosion control, reseed (no stream)

Floodplain regrading and re-vegetation (no stream)

Reconstruct stream, hillslopes roads, settling ponds

Stream and floodplain 2 miles in 24 acres reconstruction

Total stream reconstruction

Total stream and floodplain reconstruction, extensive project

Total stream and floodplain reconstruction w/ fisheries emphasis

Reconstruct large channel

4-5 miles

2.5 miles

unknown

2.7 miles
Affected Area

Cost/Unit

Reference Source

10 acres $\$ 4,300 /$ acre

Saake, pers. com.

5 acres $\$ 2,000-2,500 /$ acre Nichols, pers. com.

$<5$ acres $\$ 2,500-5,000 /$ acre

Boston, pers. com.

Mohr, pers. com.

$\$ 7-17 / \mathrm{ft}$

$\$ 19+/ f t$

Scheeler, pers. com.

$\$ 190 / \mathrm{ft}$

Richards, pers. com.

$\$ 28^{\circ}-47 / \mathrm{ft}$

Stowell, pers. com.

$\$ 21 / \mathrm{ft}$
Smith, pers. com. 


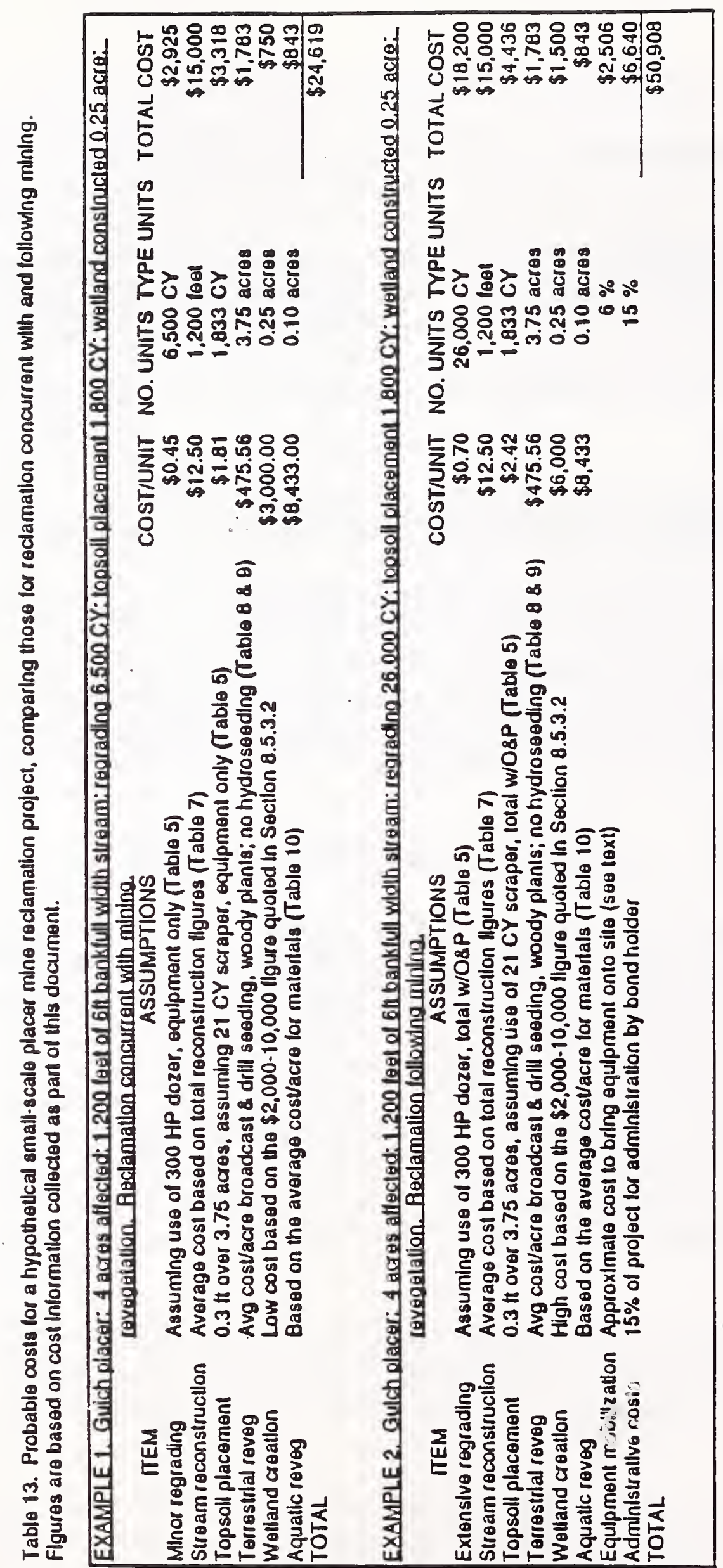




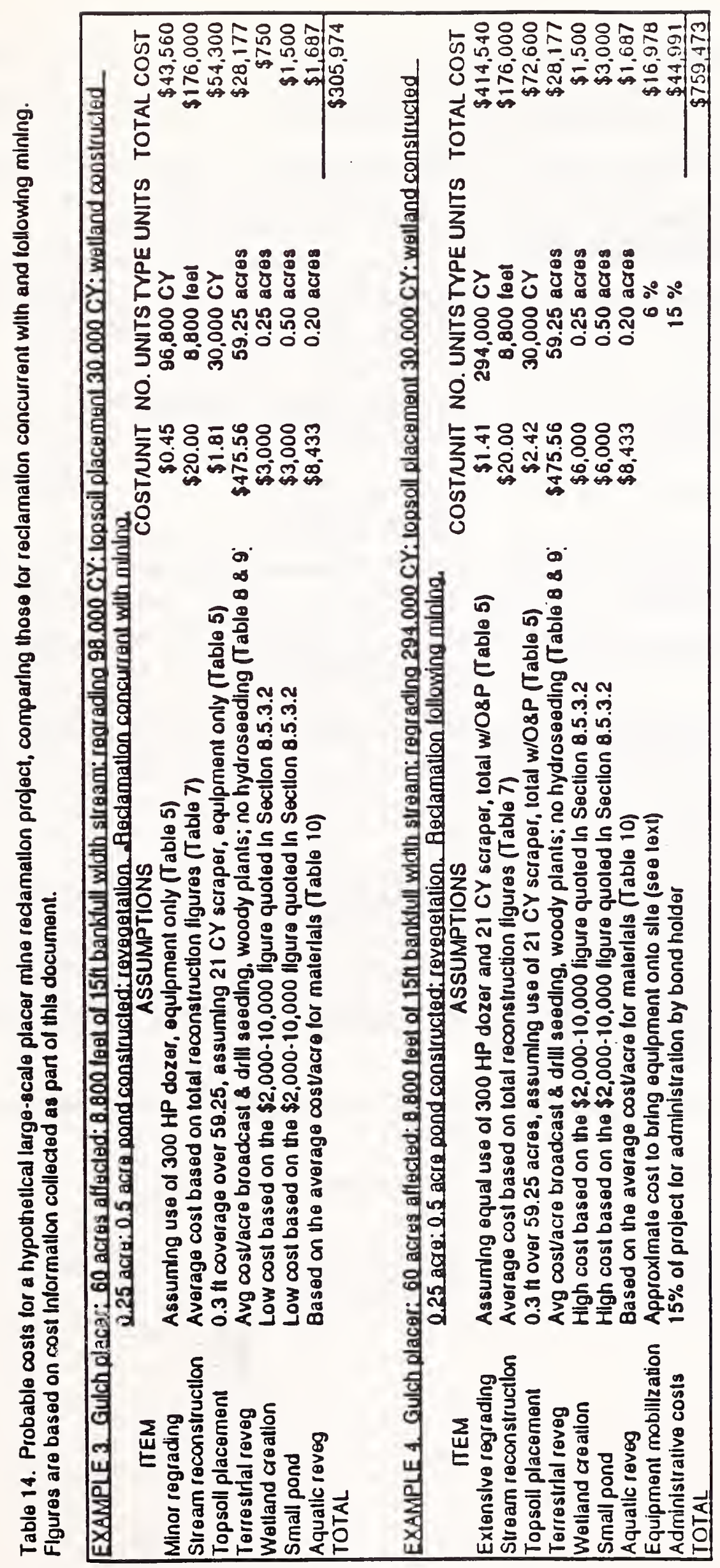


Table 15. Persons responding to request for placer mine information. Some contacts are second-hand.

\begin{tabular}{|c|c|c|c|}
\hline Person & Organization & Address & Phone \\
\hline Scott H. Nichols & Idaho Dept. Lands & Statehouse, Boise ID 83720 & $208-334-3610$ \\
\hline Jan Alexander & $\begin{array}{l}\text { Wallowa-Whitman NF } \\
\text { Unity Ranger District }\end{array}$ & PO Box 38, Unity OR 97884 & \\
\hline $\begin{array}{l}\text { Paul A. Pierce } \\
\text { John R. Norberg } \\
\text { Thomas M. Brady }\end{array}$ & Bureau of Mines & $\begin{array}{l}360 \text { 3rd Ave. } \\
\text { Spokane, WA } 99202\end{array}$ & $509-353-2737$ \\
\hline James P. Saake & Lassen NF & $\begin{array}{l}55 \text { S. Sacramento, Susanville } \\
\text { CA } 96130\end{array}$ & \\
\hline $\begin{array}{l}\text { Herb Rolfes } \\
\text { Craig Pagel }\end{array}$ & Montana DSL & $\begin{array}{l}1625 \text { Eleventh Ave } \\
\text { Helena MT } 59620\end{array}$ & $406-444-2074$ \\
\hline Lloyd Wall & $\begin{array}{l}\text { Independent mining } \\
\text { consultant }\end{array}$ & $\begin{array}{l}2180 \text { E Clayborne, Salt Lake } \\
\text { UT } 84109\end{array}$ & $801-466-7325$ \\
\hline Bruce Parker & Schafer and Assoc. & $\begin{array}{l}611 \text { North Wallace } \\
\text { Bozeman, MT } 59715\end{array}$ & $406-587-3478$ \\
\hline Cart A. Scheeler & $\begin{array}{l}\text { Confederated Tribes } \\
\text { of Umatilla Indian Res. }\end{array}$ & $\begin{array}{l}\text { PO Box 638, Pendleton OR } \\
97801\end{array}$ & $503-276-4109$ \\
\hline Cart Richards & $\begin{array}{l}\text { Shoshone-Bannock } \\
\text { Tribes }\end{array}$ & PO Box 306, Fort Hall ID 83203 & $208-238-3748$ \\
\hline Rick Stowell & Nez Perce NF & $\begin{array}{l}\text { Rt 2, PO Box } 475 \text {, Grangeville } \\
\text { ID } 83530\end{array}$ & $208-983-1950$ \\
\hline Robert J. Boston & Clearwater NF & $12730 \mathrm{Hwy} 12$, Orofino ID 83544 & $208-476-4541$ \\
\hline Rick Mohr & $\begin{array}{l}\text { James M. Montgomery } \\
\text { Consulting Engineers }\end{array}$ & 161 Mallard Dr, Boise ID 83706 & $208-345-5865$ \\
\hline \multirow[t]{2}{*}{$\begin{array}{l}\text { Scott Gillilan } \\
\text { Dale Miller }\end{array}$} & Inter-Fluve, inc & $\begin{array}{l}211 \text { North Grand, Bozeman MT } \\
59715\end{array}$ & $406-586-6926$ \\
\hline & ESA & $\begin{array}{l}41 \mathrm{~A} \text { Lafayette } \mathrm{Cr}, \text { Lafayette CA } \\
94549\end{array}$ & \\
\hline Pat Burke & $\begin{array}{l}\text { Bitterroot Native } \\
\text { Growers }\end{array}$ & $\begin{array}{l}445 \text { Quast Lane } \\
\text { Corvalis MT } 59828\end{array}$ & $406-961-4991$ \\
\hline
\end{tabular}




\subsection{SUMMARY}

Placer mine reclamation in Montana seemingly lags behind that of other states in the Pacific Northwest and Rocky Mountain states. Apparently, the difference is a result of a number of key factors. Generally, miners and resource and regulatory personnel need to be further educated on appropriate reclamation techniques. As addressed in this report, certain pre-mining data should be collected to provide appropriate reclamation designs tailored to specific sites. These designs should be sufficiently detailed to allow satisfactory implementation of reclamation measures. In this way, all involved will have a clear understanding of the expected results prior to any mining activity.

Quite often, the true cost of reclamation is not considered fully, either by miners or by regulatory personnel who determine reclamation bonding. Miners, operators and investors should consider the environmental costs in evaluating the economic viability of proposed mining activities. Similarly, regulators and bond holders should recognize the costs associated with all aspects of reclamation, from site grading to revegetation. Everyone should appreciate the difference between the costs for reclamation undertaken concurrently with mining, and those for reclamation when it occurs after bond forfeiture.

Lastly, miners, regulators and lawmakers should appreciate the need for more streamlined, and clearly defined placer mine reclamation regulations. Similariy, regulators should be given the tools to assist the miner in reclamation design and implementation when necessary, and the backing to enforce regulations to protect, preserve and enhance the environment. 



\subsection{REFERENCES CITED}

Andrews, E.D., 1983. Entrainment of gravel from naturally sorted riverbed material. Geological Society of America Bulletin, 94: 1225-1231.

Andrews, E.D., 1984 Bed-material entrainment and hydraulic geometry of gravel-bed rivers in Colorado. Geological Society of America Bulletin, 95: 371-378.

Andrews, E.D. and D.C. Erman, 1986. Persistence in the size distribution of surficial bed material during an extreme snowmelt flood. Water Resources Research, 22: 191-197.

Associated Equipment Distributors, 1991. Rental Rates and Specifications For Construction Equipment. Oak Brook, Illinois, 240 pp.

Barnes, H.H., Jr., 1967. Roughness Characteristics Of Natural Channels. U.S. Geological Survey Water Supply Paper 1849.

Beschta, R.L. and W.S. Platts, 1986. Morphological features of small streams: significance and function. Water Resources Bulletin, 22: 369-379.

Binns, N.A., 1982. Habitat Quality Index Procedures Manual. Wyoming Game and Fish Dept., Cheyenne, Wyoming, 209 pp.

Bozeman Daily Chronicle, 1990. November 2, Bozeman, Montana.

Bray, D.I., 1982. Regime equations for gravel-bed rivers. In: Gravel-Bed Rivers, ed. by R.D. Hey, J.C. Bathurst and C.R. Thorne, John Wiley and Sons, Chichester: 517-542.

Brayshaw, A.C., 1985. Bed microtopography and entrainment thresholds in gravel-bed rivers. Geological Society of America Bulletin, 96: 218-223.

Bureau of Land Management, 1989. Placer Mining In Alaska. BLM, Alaska State Office, Anchorage, Alaska, $50 \mathrm{pp}$.

Carling, P.A., 1983. Threshold of coarse sediment transport in broad and narrow naturil streams. Earth Surface Processes and Landforms, 8: 1-18.

Carson, M.A., 1987. Measures of flow intensity as predictors of bed load. Journal of Hydraulic Engineering, American Society of Civil Engineers, 113: $1402-1421$.

Caterpillar, Inc., 1990. Performance Handbook. Peoria, Illinois, 827 pp. 
Chang, H.H. River morphology and thresholds, 1985. Journal of Hydraulic Engineering, American Society of Civil Engineers, 111: 503-519.

Chorley, R.J., 1962. Geomorphology and General Systems Theory, U.S. Geological Survey Professional Paper 500-B.

Chow, V.T., 1959. Open Channel Hydraulics. McGraw-Hill Book Co., New York, $680 \mathrm{pp}$.

Costa, J.E., 1974. Response and recovery of a Piedmont watershed from tropical storm Agnes, June, 1972. Water Resources Research,1: 106-112.

Dunne, T. and L.B. Leopold., 1978. Water In Environmental Planning. W.H. Freeman and Company, New York, 877 pp.

Dury, G.H., 1973. Magnitude-frequency analysis and channel morphometry, In: Fluvial Geomorphology, State University of New York, Binghampton, Publications in Geomorphology, ed. by M. Morisawa, 91-121.

Einstein, H.A., 1950. The bed load function for sediment transportation in open channels. U.S. Department of Agriculture Technical Bulletin 1026.

Equipment Guidebook Company,1990. Rental Rate Bluebook For Construction Equipment. Palo Alto, California.

Freeze, R.A. and J.A. Cherry, 1979, Groundwater. Prentice-Hall, Inc., Englewood Cliffs, N.J., 604pp.

Graf, W.H., 1971. Hydraulics Of Sediment Transport. McGraw-Hill Book Co., New York, 513 pp.

Grant, G.E., F.J. Swanson and M.G. Wolman, 1990. Pattern and origin of stepped-bed morphology in high-gradient streams, Western Cascades, Oregon. Geological Society of America Bulletin, 102: 340-352.

Gregory, K.J. and D.E. Walling, 1973. Drainage Basin Form And Process. John Wiley and Sons, New York, 458 pp.

Grourd Water and Wells, A Reference Book For The Water-Well Industry, is 32. Johnson Division, UOP, Inc., Saint Paul, Minnesota, 440 pp.

Hamilton, J.B., 1989. Response of juvenile steelhead to instream deflectors in a high gradient stream. In: Proceedings, practical approaches to riparian resource management, May, Billings, Montana, 193 pp. 
Hamilton, K. and E.R. Bergersen, 1984. Methods To Estimate Aquatic Habitat Variables. Colorado Cooperative Fishery Research Unit for Bureau of Reclamation, Denver, Colorado.

Hartman, H.T. and D.E. Kester, 1968. Plant Propagation: Principles And Practices. Prentice-Hill, New Jersey, 702 pp.

Hedman and Osterkamp 1982. Streamflow Characteristics Related To Channel Geometry Of Streams In The Western U.S. U.S. Geological Survey Water Supply Paper 2193.

Hey, R.D., 1982. Design equations for mobile gravel-bed rivers. In: GravelBed Rivers, ed. by R.D. Hey, J.C. Batherst, and C.R. Thorne, John Wiley and Sons, Chichester: 553-574.

Ikeda, S. and G. Parker, eds., 1989. River Meandering, American Geophysical Union Water Resources Monograph 12.

Jackson, W.L. and B.P. Van Haveren, 1984. Design for a stable channel in coarse alluvium for riparian zone restoration. Water Resources Bulletin, 20: 695-703.

James, L.A., 1990. Sustained storage and transport of hydraulic gold mining sediment in the Bear River, California. Annals of the Association of American Geographers, 79: 570-592.

Jarrett, R.D., 1985. Determination Of Roughness Coefficients For Streams In Colorado. USGS Water Resources Investigation Report 85-4004, 54 pp.

Keller, E.A. and F.J.Swanson, 1979. Effects of large organic material on channel form and fluvial processes. Earth Surfaces Processes, 361-380.

Keller, E.A., 1972. Development of alluvial stream channels: a five-stage model. Geological Society of America Bulletin, 83: 1531-1536.

Kester's Wild Game Food Nurseries, Inc. 1990. Catalogue, Omro, Wisconsin, $37 \mathrm{pp}$.

Knighton, D. 1984. Fluvial Forms And Processes. Edward Arnold Publishers, Baltimore, Maryland, $218 \mathrm{pp}$.

Lane, E.W., 1953. Design of stable channels. Transactions of the American Society of Civil Engineers, 120: 1234-1260.

Leopold, L.B. and M.O. Marchand, 1968. On the quantitative inventory of the riverscape. Water Resources Research, 4: 709-717. 
Leopold, L.B., 1969. Quantitative Comparison Of Some Esthetic Factors Among Rivers. United States Geological Survey Circular 620.

Linsley, R.K., Jr., M.A. Kohler and J.L.H. Paulhus, 1982. Hydrology For Engineers. McGraw-Hill Book Co., New York, 908 pp.

Lisle, T.E., 1981. The recovery of aggraded stream channels at gaging stations in Northern California and Southern Oregon. In: Proceedings, symposium on erosion and sediment transport in Pacific Rim steeplands, Christchurch, New Zealand. International Association of Hydrological Sciences IAHS-AISH Publication 132, p. 189-211.

Lyden, C.J., 1948. The Gold Placers Of Montana. Memoir No. 46, Montana School of Mines, Butte, Montana, $152 \mathrm{pp}$.

Lyle, E.S., 1987. Surface Mine Reclamation Manual. Elsevier Press, New York, New York, 268 pp.

Macdonald, E.H., 1983. Alluvial Mining: The Geology, Technology And Economics Of Placers. Chapman and Hall, NY, 508 pp.

McCulloch, R., 1989. Operating Placer Mines In Montana. Montana Bureau of Mines and Geology, Internal Report, 15 pp.

McCulloch, R., 1991. Montana Bureau of Mines and Geology, Butte MT. Pers. com. Conversation regarding common placer gold separation plants in Montana.

Mott, R.L., 1979. Applied Fluid Mechanics. Charles Merrill Publishing Company, Columbus, Ohio, 405 pp.

Oberlender, G.D., 1986. Earthmoving And Heavy Equipment. Conference proceedings, Feb 5-7. American Society of Civil Engineers, New York, New York.

Omang, R.J., C. Parrett, and J.A. Hull, 1983. Methods For Estimating Magnitude And Frequency Of Floods In Montana Based On Data Through 1983. U.S. Geological Survey Water Resources Investigation Report 864027.

Osterkamp, W.R. and E.R. Hedman, 1977. Variation of width and discharge for natural high gradient stream channels. Water Resources Research, 2:256-258. 
Parker, G., 1978. Self-formed straight rivers with equilibrium banks and mobile bed - Part II, The gravel river. Journal of Fluid Mechanics, 89: 127148.

Parrett, C., J.A. Hull, and R.J. Omang, 1987. Revised Techniques For Estimating Peak Discharges From Channel Width In Montana. USGS Water Resources Investigations Report 87-4121, 34 pp.

Phillips, G.R. and A.B. Humphrey, 1987. Inventory Of Placer Mining Effects On Stream Resources In The Vicinity Of Helena National Forest. Montana Department of Fish, Wildlife and Parks Pollution Control Information Series, Technical Report No. 5, 51 pp.

Phipps, H.M. and D.E. Kester, 1981. The influence of collection time and storage temperature of Populus hardwood cutting development. Tree Planter's Notes, 32: 33-36.

Pickup, G., 1976. Adjustment of stream channel shape to hydrologic regime. Journal of Hydrology, 30: 365-373.

Platts, W.S., D. Armour, G.D. Booth, M. Gryant, J.L. Bufford, P. Cuplin, S. Jensen, G. W. Lienkaemper, G.W. Minshall, S.B. Monsen, R.L. Nelson, J.R. Sedell, and J.S. Tuhy, 1987. Methods For Evaluating Riparian Habitats With Applications To Management. U.S. Department of Agriculture, Forest Service General Technology Report INT 221.

Platts, W.S., W.F. Megahan, and G.W. Marshall, 1983. Methods For Evaluating Stream, Riparian, And Biotic Conditions. U.S. Department of Agriculture, Forest Service General Technology Report INT-138.

Rolfes, H., 1990. Montana Department of State Lands, Helena, MT. Pers. com. Verbal estimate of number of active placer mines in the state.

Rundquist, L.A., N.E. Bradley, J.E. Baldridge, P.D. Hampton, T.R. Jennings and M.R. Joyce, 1986. Best Management Practices For Placer Mining, Reference Manual and Technical Report. Entrix, Inc., for Alaska Department of Fish and Game, 459 pp.

Salminen, E., 1990. Unpublished Masters Thesis, Oregon State University, Corrallis, Oregon.

Sigafoos, R.S., 1964. Botanical Evidence Of Floods And Floodplain Deposition. U.S. Geological Survey Professional Paper 485-A. 
Simons and $\mathrm{Li} \&$ Associates, Inc., 1989. Surface Mining Water Diversion Design Manual. U.S. Department of the Interior, Office of Surface Mining, $\mathrm{OSM} / \mathrm{TR}-82 / 2$.

Smit, K., 1988. Means Site Work Cost Data. R.S. Means Co., Inc., Kingston, Massachusetts, 389 pp.

Stebbins, S.A., 1987. Cost Estimation Handbook For Small Placer Mines. USDI, Bureau of Mines Information Circular 9170.

Strazdas, P., 1991. Montana Department of State Lands, Helena, MT. Pers. com. Written comments on Draft Handbook.

Swanson F.J. and G.W. Lienkaemper ,1978. Physical consequences of large organic debris in Pacific Northwest streams. U.S. Department of Agriculture, Forest Service General Technical Report PNW-69.

United States Army Corps of Engineers, 1970. Hydraulic Design Of Flood Control Channels. EM 1110-2-1601.

United States Department of Agriculture, Soil Conservation Service, 1972. Hydrology: National Engineering Handbook, Section 4. Washington, D.C.

United States Department of Agriculture, Soil Conservation Service, 1977. Design Of Open Channels. Technical Release No. 25.

United States Department of Labor, 1990. General Wage Decision Number MT90-1.

United States Department of the Interior, Office of Surface Mining Reclamation and Enforcement, 1987. Handbook For Calculation Of Reclamation Bond Amounts.

United States Forest Service, 1989. Cost Estimating Guide For Road Construction. U.S. Department of Agriculture, Forest Service Northern Region, Engineering Division.120 pp.

Wang, S. and H.W. Shen,1985. Incipient sediment motion and rip-rap design. Journal of Hydraulic Engineering, American Society of Civil Engineers, 111: 520-538.

Warren-Wren, S.C., 1972. The Complete Book Of Willow. Barnes and Co., New York, 179 pp.

Wentworth, C.K., 1922. A scale of grade and class terms for clastic sediments. Journal of Geology, 30: 377-392. 
Whiting, P.J., Dietrich, W.E., Leopold, L.B., Drake, T.G. and R.L. Shreve Bedload sheets in heterogeneous sediment., 1988. Geology, 16: 105-108.

Wiberg, P.L. and J.D. Smith Calculations of the critical shear stress for motion of uniform and heterogeneous sediments, 1987. Water Resources Research, 23: 1471-1480.

Williams, G.P., 1986. River meanders and channel size. Journal of Hydrology, 88: 147-164.

Wolman, M.G. and J.P. Eiler, 1955. Reconnaissance study of erosion and deposition produced by the flood of August 1955 in Connecticut. Transactions of the American Geophysical Union, 39: 1-14.

Wolman, M.G. and J.P. Miller, 1960. Magnitude and frequency of forces in geomorphic processes. Journal of Geology, 68: 54-74.

Wolman, M.G. and L.B. Leopold, 1957. River Floodplains: Some observations on their formation. U.S. Geological Survey Professional Paper 282C.

Yu, B. and M.G. Wolman, 1987. Some dynamic aspects of river geometry. Water Resources Research, 23: 501-509. 

11.0 APPENDIXES 

APPENDIX 1.

GLOSSARY OF TERMS RELATING TO STREAMS AND STREAM RECLAMATION 

Aggradation. The geologic process by which stream beds are raised in elevation and floodplains are formed. It is the opposite of degradation. See also "channel scour and fill."

Alluvial stream - Self-formed channels composed of silts, clays, sands, and gravel. Alluvia! streams are characterized by the ability to alter their boundaries and their patterns in response to changes in discharge and sediment supply.

Alluvium - A general term for all deposits resulting directly or indirectly from the sediment transport of streams, thus including the sediments laid down in riverbeds, floodplains, lakes, fans and estuaries.

Aquifer - A water-bearing rock or soil formation capable of storing water and allowing water to pass through it.

Bankfull discharge - The discharge corresponding to the stage at which the channel is nearly full; this flow occurss, on average, about two times per year.

Bar - (a) Accumulation of sand, gravel, or other alluvial material found in the channel, along the banks, or at the mouth of a stream where a decrease in velocity induces deposition. (b) An alluvial deposit or erosion feature composed of sand, gravel, or other materials, which obstructs flow. A description of bar types follows:

Diagonal - Elongated bodies with long axes oriented obliquely to the flow. They are roughly triangular in cross-section and often teminate in riffles.

Longitudinal- Elongated bodies parallel to the local flow, of different shape, but typically with convex surfaces. Common to gravelly braided streams.

Point Bar - Bar found on the inside of meander bends. They are typically attached to the stream bank and terminate in pools.

Transverse Bar - Typically solitary lobate features that extend over much of the active stream width but may also occur in sequence down a given reach of river. They are produced in areas of local flow divergence and are always associaetd with local deposition. Flow is distributed radially over the bar. Common to sandy braided streams.

Baseflow - See "flow".

Base Level of a Stream. The elevation below which a river can no longer erode, i.e., the level of its mouth.

Bed Load - Sediment moving on or near the stream bed and frequently in contact with it. See also "suspended load."

Bed Roughness - A measure of the irregularity of the stream bed as it contributes to flow resistance. Commonly measured in terms of Darcy-Weisbach roughness coefficient.

Best Management Practices (BMPS) - The most environmentally, socially and economically appropriate instream or land treatment measure which can be applied to control a nonpoint source water quality problem. 
Biomass - The weight of the standing crop of a specified organism or group of organisms present in a specified space at any one time. Usually expressed as weight per unit area.

Braided Channel - A stream characterized by flow within several channels which successively meet and redivide. Braiding may be an adjustment to a sediment load too large to be carried by a single channel. Braided channels often occur in deltas of rivers or in the oufflow from a glacier.

Buffer Zone - An area situated between two zones which have conflicting interests. As applied to streams, a narrow strip of natural vegetation along streambanks to reduce the possibility of adverse impacts from land use on water quality.

Canopy - The overhead branches and leaves of streamside vegetation.

Canopy Cover. The vegetation that projects over the stream. Can arbitrarily be divided into two levels: Crown cover is more than 1 meter above the water surface. Overhand cover for fish is less than 1 foot above the water surface.

Carrying Capacity (biological) - The maximum average number of a given organism that a stream or section of stream can maintain under a given set of conditions and over a specified period. Carrying capacity may vary from season to season or from year to year.

Cascade - Habitat type characterized by swift current, exposed rocks and boulders, high gradient and considerable turbulence and surtace agitation, and consisting of a stepped series of drops. See "water types".

Channel - A natural or artificial waterway of perceptible extent that periodically or continuously contains moving water. It has a definite bed and banks which serve to confine the water.

Channel Scour and Fill - Words used to define erosion and sedimentation during relatively short periods of time, whereas degradation and aggradation apply to similar processes that occur over a longer period of time. Scour and fill applies to events measured in minutes, hours, days, perhaps even seasons, whereas aggradation and degradation apply to persistent trends over a period of years or decades.

Channel Stability - A relative measure of the resistance of a stream to erosion. Stable streams do not change markedly in appearance from' year to year. An assessment of stability helps determine how well a stream will adjust to and recover from changes in flow or sediment transport.

Channel Width. The horizontal distance along a transect line from bank to bank at the high water marks, measured at right angles to the direction of flow. Multiple channel widths are summed to represent total channel width.

Colluvium - A general term for loose deposits of soil and rock moved by gravity: e.g. talus.

Concave Bank of a Bend. The outer bank of a sinuous channel.

Convex Bank of a Bend". The inner bank of a sinuous channel.

Cover - An area of shelter in a stream that provides aquatic organisms with protection from predators and/or a place to rest and conserve energy.

Crossover - The point of inflection in a meander. The point where the thalweg intersects the center line of the stream in crossing from near the outside of the next bend.

Cross-Sectional Area - The area of a stream or waterway, usually taken perpendicular to the stream centerline. 
Cubic Foot per Second (cfs) - A unit of stream discharge. It represents one cubic foot of water moving past a given point in one second. Expressed another way, it is the rate of discharge of a stream whose channel is 1 square foot in cross-sectional area and whose average velocity is 1 foot per second.

cfs-DAY. The volume of water represented by a flow of 1 cubic foot per second for 24 hours. It is equivalent to 86,400 cubic feet or 646,317 gallons, and represents a runoff of 0.0372 inch from 1 square mile.

Debris - Includes gravel, cobble, rubble, and boulder-sized sediments as well as trees and other organic material scattered about by either natural processes or human influences.

Debris Jam - Log jam. Accumulation of logs and other organic debris.

Debris Loading - The quantity of debris located within a specific reach of stream channel, due to natural processes or human activities.

Degradation - The geologic process by which stream beds are lower in elevation and floodplains are removed. It is the opposite of aggradation. See "aggradation".

Deposition - The settlement or accumulation of material out of the water column and onto the stream bed or floodplain. Occurs when the energy of flowing water is unable to transport sediment load.

Depth - The vertical distance from the water surface to the stream bed.

Detritus - Organic debris from decomposing plants and animals.

Discharge - Rate of flow expressed in volume per unit of time, for instance, in cubic feet per second or liters per second. Discharge is the product of the mean velocity and the crosssectional area of flow. See "mean annual discharge".

Dissolved Load - The chemical load comtained in stream water; that acquired by solution or by decomposition of rocks followed by solution.

Dissolved Oxygen. Gaseous oxygen which becomes soluble and is absorbed by water.

Drainage Area or Drainage Basin. That area so enclosed by a topographic divide that surface runoff from precipitation drains into a stream above the point specified. (The term "watershed" is commonly misapplied to the drainage area.) A drainage area can be contained within a single watershed or include a number of watersheds.

Ecosystem - An ecological system or unit that includes living organisms and nonliving substances which interact to produce an exchange or cycling of materials.

Embeddedness - The degree that larger particles (boulders, rubble, or gravel) are surrounded or covered by fine sediment. Usually measured in classes according to percentage of coverage of larger particles by fine sediments.

Emergent Plants - Aquatic plants with parts protnding above the water surface.

Energy Dissipation. The loss of kinetic energy of moving water due to internal turbulence. bottom friction, large rock, debris and other obstacles that impede flow.

Enhancement - An improvement of conditions that provide for the betterment over existing conditions of the aquatic, terrestrial, and recreational resources. 
Environment - Apart from the dictionary definition: Surrounding; surrounding objects, region, or circumstances. The word represemts an animal's environment in four major components: (1) weather, (2) food, (3) other animals and pathogens, (4) a place in which to live. (See "habitat"). This term cannot, in its strict sense be applied to the latter category. Some environmental items may fall into more than one of these components (some of the "food" may be "other animals", for instance), but this breakdown serves well as a basis for ecological study and discussion. One can generally think of the environment of any animal in terms of these four components and the interactions between them. Since parts of an animal's environment are animals of his own kind, and since the density of the population must be regarded as part of the environment, the confusion in speaking of a population being a part of its own environment can be avoided by speaking ahways of the environment in regard to the individual.

Evapotranspiration - Water returned to the atmosphere from the land or surface waters by direct evaporation or by transpiration of plants.

Fill - See "channel scour and fill".

Fine Sediment - Silt and sand-sized materials.

Fish Habitat - The aquatic environment and the immediately sumounding terrestrial environment that, combined, afford the necessary biological and physical support systems required by fish species during various life history stages.

Flat Water or "Flats" - See "water types".

Flood - Discharge overlowing the banks of a stream.

Floodplain - A strip of relatively smooth land bordering a stream which is typically overtlowed during periods of high water. Though the floodplain is generally composed of finer material near the surface than at the base, this gradation in particte size is by no means universal. Floodplains are generally formed by the progressive channel migration and deposition from overbank flows.

Flow - (a) The movement of a stream of water and/or other mobile substances from place to place. (b) The movement of water, and the moving water itself. (c) The volume of water passing a given point per unit of time. Syn: Discharge.

Base flow - The portion of the stream discharge that is derived from natural storage i.e.. groundwater outtlow and the draining of large lakes and swamps or other source outside the net rainfall that creates surface runoff: discharge sustained in a stream channel, not a result of direct runoff and without the effects of regulation, diversion, or other works of man. Also called sustaining, normal, ordinary or groundwater flow.

Instantaneous flow - That discharge measured at any instant in time.

Interstitial flow - See intragravel flow.

Intragravel flow - That portion of the surface water that infiltrates the stream bed and moves through the substrate pores.

Low flow. The lowest discharge recursed over a specified period of time. Also called minimum flow.

Mean flow - The average discharge at a given stream location, usually expressed in cubic feet per second, computed for the period of record by dividing the total volume of flow by the number of days, months, or years in the specified period. 


\section{APPENDIX 1}

Hydraulic Radius - The cross sectional area of a stream divided by the wetted perimeter.

Hydraulics - Refers to water, or other liquids, in motion and their action.

Hydrograph - A curve showing discharge over time.

Hydrologic - Refers to water in all its stages, and its properties, distribution and circulation through the hydrologic cycle.

Ice Types -

Anchor lce - Ice formed on the stream bed materials when, due to outward radiation in the evening, they become colder than the water flowing over them.

Frazil Ice - Needle-like crystals of ice that are slightly lighter than water, but carried below the surface due to turbulence. This causes a milky mixture of ice and water. When these crystals touch a surface that is even a fraction of a degree below freezing, they instantly adhere and form a spongy, often rapidly growing mass.

Hinge lce - A marginal sheet of surface ice attached to the bank materials and extending toward the center of a stream but not spanning it completely.

Infiltration - That part of precipitation which soaks into the ground. See also "runoff" and "recharge".

Instream Cover - Areas of shelter in a stream channel that provide aquatic organisms protection from predators or competitors and/or a place in which to rest and conserve energy due to a reduction in the force of the current.

Intemal Distortion Resistance - See "resistances to flow".

Invert - Refers to the bottom, inside surface of a pipe, log, or other object. Occasionally used to refer to the bottom or base elevation of a structure.

Laminar Flow - A flow in which all particles or filaments of water move in parallel paths, characterized by the appearance of a flat ripple free surface. Does not occur in nature.

Large Organic Debris - Any large piece of relatively stable woody material having a least diameter greater than $10 \mathrm{~cm}$ and a length greater than $1 \mathrm{~m}$ that intrudes imto the stream channel. Syn: LWD, large woody debris, log. Specific types of large organic debris include:

Affixed logs - Single logs or groups of logs that are firmly embedded, lodged or rooted in a stream channel.

Bole - Term referring to the stem or trunk of the tree.

Large bole - 10 meters or more in length; often embedded, remain in the stream for extended periods.

Small bole - Less than 10 meters, usually sections of bole; seldom stable, usually move downstream on high flows.

Digger log - Log anchored to the stream banks and/or channel bottom in sucti a way that a scour pool is formed.

Free logs - Logs or groups of logs that are not embedded, lodged or rooted in the stream channel. 
Minimum flow - (a) the lowest discharge recorded over a specified period of time (preferred definition). (b) Negotiated lowest flow in a regulated stream that will sustain an aquatic population at agreed upon levels. This flow may vary seasonally. (This recently developed definition is in conflict with the older definition (a) and to avoid confusion should not be used. A suggested alternative is to apply this definition to the term least flow).

Peak flow - The highest discharge recorded over a specified period of time. Often thought of in terms of spring snowmelt, summer, fall or winter rainy season flow. Also called maximum flow.

Subsurface flow - That portion (part or all) of the water that infiltrates the stream bed and moves horizontally through and below it. It may or may not return to the stream channel at some point downstream.

Fluvial - Pertaining to streams or produced by stream action.

Freshet - A rapid rise in river discharge and level caused by heavy rains or melting snow.

Gabion - A galvanized wire basket. The basket, filled with selected stones, is used to stabilize banks to control erosion in streams and to prevent stream gravel from shifting.

Gage Height - See "stage".

Gallons Per Mlnute - A unit of stream discharge commonly used in fish hatcheries. One gallon per minute equals 0.0022 cfs. One cubic foot per second equals 449 gallons per minute.

Gradient - (a) The general slope, or rate of change in vertical elevation per unit of horizontal distance, of the water surface of a flowing stream. (b) The rate of change of any characteristic per unit of length. See "stream bed gradient"

Gravel - Stones larger than sand, but smaller than rubble. See table "Substrate Particle."

Habitat - Loosely used now, but the strict concept was that a certain habitat (an area with rather uniform physiography, vegetation or other animal-influcing quality) has a certain community of animals. However, the word "habitat" probably brings into mind a view of an animal's environment, the central aspect of which would be "a place in which to live" (see "environment"), but which would include a few other things around the fringes. The fringe aspects might be food, competitors for the food, and some of the animal's predators (not fishermen). In keeping with variability of meaning, "habitat" is used in various ways.

Habitat Management - Manipulation of physical, chemical and biological qualities of a body of water and its drainage basin with the objective of controlling living conditions for one or several kinds of animals. Fishery personnel have now and then suggested introduction of fish foods, control of predators and removal of competitory fishes as appropriate activities for the fish habitat management program. As practiced some places, habitat management seems to include all fishery practices not covered under regulation of fishing, rearing and stocking of fishes and control of fish diseases.

Hiding Cover - Used to mean places where animals can hide from predators.

Hydraulic Control Point - The top of an obstruction to which stream flow must rise before passing over, or a point in the stream where the flow is constricted.

Hydraulic Gradient - (a) The slope of the water surface. (b) The drop in head per length in the direction of stream flow.

Hydraulic Jump - An abrupt, turbulent rise in the water level of a flowing stream, normally occurring at the transition from shallow, fast flow to deeper and slower flow. 
Hydraulic Radius - The cross sectional area of a stream divided by the wetted perimeter.

Hydraulics - Refers to water, or other liquids, in motion and their action.

Hydrograph - A curve showing discharge over time.

Hydrologic - Refers to water in all its stages, and its properties, distribution and circulation through the hydrologic cycle.

Ice Types -

Anchor lce - Ice formed on the stream bed materials when, due to outward radiation in the evening, they become colder than the water flowing over them.

Frazil Ice - Needle-like crystals of ice that are slightly lighter than water, but carried below the surface due to turbulence. This causes a milky mixture of ice and water. When these crystals touch a surface that is even a fraction of a degree below freezing, they instantly adhere and form a spongy, often rapidly growing mass.

Hinge Ice - A marginal sheet of surface ice attached to the bank materials and extending toward the center of a stream but not spanning it completely.

Infiltration - That part of precipitation which soaks into the ground. See also "runoff" and "recharge".

Instream Cover - Areas of shelter in a stream channel that provide aquatic organisms protection from predators or competitors and/or a place in which to rest and conserve energy due to a reduction in the force of the current.

Internal Distortion Resistance - See "resistances to flow".

Invert - Refers to the bottom, inside surface of a pipe, log, or other object. Occasionally used to refer to the bottom or base elevation of a structure.

Laminar Flow - A flow in which all particles or filaments of water move in parallel paths, characterized by the appearance of a flat ripple free surface. Does not occur in nature.

Large Organic Debris - Any large piece of relatively stable woody material having a least diameter greater than $10 \mathrm{~cm}$ and a length greater than $1 \mathrm{~m}$ that intrudes into the stream channel. Syn: LWD, large woody debris, log. Specific types of large organic debris include:

Affixed logs - Single logs or groups of logs that are firmly embedded, lodged or rooted in a stream channel.

Bole - Term referring to the stem or trunk of the tree.

Large bole - 10 meters or more in length; often embedded, remain in the stream for extended periods.

Small bole - Less than 10 meters, usually sections of bole; seldom stable, usually move downstream on high flows.

Digger log - Log anchored to the stream banks and/or channel bottom in such a way that a scour pool is formed.

Free logs - Logs or groups of logs that are not embedded, lodged or rooted in the stream channel. 


\section{APPENDIX 1}

Rootmass- The root mass of the tree. Syn: rootwad, butt ends.

Snag - (a) A standing dead tree. (b) Sometimes a submerged fallen tree in large streams. The top of the tree is exposed or only slightly submerged.

\section{Types of large organic debris accumulation:}

Clumps - Accumulations of debris at irregularly spaced intervals along the channel margin, not forming major impediments to flow.

Jams - Large accumulations of debris partially or completely blocking the stream channel, creating major obstructions to flow.

Scattered - Single pieces of debris at irregularly spaced intervals along the channel.

Longitudinal Profile - A graph of the vertical fall of the stream bed or water surface measured along the course of the stream.

Mean Annual Discharge - Daily mean discharge in units per second averaged over a period of years. Mean annual discharge usually fills a river channel to about one-third of its bankfull depth.

Mean Velocity - The average velocity of water in one vertical segment of a cross section of a stream. Surface velocity is usually much stronger than bottom velocity. A velocity equal to mean velocity is most often found at $\mathbf{0 . 6}$ of the depth at any given point in the stream. The mean velocity can be approximated by multiplying the surface velocity, determined by a float, by the factor 0.8 . Also refers to the general velocity of the channel as a whole, and is calculated by Q/AC.

Meander - A reach of stream with a ratio of channel length/valley length greater than 1.5. By definition, any value exceeding unity can be taken as evidence of meandering, but 1.5 has been widely accepted by convention.

Morphometry - The form or shape of a lake or stream, including the contour of the bottom.

Nick Point - A break in slope along a stream profile which indicates an area of active erosion. Niagara Falls is an example of a very large nick point.

Normal Flow - An ambiguous term. May mean "baseflow" or "mean annual discharge," or refer to simplified model of streamflow used in hydraulic analysis.

Organic Matter - Any part of a substance which once had life. Organic matter, then, consists of any animal or vegetable waste or by-product.

Overhead Cover - Material (organic or inorganic) that provides protection to fish or other aquatic animals from above; generally includes material overhanging the stream less than a particular distance above the water surface. Values of less than 0.5 meter and less than 1 foot have been used.

Overland Flow - See "runoff".

Peak Flow - The maximum insta. . sneous rate of flow during a flood.

Phreatophytes - Plants growing on or near the stream bank with their roots in the ground water and decreasing streamflow by transpiration during their growing season.

Plunge Pool - Depression in stream bed material scoured out by the action of falling water. 
Point Bar - A deposit of sand, gravel or other material on the inside of a stream bend, which causes some obstruction to the flow.

Pool - (a) A portion of the stream with reduced current velocity, often with water deeper than the adjacent areas, and which is frequently usable by fish for resting and cover. (b) A small body of standing water, e.g., in a marsh or on the flood plain.

Pool Tailout - The downstream end of a pool where the bed surface gradually rises and the water depth decreases. The tailout of a pool may vary in length. This feature usually occurs immediately upstream of a riffle.

Pool Quality - An index (usually an integer from 1-5) of the estimated ability of a pool to support fish, based on measurements of length, width, depth, velocity, and cover.

Production - Growth in weight by all fish in the population during a specified period of time including growth by fish that died during the period.

Productivity or Productive Capacity - General terms meaning the capacity of a stream to sustain production of a certain weight of some organism over a certain period.

Rapids - See "water types"

Reach - (a) Any specified length of stream. (b) A relatively homogeneous section of a stream having a repetitious sequence of physical characteristics and habitat types. (c) A regime of hydraulic units whose overall profile is different from another reach.

Critical Reach - A segment of the stream that is required for the development and/or survival of a particular aquatic organism, or to a particular life stage of an aquatic organism.

Representative Reach - A length of stream which represents a large section of the stream with respect to hydraulic variables (area, depth, discharge, and slope) and biological constituents.

Specific Reach - A length of channel uniform with respect to selected habitat characteristics or elements (discharge, depth, area, slope, population or hydraulic units), fish species composition, water quality, and type and condition of bank cover.

Recharge - Water that is added to the groundwater reservoir, for instance, that part of infiltration which reaches the groundwater table.

Redd - An area of stream bed dug out by a female trout or salmon before spawning and in which she buries her eggs after spawning.

Reproductive Capacity - The capacity of a stream or part of a stream to provide for reproduction of any organisms. For instance, one section of stream may have 1,000 fingerling trout per year (measured in a given month) and another only 100.

\section{Resistances to Flow -}

Internal Distortion Resistance - The resistance to streamflow caused by turbulence and secondary circulations. Bars, bends, boulders, undulations of the bed, protuberances and sheer floow energy affect this measure of resistance.

Skin Resistance - Resistance to flow due to roughness of the stream bed and banks. Also depends also the discharge.

Spill Resistance - Caused when water impacts an obstruction and causes an abrupt reduction in velocity. 
Revetment - A facing of stone or broken rock pieces placed on a stream bank to prevent or minimize erosion from high velocity flow. See "riprap".

Riffle - A shallow, rapid section of stream where the water surface is broken into waves by obstructions that are wholly or partly submerged.

Rill - A furrow eroded in soil by runoff water.

Riparian - Relating to or living on or near the bank of a watercourse. These zones range in width from narrow bands in desert or mountainous areas to wide bands which occur in the piedmont and gulf states.

Riparian Area - The area between a stream or other body of water and the adjacent upland identified by soil characteristics and distinctive vegetation. It includes wetlands and those portions of floodplains and valley bottoms that support riparian vegetation.

Riparian Vegetation - Vegetative growth along the banks of a stream.

RipRap - Large stones, rocks or boulders placed along a stream to protect the banks from scouring and erosion.

Roughness Element - Large obstacles in a channel that deflect flow and affect a local increase in shear stress that causes scour and deposition.

Rubble - Stones larger than gravel, but smaller than boulders. A mixture of rocks with diameters of about 3-8 inches (7.5-20 centimeters) would be termed rubble.

Run - A stream section of varying depth with moderate velocity and surface turbulence. Intermediate in character between a pool and a riffle.

Run-Off - Water from precipitation flowing above or below ground to a surface water without entering the groundwater table.

Surface Runoff or Overland Flow - Runoff water flowing over the land surface.

Subsurface Runoff - Runoff water flowing beneath the land surface.

Runoff in Inches - Shows the depth to which the drainage area would be covered if all the runoff for a given period were uniformly distributed on it.

Salmonid - Refers to a member of the fish family classed as Salmonidae, including the salmons, trouts, chars, whitefishes and grayling.

Scour - The localized removal of material from the stream bed by flowing water. This is the opposite of fill.

Scour and Fill - See "channel scour and fill".

Sediment - Any mineral or organic matter from those particles measured in microns to those measured in meters.

Sediment Discharge - Rate of flow of sediment contained in a stream, expressec is volume or weight per unit time. Sediment discharge includes" suspended load discharge" and "bed load discharge". Suspended load discharge is the product of streamflow discharge and concentration of suspended sediment.

Sediment Transport - The rate of sediment movement through a given reach of stream. 
Seepage Profile - A graph showing discharge at various points along a stream's course (ideally on one given day). From this can be seen the downstream increase (or decrease) in volume of streamflow.

Seepage Run - The process of measuring discharge at various points to obtain a "seepage profile."

Shear Stress Force- The shear stress or tractive force results from the tangential pull of flowing water on the stream bed and banks, and is expressed in pounds per square foot or $\mathrm{n} / \mathrm{m}^{2}$. The energy expended on the wetted boundary of the stream increases proportionally with the energy slope and water depth. The transition zone between an area of low and high shear stress is incorrectly called a "shear zone." Instream structures that tend to increase the difference between such low and high shear stress areas have been called, also incorrectly, "shear structures."

Side Channel - Lateral channel with an axis of flow roughly parallel to the mainstem and which is fed by water from the mainstem; a braid of river with flow appreciably lower than the main channel. Side channel habitat may exist either in well-defined secondary (overflow) channels, or in poorly defined watercourses flowing through partially submerged gravel bars and islands along the margins of the mainstem.

Silt - In common usage, silt designates sediments finer than sand. Technically, however, silt is a specific grain șize, finer than sand but coarser than clay.

Sinuosity - The ratio of channel length to direct downvalley distance.

Sorting Coefficient - A measure of the distribution or variability of particle sizes in a substrate mixture. A common measure, computed as $\mathrm{d}_{75} / \mathrm{d}_{25}$ is equivalent to the standard deviation of the log transformed frequency curve, hence a measure of dispersion of particle sizes. A substrate with a large sorting coefficient is termed "well sorted". The terms $d_{75}$ and $d_{25}$ are those diameters for which $75 \%$ and $25 \%$ of the cumulative size-frequency distributions are larger.

Species - The smallest unit of plant or animal classification commonly used. Members of a species share certain characteristics which differ from those of other species, and they tend not to interbreed with other species.

Stage - (Also known as water level or gage height) Elevation of water surface above any chosen reference plane.

Standing Crop - The number or weight of organisms present per unit space at a given point in time, e.g., trout/acre, pounds of trout/acre, trout per mile, pounds of trout/mile. Units involving weight are synonymous with "biomass".

Standing Wave - A highly turbulent condition in a stream which produces a fixed wave pattern at a specific location. Standing waves are caused by a change in the internal energy condition of the flow brought about by an abrupt channel transition.

Stock Density - Used interchangeably with "standing crop".

Stream - A natural water course conta: ling flowing water, at least part of the year, supporting a community of plants and arimals within the stream channel and the riparian vegetation zone. Streams in natural channels may be classified as follows:

a) Relation to time:

Ephemeral - One that flows briefly only in direct response to precipitation in the immediate locality and whose channel is at all times above the water table. 
Intermittent or seasonal - One in contact with the ground water table that flows only at certain times of the year as when the ground water table is high and/or when it receives water from springs or from some surface source such as melting snow in mountainous areas. It ceases to flow above the stream bed when losses from evaporation or seepage exceed the available stream flow.

Perennial - One that flows continuously throughout the year. Syn: Permanent stream.

b) Relation to space:

Continuous - One that does not have interruptions in space.

Interrupted - One that contains alternating reaches that are either perennial, intermittent, or ephemeral.

c) Relation to ground water -

Insulated - A stream or reach of stream that neither contributes to nor receives water from the zone of saturation. It is separated from the zones of saturation by an impermeable bed.

Gaining - A stream or reach of stream that receives water from the zone of saturation.

Losing - A stream or reach of stream that contributes water to the zone of saturation.

Perched - Either a losing stream or an insulated stream that is separated from the underlying groundwater by a zone or aeration.

d) Other -

Incised - A stream that has, through degradation, cut its channel into the bed of the valley.

Stream Bank - The portion of the channel cross-section that restricts lateral movement of water at normal water levels. The bank often has a gradient steeper than 45 degrees and exhibits a distinct break in slope from the stream bottom. An obvious change in substrate may be a reliable delineation of the bank.

Lower bank - The periodically submerged portion of the channel cross-section from the normal high water line to the water's edge during the summer low flow period.

Upper bank - That portion of the topographic cross-section from the break in the general slope of the surrounding land to the normal high water line.

Stream Bed - The substrate plane, bounded by the stream banks, over which the water column moves. Also called stream bottom.

Stream Bed Gradient - The vertical distance a stream falls per unit of distance it flows horizontally. Commonly expressed as feet of fall per mile or meters of fall per kilometer.

Stream Bottom - See "stream bed".

Stream Power - The rate of doing work, or a measure of the potential energy available for moving rock, sedimen $n^{\prime}$ aticles, or other debris in the stream channel, as determined by the product of discharge, water surface slope, and the specific weight of water, divided by the bottom width. Also cyual to the product of shear stress and mean velocity.

Structure - (a) Any object, usually large, in the stream channel that affects water and sediment movement. (b) The diversity of physical habitat within a stream. (c) When applied to a biological community, the organization of taxa into various functional or trophic groups.

Submergent Plants - Aquatic plants having all parts submerged beneath the water surface. 
Watershed-A convex surface such as a mountain or hill which sheds water from one high point or ridge into several streams which may form its boundary. "Watershed" is commonly confused with "drainage basin": a concave surface collecting precipitation into one stream.

\section{Water Types -}

Pools - Water of considerable depth for the size of stream. Pools generally have slowly flowing water and a smooth surface, but they may often have a swift, turbulent area where the water enters them.

Flats - Water with slight to moderate current and with an unbroken surface, but with less depth than pools.

Pocket Water - Similar to "runs", however, the flow is blocked by numerous partial obstructions, usually boulders, and is fairly turbulent.

Riffles Shallow water with rapid current and with flow broken by gravel or rubble.

Runs - Moderate to rapid current flowing in a deeper, narrower channel than a riffle. Flow less turbulent than in a rapids or cascade.

Rapids - Those parts of large streams and rivers which are relatively swift and shallow with a bed of boulders. Analogous to riffles of a smaller stream.

Cascades - A reach of stream in which steep gradient and a bed of large rocks combine to produce a very irregular rapid flow, often with white water. A cascade may be somewhat deeper and narrower than a "rapids".

Weir - (a) A notch or depression in a levee, dam, embankment, or other barrier across or bordering a stream, through which the flow of water is measured or regulated. (b) A barrier constructed across a stream to divert fish into a trap. (c) A dam (usually small) in a stream to raise the water level or divert its flow.

Wetted Perimeter - The length of the wetted contact between a stream of flowing water and the stream bottom in a vertical plane at right angles to the direction of flow.

Woody Debris - See large organic debris. 

APPENDIX 2.

OUTLINE OF ELEMENTS THAT MAY BE INCIUDED IN SOME MINING AND RECLAMATION PLANS 



\section{Introduction}

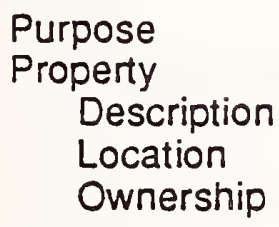

\section{Environmental Baseline Data}

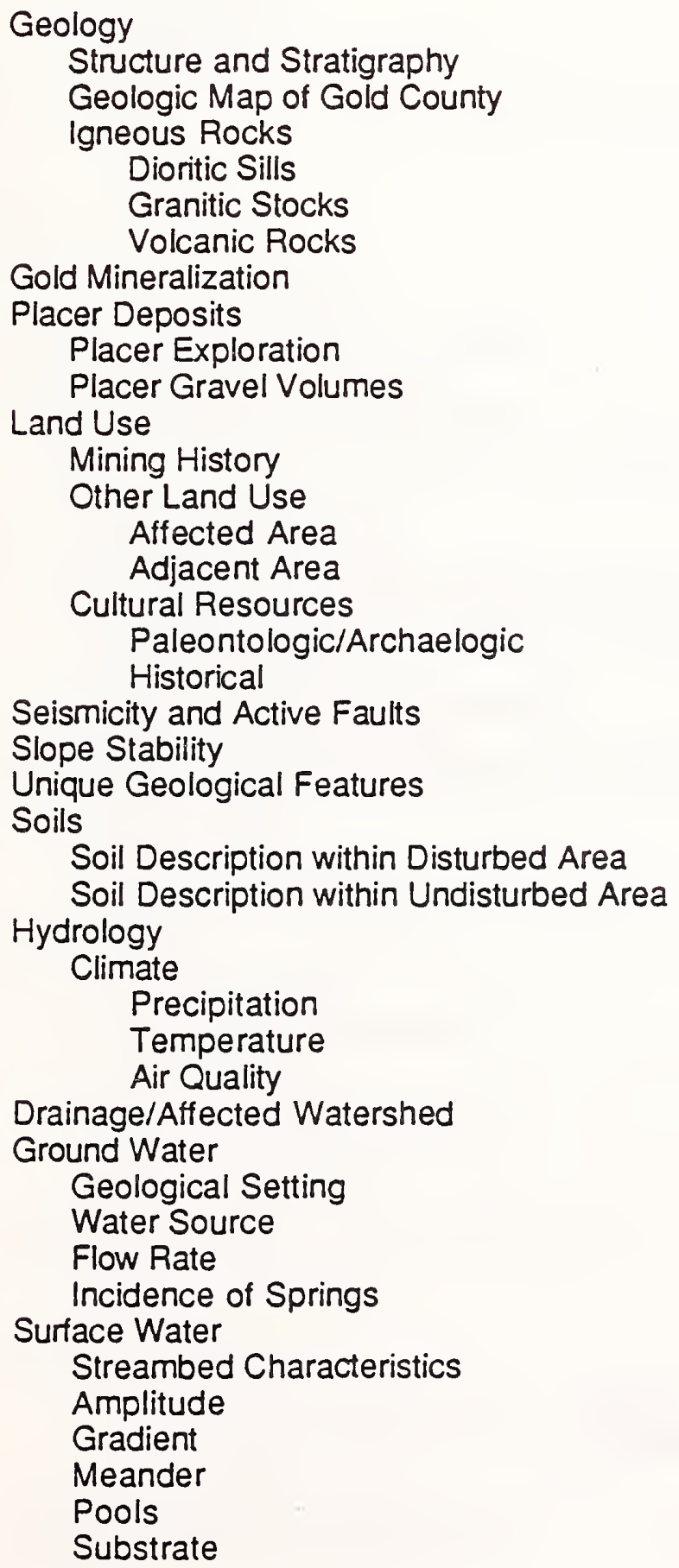


Water Quality

Baseline Data

Additional Sample Data

Wildlife Baseline Summary

Terrestrial

Avian

Fisheries

Endangered Species

Vegetation

Socioeconomic Environment

Energy

Transportation

Aesthetics

Affected Areas

Unaffected Areas

\section{General Operating Plan}

Process Description

Placer Pit Operations

Washplant

Concentrator

Tails/Ponds

Period of Operation

Area of Disturbance

Equipment

Mobile Equipment

Wash and Concentration Plant

Personnel Equipment

Site Preparation

Washplant Millsite

Stream Channel

Campsite

Open Pit

Topsoil Salvage

Water Rights

Culinary Water

Process Water

Diversion Dam

Diversion Pipeline/Ditch

Sedimentation Basin

Water Quality Monitoring

Water Consumption

Utilities

Electrical

Fuel

Fire Control

Vehicles

Millsite and Campsite

Smoking

Trash Burning

Reporting

Personnel

Oil and Hazardous Substance Spill Contingency 
Waste Management

Human Waste

Process Waste

Toxic Waste

Nontoxic Waste

Security

Roads

Access Roads

Haul Roads

Communications

Personnel Requirements

Winterization

Diversion Dam and Pipeline

Placer Open Pit

Settling Pond

Washplant

Roads

Stream

Campsite

\section{Reclamation Plan}

Reclamation Philosophy

Sequence of Reclamation Activities

Material Handling

Rough Valley and Channel Grade

Return of Processed Material to Reclamation

Site

Grade Specifications

Backfilling Pit to Grade

Construction Details for Hillslope Terraces

Construction Details for Inactive and Active Floodplains

Topsoil Spreading

Placement of Large Woody Debris

Placement of Large Rock

Channel Construction Specifications and Details

Channel Profile

Channel Plan

Channel Cross Section

Construction Sequence

Revegetation

Existing Vegetation

Ecological Site Classification

Grass Seeding

Tree and Shrub Planting

Riparian Seeding and Planting

Noxious Weed Control

Post Revegetation Monitoring

Site-Specific Construction Specifications

Slurry Trenches

Tributaries

ivillsite Reclamation

Wash and Concentration Plant - Test Unit

Wash and Concentration Plant - Production Unit

Settling Ponds

Diversion Dam and Pipeline Reclamation

Sedimentation Basin Reclamation

Campsite 
Roads

Project Monitoring Stability

\section{Environmental Impacts}

Introduction

Direct Wildlife Mortality

Presence of Development and Associated Humans

Modification of Vegetation

Topographic Changes

Hydrology Alterations

Noise Ground Shock and Airborne Emissions

\section{Mining Schedule}

First Year

Subsequent Production Years

\section{Figures}

Figure 1

Figure 2

Figure 3

Figure 4

Figure 5

Figure 6

Figure 7

Figure 8

Figure 9

Figure 10

Figure 11

Figure 12

Figure 13

Figure 14

Figure 15

Figure 16

Figure 17

Figure 18

Figure 19

Figure 20

Figure 21

\section{Drawings}

Drawing 1

Drawing 2

Drawing 2

Drawing 3

Drawing 4

Drawing 5

Drawing 6

Drawing 7

Drawing 8

Drawing 9

Drawing 10

Drawing 11

Drawing 12

Drawing 13
Project Map

Original Mineral Survey Property Sale

Lease Agreement

Geological Map of Gold County

Tetonic Map of Gold County

Montana Historical Society Letter

Soils Description

Runoff Calculation

Water Baseline Certified Report

Additional Water Certified Report

U.S. Forest Service Game Report

MDFW\&P Wildlife Report

MDFW\&P Fisheries Report

Transportation Analysis

Gold Recovery Data Sheet

Water Rights

Transfer of Water Rights

Road Specifications

First Year Schedule

2 Through 6th Year Production Schedule

Wash Plant Plan and Cross-Section View

Construction Details: Roads

Construction Details: Ponds

Construction Detail: Diversion Dam

Construction Detail: Pipeline/Ditch

Winterization

Watershed of Washington Creek Drainage

Mining Plan

Ownership Plat

Soils

Process Flow Chart

Placer Mining Plan

Water Quality Monitoring Stations

Vegetation Inventory 
Drawing 14 Streambed Profile (3 sheets)

Drawing 15 Stream Reclamation Cross-Section

Drawing 16 Channel Cross-Section

Drawing 17 Rock Placement Details

Drawing 18

Streambed Construction Details

Drawing 19 Tributary Stabilization Details

Drawing $20 \quad$ Campsite Plan

Drawing 21 Septic System Details

Map Pocket A USGS Quadrangle: Placer City 

APPENDIX 3.

STATE Of MONTANA PlaCER, DREDGE, AND CYANIDE RULES AS SUBMITTED THE LAND BOARD IN MARCH, 1991 

RULE I DEFINITIONS. As used in Rules II through X, unless the context indicates otherwise, the following definitions apply:

(1) "Commence reclamation within 6 months" means to commence reclamation within 6 months or the first seasonal opportunity after mining is not resumed after a seasonal closure;

(2) "Live stream" means a stream with flowing water;

(3) "Pay gravel" means gravels containing sufficient mineralization to be economic;

(4) "Plant" means a support facility, including a wash or processing plant, for a placer or dredge operation;

(5) "Sedimentation" means solid material settled from suspension in a liquid; mineral or organic solid material that is being transported or has been moved from its site of origin by air, water, or ice, and has come to rest on the earth's surface either above or below sea level; or inorganic or organic particles originating from weathering, chemical precipitation or biological activity. AUTH: Sec. 82-4-321, MCA; IMP: Sec. 82-4-305, 82-4-335, MCA.

RULE \| SMES PLACER AND DREDGE BONDING.

(1) (a) A small miner who operates a placer or dredge mine shall post a $\$ 5,000$ bond unless the department approves a lower amount based on the criteria below or unless it is documented that a bond for reclamation is posted with another government agency.

(b) Bond must be filed in the form of a surety, payable to the state of Montana or the the state and the appropriate federal agency, a cash deposit, an assignment of certificate of deposit, letter of credit, or other surety acceptable to the department.

(c) The bond must be accompanied by an appropriate map showing the location of the mine, anticipated disturbances, and perennial streams in the vicinity.

(2) The department shall reduce the required bonding amount if the small miner submits an operating plan documenting that the cost of reclamation to the department would be less than $\$ 5,000$. The information needed to make such a determination includes the following:

(a) a description of the proposed mining operation and foreseeable expansion;

(b) a description of mine support facilities;

(c) the type of equipment and capacity of the plant;

(d) an estimate of pit and pond sizes and volumes of all soil, overburden and placer gravel stockpiles;

(e) description of mining sequence and maximum acreage to be disturbed and unreclaimed at any one time at the mine being bonded;

(f) a description of any water diversions required by the operation;

(g) a topographic map locating mine pit, ponds, diversions, roads, process area, and stream drainages and materials storeage sites. This map should include a reference to existing locatable monuments or landmarks on the ground, be 1 inch to 100 feet unless a different scale is approved by the department, and be based on fixed reference points so that all mapped information is interchangeable;

(h) the depth of soil, overburden and pay zones to be excavated; 
(i) the average and maximum rate of pay gravel removal;

(j) the length and width of roads and average size of the plant area;

(k) any proposal to use suitable settling pond sediments as soil amendment if limited soil is available;

(l) a proposed permanent seed mixture and rate of application (Ibs/ac);

(m) characterization of stream channel and riparian conditions for locations where disturbance is proposed;

(n) identification of the construction method and materials to be used to reclaim soils, overburden, gravel stockpiles, and other disturbances and to reestablish functioning streams and associated floodplains where stream channels have been disturbed; Rule III;

(o) an erosion control plan which contains the appropriate elements from

(p) whenever applicable, a description of the status of 404 permits issued pursuant to the federal Clean Water Act and plans of operation required by federal land management agencies;

(q) status of 310 permit compliance, pursuant to 75-7-101, MCA, et seq., and status of Montana pollution discharge elimination permit compliance pursuant to 75-5-401, MCA.

RULE III (INTERPRETIVE RULE) OPERATIONAL RECOMMENDATIONS.

(1) In order for SMES placer and dredge operators to meet the requirements of 82-4-305 (1), MCA, which requires that the small miner agree in writing not to pollute or contaminate any stream, the department recommends the following best management practices as minimally necessary to assure that operations do not result in water quality violations:

(a) Mining equipment should not be operated in a live stream or diversion, or in any manner to cause bank caving or erosion of the bank of any live stream or diversion.

(b) The amount of make-up water should be limited to only the amount required to operate the wash plant with spent water being recirculated back to the wash plant.

(c) Runoff from undisturbed areas should be minimized through use of temporary berms.

(d) Adequate temporary berms and/or natural undisturbed areas of vegetation should be placed or left as a buffer zone around diversion ditches and live streams to prevent water quality degradation and erosion of disturbed areas as a result of runoff from a 10-year, 24-hour precipitation event.

(e) During operations, care should be taken to protect streambanks and streambank vegetation, stream banks, ditches, and diversions should be lined, riprapped, or otherwise stabilized to prevent excess erosion.

(f) Roads shorid:

(i) be constructed to provide controlled drainage, include culverts, waterbars, and slash filters necessary to facilitate drainage and minimize erosion and be constructed to reduce concentrated flows;

(ii) be located on well-drained soils and located back from stream bottoms in order to provide a buffer zone for preventing road sediments from washing into stream channels; 
(iii) be located outside slide-prone areas characterized by seeps, steep slopes, highly weathered bedrock, clay beds, concave slopes, hummocky topography, and rock layers that dip parallel to the slope;

(iv) be constructed to stabilize sloped exposed surfaces by seeding, compacting, riprapping, benching, mulching or other suitable means prior to fall or spring runoff;

(v) not be left in an erosive condition over a winter season; and

(vi) be used only minimally during wet periods and spring breakup when damage to the roads, which would result in increased sedimentation, is likely to occur.

(g) Cut-and-fill slopes should be constructed at a stable angle and stabilized by seeding, mulching, benching or other suitable means during the same season as construction.

(h) Clearing, grubbing or logging debris should not be placed in streams or used for diversions or cause water quality degradation.

(i) Diversions and impoundments should be sized to pass the 10-year, 24-hour precipitation event. Diversions should be constructed with drop structures or energy dissipators whenever necessary to prevent erosion. Diversion ditch berms should be sloped to account for site-specific conditions, including soils, climate, height of structure and existing natural slopes, and should be revegetated, riprapped, or otherwise stabilized to minimize stream sedimentation.

(j) Before winter shutdown, a small miner should take the following precautions:

(i) Diversions should be sized to pass spring runoff (minimum 10-year, 24-hour event) or streams should be returned to original channels.

(ii) Ponds should have adequate freeboard to prevent over-topping during spring runoff from direct precipitation and over-land flow. Whenever ponds are located within a flood plain and diversions are not sized to pass the 10-year, 24-hour precipitation event, ponds should be filled and reclaimed prior to onset of winter.

(iii) Soil, overburden, and tailings stockpiles should not be placed near streams, unless necessary, and, if so placed, should be bermed at the toe to prevent erosion of sediments into streams.

(iv) Fuel storage tanks should be drained before winter shut down and should be drained and disposed of in a manner which protects adjacent streams.

(k) Dikes shouid be constructed around fuel storage areas to prevent a spill or discharge of fuel to any waters.

(2) A placer or dredge operator who proposes a "project", as that term is defined in 75-7-103, MCA, on a perennial stream, must comply with the requirements of the Natural Streambed and Land Preservation Act, as amended, by obtaining a permit required by the appropriate Conservation District.

(3) In order for a SMES placer or dredge operator to meet the reclamation requirements for bond release, the following reclamation planning guidelines should be followed:

(a) A reclamation plan, or appropriate waiver, for all roads is necessary. 
(b) The postmine land use should be identified and a reclamation timetable should be established.

(c) Soil should be salvaged from all areas to be disturbed and should be stockpiled for use in reclamation.

(d) Site disturbances should be recontoured to a minimum of 3:1 slopes or flatter by backfilling excavated material, unless otherwise approved by the department as achieving comparable stability and utility in the postmining landscape.

(e) Soil and approved soil amendments should be redistributed over all areas disturbed by mining.

(f) The site should be seeded with perennial non-weedy species.

(g) Stream channels should be reconstructed, using coarse placer tails as necessary to dissipate energy. Riprap, temporary synthetic erosion control, or biodegradable revegetation fabrics in combination with permanent vegetation should be used to stabilize streambanks, as necessary. Streams should be reconstructed with grades, pools, and meanders comparable to premine drainage.

(h) Clays and fines available on-site should be sued to create a relatively impermeable layer beneath reclaimed channels and floodplains.

(i) The floodplain should be returned to original contour with the gravel, overburden, and soils replaced to resemble their original stratigraphy. AUTH: Sec. 82-4-321, MCA; IMP: Sec. 82-4-305(1), (3), (4) and (5), MCA.

\section{RULE IV COMPARABLE UTILITY AND STABILITY OF RECLAIMED} AREAS - STANDARDS FOR BOND RELEASE.

(1) In order for the department to release bond, the area must be reclaimed to a post-mining land form and land use that are at least comparable to that of adjacent areas. Reclamation must provide for comparable stability and utility as that of adjacent areas, insure public safety, and prevent pollution of air and water and the degradation of adjacent lands.

(2) Bond may not be released unless the following reclamation standards for placer and dredging operations are achieved:

(a) Pits must be backfilled with overburden and washed gravels unless otherwise approved by the department as part of an alternate postmining land use that provides comparable stability and utility. graded.

(b) Excess overburden must also have been appropriately placed and

(c) Soils and soil substitutes must have been respread and graded on the backfilled, regraded overburden surface.

(d) Slopes must have been reduced to a grade comparable utility and stability in the post-mining landscape.

(e) Disturbed areas must have been revegetated with appropriate perennial non-weedy species similar to that of adjacent areas.

(f) Roads must have been reclaimed to approximate original contour consistent with the postmining land form and land use in compliance with section (1) above unless otherwise approved by the department and concurred with by the landowner.

(g) Stream and floodplain disturbances must be reclaimed to their approximate premining condition so that comparable beneficial uses, such as 
fisheries, comparable flow capacity, and fluvial functions are restored. In most instances, this will require removal of berms.

(h) Noxious weeds must have been controlled, consistent with county weed board requirements. JAUTH: Sec. 82-4-321, MCA; IMP: Sec. 82-4-305 (3), (4) and (5), MCA.

RULES V SMES BOND FORFEITURE AND SMES REVOCATION.

(1) If a small miner who conducts a placer or dredge operation fails to commence reclamation within 6 months after cessation of mining or within an extended period allowed by the department for good cause shown pursuant to (4), or fails to diligently complete reclamation, the department shall notify the small miner by certified mail at his last reported address that bond will be forfeited and the department will reclaim the site unless the small miner commences reclamation within 30 days and diligently completes reclamation.

(2) The department shall revoke the small miner exclusion statement for any small miner whose bond is forfeited.

(3) Cessation of mining is considered to have occurred:

(a) whenever a small miner notifies the department of intent to cease operations, or

(b) whenever a site has been inactive through one operating season and the operator has failed to seek an extension for good cause shown.

(4) The department may grant an extension only when a site is temporarily stabilized in a manner which assures stability through spring runoff, when impact to the environment will be minimized, and when public safety is ensured.

(5) Diligent completion of reclamation will be considered to have occurred whenever:

(a) a site has been graded and seeded in compliance with the requirements of Rule IV during the first planting season, after cessation of activity; and

(b) reclamation standards are achieved within 2 years of completion of reclamation.

(6) An extension of time to reclaim must be renewed annually.

(7) A forfeited bond must be used as follows:

(a) Whenever reclamation can be achieved using the amount of the forfeited bond, excess funds must be returned to the small miner.

(b) Whenever the department documents in a written finding that reclamation cannot be achieved using the amount of the forfeited bond, funds may be deposited in the hard rock mining account established by 82-4-311, MCA, and reclamation must be conducted as priorities and additional funding allow. Forfeited funds deposited in the account may not be used for reclamation of other sites.

(c) Whenever reclamation costs exceed the bonded amount, the department may issue a notice to the placer or dredge operator that the excess costs are due and payable within 30 days, pursuant to 82-4-305(6), MCA. The department may bill the operator only for the cost of activities that are reasonably necessary to return the site to comparable stability and utility and to prevent pollution of state water as defined in Title 75, Chapter 5, MCA. AUTH: Sec. 82-4-321, MCA; IMP: Sec. 82-4-305(4), (5) and (6), MCA. 

APPENDL 4.

EXCERPT FROM THE MONTANA METAL MINE RECLAMATION ACT (ARM 26.401.101-121) 



\section{Sub-Chapter 1}

Rules and Regulations Governing the Montana METAL MINE RECLAMATION ACT

26.4.101 GENERAL STATUTORY PROVISIONS (1) Effective sixty (60) days after the board shall promilgate rules and regulations authorized by the act, the act orovides that no person shall engage in exploration for, or development or mining of minerals on or below the surface of the earth without first obtaining the appropriate license or permit from the board. Upon receipt of a development or operating permit, the permittee, other than a public or governmental agency, shall not commence operation until the oermittee has deposited with the board an acceptable performance bond on forms furnished by the board.

(2) Certain minerals are excluded. See definition of mineral below.

(3) Should small miners sign an agreement described in section 32-4-305, they are excluded from the other reouirements of the act. See definition of small miner below.

(4) The act shall not be apolicable to operations on certain federal lands as specified by the board if federal law, or regulations issued by the federal agency administering such land, impose controls for reclamation of said lands substantially equal to or greater than those imposed by the act.

(5) The act is not applicable to any person or persons collecting rock samples as a hobby or when the collection of rocks and minerals is offered for sale in any amount not exceeding $(\$ 100)$ per year.

(6) Definitions from the act are as follows:

(a) "Person" shall mean and include any person, corporation, firm, association, partnership or other legal entity engaged in exploration for or development or mining of minerals on or below the surface of the earth.

(b) "Exploration" shall mean and include all activities conducted on or beneath the surface of lands resulting in material disturbance of the surface for the purpose of determining the presence, location, extent, depth, grade, and economic viability of mineralization in those lands, if any, other than mining for production and economic exploitations, as well as all roads made for the purpose of facilitating exploration, except as noted in sections 82-4-305 and 310 .

(c) "Surface mining" shall mean and include all or any part of the process involved in mining of minerals by removing the overburden and mining directly from the mineral 
deposits thereby exposed, including, but not limited to, open-pit mining of minerals naturally exposed at the surface of the earth, mining by the auger method, and any and all similar methods by which earth or minerals exposed at the surface are removed in the course of mining. Surface mining shall not include the extraction of oil, gas, bentonite, clay, coal, sand, gravel, phosphate rock, or uranium nor excavation or grading conducted for on-site farming, on-site road construction, or other on-site building construction.

(d) "Mining" shall be deemed to have commenced at such time as the operator shall first mine ores or minerals in commercial quantities for sale, benefication, refining, or other processing or disposition or shall first take bulk samples for metallurgical testing in excess of aggregate of 10,000 short tons.

(e) "Development" shall mean and include all operations between exploration and mining.

(f) "lineral" shall mean and include any ore, rock or substance, other than oil, gas, bentonite, clay, coal, sand, gravel, phosphate rock or uranium, taken from below the surface or from the surface of the earth for the ourpose of milling, concentration, refinement, smelting, manufacturing, or other subsequent use (emphasis added) or processing or for stockpiling for future usage, refinement or smeltim

(g) "Small miner" shall mean any person, firm, or corporation engaged in the business of mining who does not remove from the earth during any 24 hour period material in excess of 100 tons in the aggregate.

(7) Definitions promulgated for administration of the act are as follows:

(a) "Act" means Part 3, Chapter 7, Title 82 MCA.

(b) "Board" means the State Board of Land Commissioners.

(c) "Director" means the Commissioner, Deoartment of State Lands.

(d) "Placer or dredge mining" means the washing or sorting of unconsolidated surficial detritus for gold, silver, tungsten or other valuable minerals. This definition includes, but is not limited to, mining by hydraulic giant, ground sluice, rocker or sluice box methods, the use of a dry land dredge or washing plant, and bucket type floating dredges, all as referred to in Mining Methods and Eauipment Illustrated, Montana Bureau of Mines and Geology, Bulletin $63,1967$.

(e) "To Pollute or contaminate any stream" (as referr$\therefore$ to in section 82-4-305) means to conduct any exploration, development, assessment or mining activity which will result in deterioration of water quality as specified by 
standards adopted by the Montana Water Pollution Control Council, 1967. Any future revisions of these standards adopted in accordance with the provisions of the Montana Water Pollution Control Act, 1971, will apply to this definition.

(f)

"Disturbed and Unreclaimed Surface"

(as referred to in section 82-4-305) means land affected by exploration, development, assessment or mining activities that has not been restored to a continuing beneficial use, with proper grading and revegetative procedures to assure:

(i) slope stability;

(ii) minimal erosion;

( $i \mathrm{i}$ ) adequate vegetative ground cover (if in keeping with reclaimed use);

(iv) that no mine water or surface water passing through a disturbed area will pollute or contaminate any flowing stream.

(g) "Bulkhead" (as referred to in section 82-4$331(2)$ means a door, fence or other construction which allows periodic entry to a mine shaft, adequately secured and locked so that animals and unauthorized persons are denied entry.

(8) Applicability of the Act:

(a) subject to the exclusions set forth in the act and pursuant to the definitions of "surface mining," "mining" and "mineral" in the act, placer or dredge mining, rock quarrying and peat mining operations are included in the application of the act. This rule is adopted to clarify the application of the act.

(b) Section 82-4-331(2) states, "Employees of oersons holding a valid license or permit under this act shall be deemed included in and covered by such license or permit." This provision is interpreted to cover subcontractors and their employees. With the adoption of this rule by the board, the parent company is liable for violations of the act by subcontractors (drilling, construction, maintenance or otherwise) and the subcontractor's employees. (History: Sec. $32-4-321$ MCA; Eff. 12/21/72.)

26.4.102 EXPLORATION LICENSE--APPLICATION AND CONOI TIONS (1) TO secure an exploration license the applicant shaTt:

(a) pay a fee of $\$ 5$ to the board

(b) agree to reclaim any surface area damaged by the applicant during exploration operations, all as may be reasonably required by the board, unless the applicant shall have applied for and been issued a development or operating permit for the lands so damaged; 
(c) not be in default of any other reclamation obligation under this law.

On approval by the board, the applicant will be issued an exploration license renewable annually on application and payment of renewal fee. The license will not be renewed if the applicant is held by the board to be in any violation of the act or rules and regulations promulgated by the board. As per the provisions of sections 82-4-353 an aggrieved aoplicant, licensee or permittee may appeal, the decision of the appeais board being subject to judicial review.

(2) An exploration licensee is subject and must agree to the following minimal provisions ARM 26.4.103-105 for reclamation of surface areas damaged by exploration operations. Recognizing the inherent difficulites of promulgating regulations of state-wide applicability, the board will allow variance from the following provisions of this rule, if a written request submitted prior to commencement of the subject disturbance is accompanied by the landowner's or land administrator's written consent to the variance and is sufficient to convince the board that the public interest and the intent of the act are best served by allowing such variance. (History: Sec. 82-4-321 MCA: IMP, Sec. 82-4-332 MCA; Eff. 12/31/72.)

26.4 .103 EXPLORATION (TEMPORARY) ROADS (1) InSOfar as possible, all roads shall be located on benches, ridge toos and flatter slopes to mininize disturbance and enhance stability.

(2) Road widths may not exceed a fourteen (14) foot single lane standard. Turn-outs may be constructed according to the licensee's needs, but the turn-out area may not exceed 30 feet in total width.

(3) No road may be constructed up a stream channel proper or so close. that material will be spilling into the channel. Minor alterations and relocations of streams may be permitted if the stream will not be blocked and if no damage is done to the stream or adjoining landowners. No alteration which affects more than one hundred (100) linear feet of the channel of a flowing stream may be approved by the board without advice from the Montana State Fish and Game Department.

(4) Road gradients must be kept low except for short pitches to take advantage of topography. Maximum susta ned grades may not exceed 8 percent. Pitch maximum may not. exceed 12 percent and may not be over 300 feet in length.

(5) Insofar as possible, the licensee must keep road cuts reasonably steep to minimize surface disturbances. Cut 
slopes may not be steeper than 1:1 in soil, sand, gravel, or colluvium; ! $:$ in lake silts, or more than $0: 1$ in rock.

Where necessary to prevent significant sloughing or slumoing, the top of road cuts must be rounded back to a more gentle slope. In selecting a slope angle, to prevent slope failure the licensee should consider at least the following factors: the nature of the material, compaction, slope height and moisture conditions.

(6) A ditch must be provided on both sides of a throughcut and with the exception of outsloping roads, on the inside shoulder of a cut-fill section, with ditch relief cross drains being spaced according to grade. Water must be intercepted before reaching a switchback or large fill and be led off. Water on a fill or switchback must be released below the fill or switchback, not over it.

(7) Streams shall be crossed at or near right angles unless contouring down to the stream bed will result in less potential stream bank erosion. Structure or ford entrances and exits must be constructed to prevent water from flowing down the roadway.

(8) Culverts must be installed at prominent drainage way, small creeks and springs. Udon abandonment of the road, culverts must be removed and the drainage way reopened. Such culverts must be sufficient to handle run-off expected from a statistical five-year storm and where necessary must be protected from erosion by adequate rock riprap.

(9) Trees and vegetation may be cleared for only the essential width necessary to maintain soil stability and to serve traffic needs.

(10) Orainage facilities must be installed as road construction progresses.

(11) Adequate diagonal drainage barriers, open tops of Kelly dips must be placed at the following specified intervals:

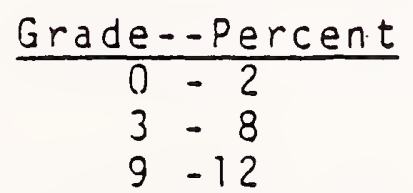

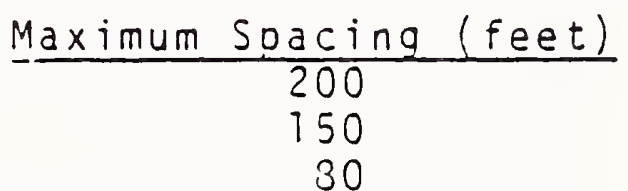

(12) When sideslopes are 15 percent or less, vegetative debris from clearing operations must be completely disposed of or stockpiled at specific areas. On sideslopes steeper than 15 percent such vegetative debris must be oiled neatly parallel to and below the toe of the fill.

(13) Roads must be outsloped whenever possible. If roads are to be used during snow season, insloping with proper drainage consideration is acceptable for vehicle safety reasons. 
(14) Snowplowing must be done in such a manner that run-off water will not be trapped between the snow berms and run down the road.

(15) Materials which slough or slump onto the road bed or into the roadside drainage ditch before the licensee abandons the area must be disposed of in the road bed or on the side hill fill in a manner that will not obstruct any of the drainage facilities heretofore described. (History: Sec. 82-4-321 MCA; IMP. SeC. 82-4-332 MCA; Eff. 12/31/72.)

\subsubsection{CONOUCT OF EXPLORATION OPERATIONS}

Drilling mud from drilling operations shall be permanently confined.

(2) Drill sites may not be constructed in natural flowing streams.

(3) Areas disturbed by removal of vegetation or grading must be kept to the minimum for drilling ooeration.

(4) Insofar as possible, discovery pits or other excavations must be located out of natural flowing streams.

(5) Spoil from the pits or excavations may not be 10 cated in drainage ways. The lower edge of the spoil bank must be at least 5 vertical feet above high flood flow level. Spoil piles must be neatly sloped and rounded to allow vegetation to be re-established.

(6) Exploration excavations, such as shafts (vertical or inclined), tunnels or adits, which involve the removal of rock, mineral or soil material in excess of 50 cubic yards in the aggregate shall be reclaimed in keeping with the standards described in sections 82-4-303(9) and 336 and ARM 26.4 .107 .

(7) When such action will not ohysically hinder further development of the claim, all land surfaces disturbed by assessment work (that may be properly considered exploration) must be graded promptly to facilitate revegetation and to prevent excessive erosion.

(8) All refuse connected with exploration activities shall be collected, removed and disposed of in oroper disposal sites. (History: Sec. 82-4-321 MCA; IMP), Sec. 82-4332 MCA; Eff. $12 / 31 / 72$.)

\subsubsection{REVEGETATION REQUIREMENTS- (1) The first} objective in revegetation is to stabilize the area as quickly as possible after it has been disturbed. Plants that will give a quick, protective cover or those that will enrich the soil shall be given priority. Plants reestablished must be in keeping with the intended reclaimed use of the land. 
(2) Appropriate revegetation shail be accomplished as soon after necessary grading as possible; however, revegetation must be performed in the proper season in accordance with accepted agricultural and reforestation practices.

(3) All fill and cut slopes, with the exception of rock faces, must be seeded or planted or both during the first appropriate season following construction of the road.

(4) All drill sites and spoils from discovery pits or other excavations must likewise be seeded or planted or both, if feasible, in the first appropriate season following completion of the work. Exceptions may be made if such revegetation would hide or obscure significant evidence relating to the possible presence of an ore deposit.

(5) Upon abandonment, and closure, the exploration road itself must be adequately prepared for suitable revegetation; such revegetation must be undertaken in the first appropriate season following abandonment, closure, and soil preparation.

(6) In the event that any of the above revegetation efforts are unsuccessful, the licensee must seek the advice of the board and make a second attempt, incorporating such changes and additional procedures as may be expected to orovide satisfactory revegetation. (History: Sec. 82-4-321 MCA; IMP, SeC. 82-4-332 MCA; Eff. 12/31/72.)

26.4.106 RECLAMATION PLANS The definition of reclamation plan (section 82-4-303(a) lists 9 considerations which "to the extent practical at the time of application" must be included in the plan. Using the same letter headings as in the above-referenced definition, the following are the board's standards for each of the required provisions that must be included in the plan:

(1) land disturbed by development or mining activities must be reclaimed for one or more specified uses, including, but not limited to: forest, pasture, orchard, cropland, residence, recreation, wilderness, industry, habitat (including food, cover or waterl for wildlife or other uses. Proposed reclamation need not reclaim subiect disturbed areas to a better condition or different use than that which existed prior to development or mining. The applicant must describe:

(a) current uses(s) of area to be disturbed;

(b) current and proposed uses of nearby land that by its proximity may influence or guide the choice of a re claimed use of the disturbed area; 
(c) pertinent climatic, topographical, soil, water and wildife data that govern choice of proposed use of the reclaimed land.

(2) With the use of cross-sections, topograotic mads or detailed prose, the proposed topography of the reclaimed land must be adequately described. As specific situations warrant, proper grading must provide for adequately designed contour trenches, benches and rock-lined channelways on disturbed areas. The apolicant must submit evidence to assure the board that upon partial or complete saturation with water, graded fill, tailings or spoil slopes will be stable. The proposed grading methods must be described. Where practicable, soil materials from all disturbed areas must be stockpiled and utilized.

(3) To the extent reasonable and oracticable, the permittee must establish vegetative cover comensurate with the proposed land use specified in the reclamation plan. Should an initial revegetation attempt be unsuccessful, the permittee must seek the advice of the board and make another attempt. The second revegetation operation, insofar as possible, shall incorporate new methods necessary to reestablish vegetation.

(4) Where operations result in a need to prevent acid drainage or sedimentation, on or in adjoing lands or streams, there shall be provisions for the construction of earth dams or other reasonable devices to control water drainage, provided the formation of such impoundments or devices shall not interfere with other landowners rights or contribute to water pollution (as defined in the Montana llater Pollution Control Act as amended).

(5) The plan must provide that all water, tailings or spoil impounding structures be equipped with spillways or other devices that will protect against washouts during a one hundred (100) year flood.

(6) Alt applicants must comply with all applicable county, state and federal laws regarding solid waste disposal. All refuse shall be disposed of in a manner that will prevent water pollution or deleterious effects upon the revegetation efforts.

(7) Upon abandonment, water from the development or mining activities shall be diverted or treated in a manner designed to control siltation, erosion or other water pollution damage to streams and natural water courses.

(8) All access, haul and other support roads shall be located, constructed and maintained in such amanner as to control and minimize channeling and other esosiou.

(9) All operations shall be conducteo so as to avoid range and forest fires and spontaneous combustion. 
(10) Archaeological and historical values in area to be developed shall be given appropriate protection.

(11) Provisions shall be made to avoid accumulation of stagnant water in the development area which may serve as a host or breeding ground for mosquitoes or other diseasebearing or noxious insect 1 ife.

(12) All final grading shall be made with non-noxious, nonflammable, noncombustible solids unless approval has been granted by the board for a supervised sanitary fill.

(13) Proper precautions must be taken to assure that exposed cuts and tailings or spoil disposal areas will not be subject to wind erosion to the extent that air-borne detritus becomes a public nuisance or detriment to the flora and fauna of the area.

(14) In a reclamation plan accompanying an application for operating permit, the applicant shall provide the board with sufficiently detailed information regarding method(s) of disposal of mining debris, including mill tailings, and the location and size of such areas.

(15) The plan must describe the location of the surface water diversions as well as the methods of diverting surface water around the disturbed areas. Properly protected culverts, conduits or other artificial channels may carry surface water through the disturbed areas providing such procedures prevent pollution of such waters and unnecessary erosion.

(16) Requirements regarding reclamation of stream channels and stream banks must be flexible to fit circumstances of each stream site. Many stream relocations, however, will be permanent and thus will represent the reclaimed condition of stream channels and stream banks. Accordingly, reclamation plans must contain the following provisions should stream channels or banks be permanently relocated:

(a) the relocated channel shall be of a length equal to or greater than the original channel, unless the board after consideration of the local circumstance shall grant a variance;

(b) the relocated channel shall contain meanders, riffles and pools similar to those in the original channel;

(c) stream banks shall be rounded to prevent slumping and sloughing and shall be revegetated in keeping with accepted agriculture or reforestation practices the first appropriate season following channel relocation;

(d) rock riprap shall be used wherever aporopriate.

(17) Sections 7 and 8 of the act require that maps of the intended development or mining ooeration(s) accompany applications for permit. Should a copy of such maps, to 
scale, contain the following additional information (transparent overlays are acceptable), a separate map need not accompany the reclamation plan:

(a) outline of the area to be disturbed in the first permit year:

(b) outiine of areas where soil materials will be replaced;

(c) outiine of intended revegetation areas showing plant or seed densitities and species chosen;

(d) location of such structures, drainage features, etc. as may be necessary to prevent erosion of bare slopes and subsequent siltation or other pollution of natural flowing streams or other natural water bodies.

(18) Reclamation shall be as concurrent with development or mining operations as feasible and must be completed within a specified reasonable length of time. Revegetation must be accomplished in the first approoriate season after necessary grading, in accordance with acceoted agricultural or reforestation practices. (History: Sec. 2,2-4-321 MCA; IMP, Sec. 82-4-335, Sec. 82-4-336 HCA; Eff. 12/31/72.)

\subsubsection{OPERATING PERMIT: APPLICATION REOUIREMEITS}

(1) Applicant must obtain an operating permit for each mine complex on a form prescribed by the board.

(2) To obtain an oderating permit the applicant shall:

(a) pay a $\$ 25.00$ fee;

(b) indicate proposed date for commencement of mining and minerals to be mined;

(c) provide a map to scale of the mine area and area to be disturbed (such map will locate and identify streams, and proposed roads, railroads and utility lines in the immediate area);

(d) submit a plan of mining which will provide, within limits of normal operating procedures of the industry, for completion of mining and associated land disturbances;

(e) provide a reclamation plan that meets the requirements of section 9 of the act and the rules and regulations of the board. (History: SeC. 82-4-321 MCA; IMP, SeC. $82-4-$ 336 MCA; Eff. 12/31/72.)

For the purposes of administering the act the board will presume that an operation is abandoned or completed (and thus subject to the reclamation time schedule outlined in section $g$ of the act) as soon as ore ceases to be extracted for future use or processing. Should the permittee wish to rebut said assumption, he must provide evidence satisfactory to the board that his operations have not in fact been abandoned or completed. 
(2) Documentation of any of the following situations will be adequate evidence of intent not to abandon operations:

(a) the mine or mill work force is on strike while negotiating a new contract;

(b) the mine or mill is shut down because of some failure of the transportation network in moving ore or processed material;

(c) the mine or mill is shut down because of a natural catastrophe and plans to resume operations are being formulated;

(d) the mine or mill is seasonally shut down due to predictable annual variance in the mined product's market or because of inclement weather or seasonal inaccessibility;

(e) the mine or mill is shut down for maintenance or the construction of new facilities;

(f) the mine or mill is forced to temoorarily shut down because of violation of other state or federal laws and efforts are being made to remedy the cause of the violation.

(3) At the discretion of the board, the following evidence and any other relevant evidence may be satisfactory to show intent to resume operations:

(a) exhibition of drill core and accompanying assay reports to show that ore minerals still remain in the mine and that they are present in veins or accumulations of sufficient size, grade and accessibility to warrant continued development --geological, geochemical or geophysical

indications of valuable mineralization sufficient to warrant further development or mining will also be considered by the board;

(b) continued employment of a maintenance crew to dewater the mine or replace timbers, etc.;

(c) data recording present and predicted commodity prices, labor and transportation costs, etc., or any other evidence which may show that mining may soon resume on a profitable basis. Board comment: It is recognized that "abandonment or completion of mining" under the operating permit (see section 9 of the act) is an action commonly predicated upon complex and changing economic circumstances; that cessation of mining need not mean abandonment or completion; and that short of obtaining an operator's records and examining his mine development drill core, the board may be unable to determine the operator's true intent. (History: Sec. 82-4-321 MCA; IMP, Sec. 82-4-336 liCA; Eff. 12/31/72.)

26.4.109 ABANDONED PITS: OBJECTIONABLE EFFLUENTS Section 9 , part $F$, concerns abandoned open pits greater than two (2) acres in size and gives the board the responsibility 
OE srteing levels of objectional feffluents safe to humans and the envicomment that may flor: or be puinied out of the pit, with or without trcatment.

(2) The bourd rules thai subjest reclamation plans must. provide that all discharges from such abandorral pits will be consistent with provisions of the liontana vaier pellution Control Act, sections 75-5-102, 75-5-306, 75-..563:-635 as amencied.

(3) E.ffluents from a subject abanioned pit must rieet the suter quality standards adopted by tie rontania :aler Pollution control Council, cciober 5, 1967, or any future revisions of these standards in cefoct at the tjme of pit abancionment. In accordance with criteria for olhur materials exhibiting a residual life exreeding 30 diys in ivater, no heavy metals or hadvy metal compounds shall be pumped or allowed to flow Erom subject open pits in concentrations exceeding tolel:ance limit (TIm 96) for game fish present j.n the receiving witer. (History: Sec. 82-4-321 MCA; IMP. SeC. $82-4-336$ : $\because$ CA; EEE. 12/31/72.)

26.4.LIO DISCEOSURE OE INEORNATION UPON APELI.LAtion, tha bo ard shall ralease information acculucd through the adninistration of the act to propcr intertsled per:sons. Eor cinese purposes "proper interested persons" is definod as foilons:

(1) as to information, contained in or accompanying apzications for licenscs or perlitits, "groper intarcsied porsons" are those persons so designated, in uriting, by the opprator or his autiorized dients;

(.2) as to all other information (except information socified in section 82-4-306, acquired through the administration of the act, all members of the public are "proper interested persons". (ifistory: Sec. 82-4-321 MCA; EE. $12,31 / 72$.)

26.4.111 GE:EPAL COHPL[ANCE The licensee shall comply with all feceral and state laws, and such rules and regulations as are pronulgated by the comnission under this act. (History: SeC. 82-4-321 MCA; EEf. 12/31/72.)

Rules 12 through 20 reserved.

26.4.121 ABANDONED MINE LAND RECLAMATION: DEEINITIONS Fer the pliposes of Rules 26.4 if? through 132 , the following definitions shall apply:

(1) "abandoned mine land reclamation fund" means a separate fund established pursuant to sections $82 \cdots 4-242$, 
82-4-323 and 82-4-424 Eor the purgose of accounting Eur monies granted by the office of surface mining umrer an approved state reclamation prociam and other monics authorizcd by these regulations to be dejosited in the abanduned mine reclamation fund;

(2) "emergency" menns a suclden dauger of impairment that presents a high probability of substantial physical harm to the harlth, safety, or general welfare of pcople beforc the danger can be abated under normal program oper¿ion proceclures;

(3) "expended" means that monics have bcen paid out by the dopartment for work that has bcen accomplished or scivices rendered;

(4) "extreme danger" means a condition that could resonably be expected to cause substantial physical harm to persons, property, or the enviromment and to which persons or improvements on real property are currently exposed; Eund;

(5) "fund" means the abandoned mine land reclamation

(6) "left or abandoned in either an unreclaimed or inadequately reclaimed condition" means lands and \%atci:

(a) where all mining processes ceascd and no current fermit for continuing operations existcd as of August 3,1977, or, if a permit did exist on that date, but all mining processes had ceased, the permit has since lapsed and has not been rencived or superseded by a new permit as of the date of the request for reclamation assistance; and

(b) which continue, in their present condition, to sibstantially degrade the quality of the enviloumcint, prevent, or danage the beneficial use of land or water resources, or enianger the health or safety of the public.

(7) "Montana abandoned mine reclamation plan" means a plan zpproved by the office of surface mining under 30 CFR Part 884 ;

(3) "Montana abandoned mine recla:nation program" means z program established by the board in accordance with 30 CF'R Part 870 and 30 CFR part 880 for reclination of land and water adversely affected by past mining;

(9) "reclamation activities" means restoration, reclamation, abatement, control, or prevention of adverse effects of mining:

(10) "Regional director" means the dircctor of the region $V$ office of the office of surface mining or the director's representative. (History: Sec. 82-4-321 MCA; IMP, SEC. 82-4-311 MCA; NEW, 1980 MAR p. 725, EEE. 4/1/SO.)

26.4 .122 ABANDONED MINE RECLAMATION EUND

(1) An account to be known as the abandoned mine land reclamation fund is established by the department and shall 

APPENDL 5.

U.S. FORES: ' (36 CFR 228) 

dar days, the Forest Service upon the purchaser's request, may refund the cash portion of such excess that is attributable to the redetermined contract rates.

(f) Future sales. Timber sales in Alaska advertised after July 31, 1985 shall provide for an emergency rate redetermination in accordance with standard Forest Service timber sale contract procedures, except that completion of a scheduled rate redetermination shall not be required as a prerequisite for the $\in$ mergency rate redetermination.

[50 FR 30936, July 31, 1985]

\section{PART 228-MINERALS}

\section{Subpart A-Locatable Minerals}

Sec.

228.1 Purpose.

228.2 Scope.

228.3 Definitions.

228.4 Plan of operations-notice of intentrequirements.

228.5 Plan of operations-approval.

228.6 Availability of information to the public.

228.7 Inspection, noncompliance.

228.8 Requirements for environmental protection.

228.9 Maintenance during operations, public safety.

228.10 Cessation of operations, removal of structures and equipment.

228.11 Prevention and control of fire.

228.12 Access.

228.13 Bonds.

228.14 Appeals.

228.15 Operations within National Forest Wilderness.

\section{Subpart B-Leasable Minerals}

228.20-228.39 [Reserved]

\section{Subpant C-Disposal of Mineral Materials}

228.40 Authority.

228.41 Scope.

228.42 Definitions.

228.43 Policy governing disposal.

228.44 Disposal on existing Federal leased areas.

228.45 Qualifications of applicants.

228.46 Application of other laws and regulations.

\section{Generar Provistons}

228.47 General terms and conditions of contracts and permits.

228.48 Appraisal and measurement.
228.49 Reappraisal.

228.50 Production records.

228.51 Bonding.

228.52 Assignments.

228.53 Term.

228.54 Single entry sales or permits.

228.55 Cancellation or suspension.

228.56 Operating plans.

Types and Methods of Disposal

228.57 Types of disposal.

228.58 Competitive sales.

228.59 Negotiated or noncompetitive sales.

228.60 Prospecting permits.

228.61 Preference right negotiated sales.

228.62 Free use.

228.63 Removal under terms of a timber sale or other Forest Service contraci.

228.64 Community sites and common-use areas.

228.65 Payment for sales.

228.66 Refunds.

228.67 Information collection requirements.

Subpent D-Miscollaneous Minerals Provisions

228.80 Operations within Misty Fjords and Admiralty Island National Monuments, Alaska.

AUTBORITY. 30 Stat. 35 and 36 , as amended (16 U.S.C. 478, 551), and 94 Stat. 2400.

SOURCE: 39 F'R 31317, Aug. 28, 1974, unless otherwise noted. Redesignated at $46 \mathrm{FR}$ 36142. July 14, 1981.

\section{Subpart A-Locatable Minerals}

\section{\$228.1 Purpose.}

It is the purpose of these regulations to set forth rules and procedures through which use of the surface of National Forest System lands in connection with operations authorized by the United States mining laws (30 U.S.C. 21-54), which confer a statutory right to enter upon the public lands to search for minerals, shall be conduct. ed so as to minimize adverse envirormental impacts on National Furest System surface resources. It is not the purpose of these regulations to provide for the management of mineral resources; the responsibility for managing such resources is in the Secretary of the Interior.

\section{$\S 228.2$ Scope.}

These regulations apply to operations hereafter conducted under the United States mining laws of May 10. 
1872, as amended ( 30 U.S.C. 22 et seq.), as they affect surface resources on all National Forest System lands under the jurisdiction of the Secretary of $\mathrm{Ag}$ riculture to which such laws are applicable: Provided, however, That any area of National Forest lands covered by a special Act of Congress (16 U.S.C. $482 a-482 q$ ) is subject to the provisions of this part and the provisions of the special act, and in the case of conflict the provisions of the special act shall apply.

\section{§228.3 Definitions.}

For the purposes of this part the following terms, respectively, shall mean:

(a) Operations. All functions, work, and activities in connection with prospecting, exploration, development, mining or processing of mineral resources and all uses reasonably incident thereto, including roads and other means of access on lands subject to the regulations in this part, regardless of whether said operations take place on or off mining claims.

(b) Operator. A person conducting or proposing to conduct operations.

(c) Person. Any individual, partnership, corporation, association, or other legal entity.

(d) Mining claim. Any unpatented mining claim or unpatented millsite authorized by the United States mining laws of May 10, 1872, as amended (30 U.S.C. 22 et seq.).

(e) Authorized officer. The Forest Service officer to whom authority to review and approve operating plans has been delegated.

\section{$\$ 228.4$ Plan of operations-notice of intent-requirements.}

(a) Except as provided in paragraph (a)(2) of this section, a notice of iritention to operate is required from any person proposing to conduct operations which might cause disturbance of surface resources. Such notice of intention shall be submitted to the District Ranger having jurisdiction over the area in which the operations will be conducted. If the District Ranger determines that such operations will likely cause significant disturbance of surface resources, the operator shall submit a proposed plan of operations to the District Ranger.
(1) The requirements to submit a plan of operations shall not apply: (i) To operations which will be limited to the use of vehicles on existing public roads or roads used and maintained for National Forest purposes, (ii) to individuals desiring to search for and occasionally remove small mineral sam. ples or specimens, (iii) to prospecting and sampling which will not cause sig. nificant surface resolurce disturbance and will not involve removal of more than a reasonable amount of mineral deposit for analysis and study, (iv) to marking and monumenting a mining claim and $(v)$ to subsurface operations which will not cause significant surface resource disturbance.

(2) A notice of intent need not be filed: (i) Where a plan of operations is submitted for approval in lieu thereof, (ii) for operations excepted in paragraph (a)(1) of this section from the requirement to file a plan of operations. (iii) for operations which will not involve the use of mechanized earthmoving equipment such as bulldozers or backhoes and will not involve the cutting of trees. Each notice of intent to operate shall provide information sufficient to identify the area involved, the nature of the proposed operations, the route of access to the area of operations and the method of transport. If a notice of intent is filed, the District Ranger will, within 15 days of receipt thereof, notify the operator whether a plan of operations is required.

(b) Any person conducting operations on the effective date of these regulations, who would have been required to submit a plan of operations under $\$ 228.4(a)$, may continue operations but shall within 120 days thereafter submit a plan of operaticns to the District Ranger having jurisa :tion over the area within which operations are being conducted: Provided, however, That upon a showing of good cause the authorized officer will grant an extension of time for submission of a plan of operations, not to exceed an additional 6 months. Operations may continue according to the submitted plan during its review, unless the authorized officer determines that the operations are unnecessarily or unreasonably causing irreparable damage to 
surface resources and advises the operator of those measures needed to avoid such damage. Upon approval of a plan of operations, operations shall be conducted in accordance with the approved plan. The requirement to submit a plan of operations shall not apply: (1) To operations excepted in $\$ 228.4(a)$ or (2) to operations concluded prior to the effective date of the regulations in this part.

(c) The plan of operations shall include:

(1) The name and legal mailing address of the operators (and claimants if they are not the operators) and their lessees, assigns, or designees.

(2) A map or sketch showing information sufficient to locate the proposed area of operations on the ground, existing and/or proposed roads or access routes to be used in connection with the operations as set forth in \$ 228.12 and the approximate location and size of areas where surface resources will be disturbed.

(3) Information sufficient to describe or identify the type of operations proposed and how they would be conducted, the type and standard of existing and proposed roads or access routes, the means of transportation used or to be used as set forth in \$228.12, the period during which the proposed activity will take place, and measures to be taken to meet the requirements for environmental protection in $\$ 228.8$.

(d) The plan of operations shall cover the requirements set forth in paragraph (c) of this section, as foreseen for the entire operation for the full estimated period of activity: Provided, however, That if the development of a plan for an entire operation is not possible at the time of preparation of a plan, the operato shail file an initial plan setting forth his proposed operation to the degree reasonably foreseeable at that time, and shall thereafter file a supplemental plan or plans whenever it is proposed to undertake any significant surface disturbance not covered by the initial plan.

(e) At any time during operations under an approved plan of operations, the authorized officer may ask the operator to furnish a proposed modifica- tion of the plan detailing the means of minimizing unforeseen significant disturbance of surface resources. If the operator does not furnish a proposed modification within a time deemed reasonable by the authorized officer, the authorized officer may recommend to his immediate superior that the operator be required to submit a proposed modification of the plan. The recommendation of the authorized officer shall be accompanied by a statement setting forth in detail the supporting facts and reasons for his recommendations. In acting upon such recommendation, the immediate superior of the authorized officer shall determine: (1) Whether all reasonable measures were taken by the authorized officer to predict. the environmental impacts of the proposed operations prior to approving the operating plan, (2) whether the disturbance is or jrob. ably will become of such significance as to require modification of the operating plan in order to meet the requirements for environmental protection specified in $\$ 228.8$ and (3) whether the disturbance can be minimized using reasonable means. Lacking such determination that unforeseen significant disturbance of surface resources is occurring or probable and that the disturbance can be minimized using reasonable means, no operator shall be required to submit a proposed modification of an approved plan of operations. Operations may continue in accordance with the approved plan until a modified plan is approved, unless the immediate superior of the authorized officer determines that the operations are unnecessarily or unreasonably causing irreparable injury, loss or damage to surface resources and advises the operator of those measures needed to avoid such damage.

(f) Upon completion of an environmental analysis in cormection wiin each proposed operating plan, the authorized officer will determine whether an environmental statement is required. Not every plan of operations, supplemental plan or modification will involve the preparation of an environmental statement. Environmental impacts will vary substantially depending on whether the nature of operations is prospecting, exploration, development. 
or processing, and on the scope of operations (such as size of operations, construction required, length of operations and equipment required), resulting in varying degrees of disturbance to vegetative resources, soil, water, air, or wildlife. The Forest Service will prepare any environmental statements that may be required.

(g) The information required to be included in a notice of intent or a plan of operations, or supplement or modification thereto, has been assigned Office of Management and Budget Control \#0596-0022. The public reporting burden for this collection of information is estimated to vary from a few minutes for an activity involving little or no surface disturbance to severa! months for activities involving heavy capital investments and significant surface disturbance, with an average of 2 hours per individual response. This includes time for reviewing instructions, searching existing data sources, gathering and maintaining the data needed, and completing and reviewing the collection of information. Send comments regarding the burden estimate or any other aspect of this collection of information, includ. ing suggestions for reducing this burden, to Chief (2800), Forest Service, USDA, P.O. Box 96090, Washington, DC 20090-6090 and to the Office of Information and Regulatory Affairs, Office of Management and Budget, Washington, DC 20503.

[39 FR 31317, Aug. 28, 1974. Redesignated at 46 FTR 36142, July 14,1981, and amended at 54 FR 6893 , Feb. 15, 1989]

\section{§228.5 Plan of operations-approval.}

(a) Operations shall be conducted in accordance with an apisived plan of operations, except is piovided in paragraph (b) of this section and in $\$ 228.4$ (a), (b), and (e). A proposed plan of operation shall be submitted to the District Ranger, who shall promptly acknowledge receipt thereof to the operator. The authorized officer shall, within thirty (30) days of such receipt, analyze the proposal, considering the economics of the operation along with the other factors in determining the reasonableness of the requirements for surface resource protection, and;
(1) Notify the operator that he has approved the plan of operations; or

(2) Notify the operator that the proposed operations are such as not to require an operating plan; or

(3) Notify the operator of any changes in, or additions to, the plan of operations deemed necessary to meet the purpose of the regulations in this part; or

(4) Notify the operator that the plan is being reviewed, but that more time, not to exceed an additional sixiy (60) days, is nacessary to complete such review, setting forth the reasons why additional time is needed: Provided, however, That days during which the area of operations is inaccessible for inspection shall not be included when computing the sixty (60) day period; or

(5) Notify the operator that the plan cannot be approved until a final environmental statement has been prepared and filed with the Council on Environmental Quality as provided in § 228.4(f).

(b) Pending final approval of the plan of operations, the authorized officer will approve such operations as may be necessary for timely compliance with the requirements of Federal and State laws, so long as such operations are conducted so as to minimize environmental impacts as prescribed by the authorized officer in accordance with the standards contained in $\S 228.8$.

(c) A supplemental plan or plans of operations provided for in $\S 228.4$ (d) and a modification of an approved operating plan as provided for in $\S 228.4(e)$ shall be subject to approval by the authorized officer in the same manner as the initial plan of operations: Provided, however, That a modification of an approved plan of operations under $\S 228.4(e)$ shall be subject to approval by the immediate superior of the authorized officer in cases where it has been determined that a modification is required.

(d) In the provisions for review of operating plans, the Forest Service will arrange for consultation with appropriate agencies of the Department of the Interior with respect to significant technical questions concerning the character of unique geologic condi- 
tions and special exploration and development systems, techniques, and equipment, and with respect to mineral values, mineral resources, and min. eral reserves. Further, the operator may request the Forest Service to arrange for similar consultations with appropriate agencies of the U.S. Department of the Interior for a review of operating plans.

\section{\$228.6 Availability of information to the public.}

Except as provided herein, all information and data submitted by an operator pursuant to the regulations in this part shall be available for examination by the public at the Office of the District Ranger in accordance with the provisions of 7 CFR 1.1-1.6 and 36 CF'R 200.5-200.10. Specifically identified information and data submitted by the operator as confidential concerning trade secrets or privileged commercial or financial information will not be available for public examination. Information and data to be withheld from public examination may include, but is not limited to, known or estimated outline of the mineral deposits and their location, attitude, extent, outcrops, and content, and the known or planned location of exploration pits, drill holes, excava. tions pertaining to location and entry pursuant to the United States mining laws, and other commercial information which relates to competitive rights of the operator.

\section{§ 228.7 Inspection, noncompliance.}

(a) Forest Officers shall periodically inspect operations to determine if the operator is complying with the regulations in this part and an approved plan of operations.

(b) If an operator fails to comply with the regulations or his approved plan of operations and the noncompliance is unnecessarily or unreasonably causing injury, loss or damage to sur. face resources the authorized officer shall serve a notice of noncompliance upon the operator or his agent in person or by certified mail. Such notice shall describe the noncompliance and shall specify the action to comply and the time within which such action is to be completed, gener- ally not to exceed thirty (30) days: Provided, however, That days during which the area of operations is inaccessible shall not be included when computing the number of days allowed for compliance.

\section{\$228.8 Requirements for environmental protection.}

All operations shall be conducted so as, where feasible, to minimize adverse environmental impacts on National Forest surface resources, including the following requirements:

(a) Air Quality. Operator shall comply with applicable Federal and State air quality standards, including the requirements of the Clean Air Act, as amended (42 O.S.C. 1857 et seq.).

(b) Water Quality. Operator shall comply with applicable Federal and State water quality standards, including regulations issued pursuant to the Federal Water Pollution Control Act, as amended (33 U.S.C. 1151 et seq.).

(c) Solid Wastes. Operator shall comply with applicable Federal and State standards for the disposal and treatment of solid wastes. All garbage, refuse, or waste, shall either be removed from National Forest lands or disposed of or treated so as to minimize, so far as is practicable, its impact on the environment and the forest sur. face resources. All tailings, dumpage, deleterious materials, or substances and other waste produced by operations shall be deployed, arranged, disposed of or treated so as to minimize adverse impact upon the environment and forest surface resources.

(d) Scenic Values. Operator shall, to the extent practicable, harmonize operations with scenic values through such measures as the design and location of operating facilities, including roads and other means of access, vegetative screening of operations, and construction of structures and improvements which blend with the landscape.

(e) Fisheries and Wildifie Habitat. In addition to compliance with water quality and solid waste disposal standards required by this section, operator shall take all practicable measures to maintain and protect fisheries and 
wildlife habitat which may be affected by the operations.

(f) Roads. Operator shall construct and maintain all roads so as to assure adequate drainage and to minimize or, where practicable, eliminate damage to soil, water, and other resource values. Unless otherwise approved by the authorized officer, roads no longer needed for operations: (1) Shall be closed to normal vehicular traffic, (2) bridges and culverts shall be removed, (3) cross drains, dips, or water bars shall be constructed, and (4) the road surface shall be shaped to as near a natural contour as practicable and be stabilized.

(g) Reclamation. Upon exhaustion of the mineral deposit or at the earliest practicable time during operations, or within 1 year of the conclusion of operations, unless a longer time is allowed by the authorized officer, operator shall, where practicable, reclaim the surface disturbed in operations by taking such measures as will prevent or control onsite and off-site damage to the environment and forest surface resources including:

(1) Control of erosion and landslides;

(2) Control of water runoff;

(3) Isolation, removal or control of toxic materials;

(4) Reshaping and revegetation of disturbed areas, where reasonably practicable; and

(5) Rehabilitation of fisheries and wildlife habitat.

(h) Certification or other approval issued by State agencies or other Fed. eral agencies of compliance with laws and regulations relating to mining operations will be accepted as compliance with similar or parallel requirements of these regulations.

\section{\$228.9 Maintenance during operations, public safety.}

During all operations operator shall maintain his structures, equipment, and other facilities in a safe, neat and workmanlike manner. Hazardous sites or conditions resulting from operations shall be marked by signs, fenced or otherwise identified to protect the public in accordance with Federal and State laws and regulations.
$\$ 228.10$ Cessation of operations, removal of structures and equipment.

Unless otherwise agreed to by the authorized officer, operator shall remove within a reasonable time fol. lowing cessation of operations all structures, equipment and other facilities and clean up the site of operations. Other than seasonally, where operations have ceased temporarily, an operator shall file a statement with the District Ranger which includes: (a) Verification of intent to maintain the structures, equipment and other facilities, (b) the expected reopening date, and (c) an estimate of extended duration of operations. A statement shall be filed every year in the event operations are not reactivated. Operator shall maintain the operating site, structures, equipment and other facilities in a neat and safe condition during nonoperating periods.

\section{$\$ 228.11$ Prevention and control of fire.}

Operator shall comply with all app. cable Federal and State fire laws and regulations and shall take all reason:ble measures to prevent and supprer: fires on the area of operations ans shall require his employees, contractors and subcontractors to do likewise.

\section{\$228.12 Access.}

An operator is entitled to access in connection with operations, but no road, trail, bridge, landing area for aircraft, or the like, shall be constructed or improved, nor shall any other means of access, including but not limited to off-road vehicles, be used until the operator has received approval of an operating plan in writing from the authorized officer when required by $\S 228.4(a)$. Proposa's 'or construction, improvement or ise of such access as part of a plan of operations shall include a description of the type and standard of the proposed means of access, a map showing the proposed route of access, and a description of the means of transportation to be used. Approval of the means of such access as part of a plan of operations shall specify the location of the access route, design standards, means of transportation, and other conditions reasonably necessary to protect the 
environment and forest surface resources, including measures to protect scenic values and to insure against erosion and water or air pollution.

\section{\$228.13 Bonds.}

(a) Any operator required to file a plan of operations shall, when required by the authorized officer, fur. nish a bond conditioned upon compliance with $\$ 228.8(\mathrm{~g})$, prior to approval of such plan of operations. In lieu of a bond, the operator may deposit into a Federal depository, as directed by the Forest Service, and maintain therein, cash in an amount equal to the required dollar amount of the bond or negotiable securities of the United States having market value at the time of deposit of not less than the required dollar amount of the bond. A blanket bond covering nationwide or statewide operations may be furnished if the terms and conditions thereof are sufficient to comply with the regulations in this part.

(b) In determining the amount of the bond, consideration will be given to the estimated cost of stabilizing, rehabilitating, and reclaiming the area of operations.

(c) In the event that an approved plan of operations is modified in accordance with $\$ 228.4$ (d) and (e), the authorized officer will review the initial bond for adequacy and, if necessary, will adjust the bond to conform to the operations plan as modified.

(d) When reclamation has been completed in accordance with $\S 228.8(\mathrm{~g})$, the authorized officer will notify the operator that performance under the bond has been completed: Provided, however, That when the Forest Service has accepted as completed any portion of the reclamation, the authorized officer shall notify. the operator of such acceptance and reduce proportionally the amount of bond thereafter to be required with respect to the remaining reclamation.

[39 F'R 31317. Aug. 28, 1974; 39 F'R 32029. Sept. 4. 1974]

\section{§ 228.14 Appeals.}

Any operator aggrieved by a decision of the authorized officer in connection with the regulations in this part may file an appeal under the provisions of 36 CFR Part 251, Subpart C.

[54 FR 3362, Jan. 23, 1989]

\section{\$228.15 Operations within National Forest Wilderness.}

(a) The United States mining laws shall extend to each National Forest Wilderness for the period specified in the Wilderness Act and subsequent es. tablishing legislation to the same extent they were applicable prior to the date the Wilderness was designated by Congress as a part of the $\mathrm{Na}$ tional Wilderness Preservation System. Subject to valid existing rights, no person shall have any right or interest in or to any mineral deposits. which may be discovered through prospecting or other information-gathering activity after the legal date on which the United States mining laws cease to apply to the specific Wilderness.

(b) Holders of unpatented mining claims validly established on any $\mathrm{Na}$ tional Forest Wilderness prior to inclusion of such unit in the National Wilderness Preservation System shall be accorded the rights provided by the United States mining laws as then ap: plicable to the National Forest land involved. Persons locating mining claims in any National Forest Wilderness on or after the date on which said Wilderness was included in the National Wilderness Preservation System shall be accorded the rights provided by the United States mining laws as applicable to the National Forest land involved and subject to provisions specified in the establishing legislation. Persons conducting operations as defined in $\S 228.3$ in National Forest Wilderness shall comply with the regulations in this part. Operations shall be conducted so as to protect National Forest surface resources in accordance with the general purposes of maintaining the National Wilderness Preservation System unimpaired for future use and enjoyment as wilderness and to preserve its wilderness character, consistent with the use of the land for mineral location, exploration, development, drilling, and production and for transmission lines, water lines, telephone lines, and processing oper- 
ations, including, where essential, the use of mechanized transport, aircraft or motorized equipment.

(c) Persons with valid mining claims wholly within National Forest Wilderness shall be permitted access to such surrounded claims by means consist. ent with the preservation of National Forest Wilderness which have been or are being customarily used with respect to other such claims surrounded by National Forest Wilderness. No op. erator shall construct roads across $\mathrm{Na}$ tional Forest Wilderness unless authorized in writing by the Forest Supervisor in accordance with § 228.12.

(d) On all mining claims validly es. tablished on lands within the National Wilderness Preservation System, the operator shall take all reasonable measures to remove any structures, equipment and other facilities no longer needed for mining purposes in accordance with the provisions in \$228.10 and restore the surface in accordance with the requirements in $\S 228.8(\mathrm{~g})$.

(e) The title to timber on patented claims validly established after the land was included within the National Wilderness Preservation System remains in the United States, subject to a right to cut and use timber for mining purposes. So much of the mature timber may be cut and used as is needed in the extraction, removal, and beneficiation of the mineral deposits, if needed timber is not otherwise reasonably available. The cutting shall comply with the requirements for sound principles of forest management as defined by the National Forest rules and regulations and set forth in stipulations to be included in the plan of operations, which as a min. imum incorforate the following basic principles oi furt it management:

(1) Harvesting operations shall be so conducted as to minimize soil movement and damage from water runoff; and

(2) Slash shall be disposed of and other precautions shall be taken to minimize damage from forest insects, disease, and fire.

(f) The Chief, Forest Service, shall allow any activity, including prospecting, for the purpose of gathering information about minerals in National
Forest Wilderness except that any such activity for gathering information shall be carried on in a manner compatible with the preservation of the wilderness environment as specified in the plan of operations.

\section{Subpart B-Leasable Minerals}

$8 \S 228.20-228.39$ [Reserved]

\section{Subpart C-Disposal of Mineral Materials}

SOORCE: 49 FR 29784, July 24, 1984, unless otherwise noted.

\section{$\S 228.40$ Authority.}

Authority for the disposal of mineral materials is provided by the Materials Act of July 31, 1947 (30 U.S.C. 601 et seq.), as amended by the Acts of August 31, 1950 (30 U.S.C. 603-604), July 23, 1955 (30 U.S.C. 601, 603), and September 25, 1962 (30 U.S.C. 602), and by the following: the Act of June 4, 1897 (16 U.S.C. 477); the Act of March 4, 1917 (16 U.S.C. 520); the Bankhead-Jones Farm Tenant Act of July 22, 1937 (7 O.S.C. 1010); the Act of September 1, 1949 (section 3) (30 U.S.C. 192c); the Act of June 30, 1950 (16 U.S.C. $508 \mathrm{~b}$ ); the Act of June 28, 1952 (section 3) (66 Stat. 285); the Act of September 2, 1958 (16 U.S.C. 521a); the Act of June 11, 1960 (74 Stat. 205); the Federal Highway Act of August 27, 1958 (23 U.S.C. 101 et seq.); and the Alaska National Interest Lands Conservation Act of December 2, 1980 (section 502) (16 U.S.C. 539a).

\section{$\S 228.41$ Scope.}

(a) Lands to which this subpart applies. This subpart applies to all $\mathrm{Na}$ tional Forest System lands reserved from the public domain of the United States, including public domain lands being administered under the Bankhead-Jones Farm Tenant Act of July 22, 1937 (7 U.S.C. 1010); to all National Forest System lands acquired pursuant to the Weeks Act of March 1, 1911 (36 Stat. 961); to all National Forest System lands with Weeks Act status as provided in the Act of September 2, 1958 (16 U.S.C. 521a); and to public lands within the Copper River adii- 
APPENDLX 6.

MEMORANDUM OF UNDERSTANDING BETWEEN USFS AND DSL DATED DECEMBER 11, 1989 


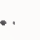




\section{MEMORANDUM OF UNDERSTANDING \\ BETWEEN . \\ STATE OF MONTANA, DEPARTMENT OF STATE LANDS AND \\ U.S. DEPARTMENT OF AGRICULTURE, FOREST SERVICE}

This Memorandum of Understanding is entered into between the Unilod States of America, acting through the U.S. Department of Agriculture, Forest Service (hereinater FS); and Stato of Montana, Department of Stato Lands (hereinafter OSL).

\section{A. AUTHORITY}

This Memorandum is entered into under the following State and Foderal authorities:

Stato:

1. Metal Mine Reclamation Act (Titio 82, Chapter 4, Part 3, MCA):

2. Rules governing tho Montana Metal Mine Reclamation Ars (AFM 20.4.101, ef seq., );

3. The Open Cut Mining Act (Tito 82. Chapter 4, Part 4, MCA);

4. Rules governing the Opencut Mining ACl (ARM 20.4.201, et seg.);

5. Montana Environmental Policy Act (MEPA) (Titso 75, Chapter 1, MCA);

6. Rules governing MEPA (Title 26, Chapter 2, Subchapter 6, ARM).

Federal:

1. General Mining Laws (30 U.S.C. 22 ol seg.), as amended;

2. Materials Act of 1947 (30 U.S.C. 601 et seq.), as amended;

3. Natlonal Environmental Policy Act (42 U.S.C. 4371, ot seq.);

4. . 1920 Mineral Leasing Act (as it applies to phosphate onfy-joint authorty with U.S. Department of interior, BLM)

5. Locatable Mineral Regulations (36 CFR 228, Subpart A);

B. Disposal of Mineral Material Rogulations, 30 CFA 228, Subpart C;

7. NEPA Regulations, 40 CFA 1500 - 1508;

8. Forest Service Manual - FSM 1900 - NEPA;

9. Forest Servleg Manual - FSM 2800 - Minerals.

\section{B. PURPOSE}

The purpose of this Memorandum is 10 promote efficlency and effectiveness by the DSL and FS in their administration and regulation of locatable mineral (nardrock) activiss, salable minerals (open cut), and leasable minerals (phosphate onty, open cur), under their respective authorities and responsibilites. This Memorandum will provide for ellmination of duplication of analysls, monitoring, and administralion; prepara. tion of joint ertvironmental analyses; and sharing of informatlon, personnel, and funos; as fas as it is lawtul and practical. This Niemorandum applies to operations on National Forest Systern (NFS) lands and to similar mineral actlvity on other land which might affect NFS lands. 


\section{AGENCY RESPONSIBILITIES}

Forest Servlce regulations, cited above, apply to all operatlons, conducted under the United States mining laws as they affect surface resources on all NFS lands.

The Metal Mine Reclamation Act, clied above, shall the applicable to mining operatlons located on NFS land to the extent provided by law, and upon all private lands located within the boundaries of National Forests. However, the Metal Mine Reclamation Acr shall nor be applicable to operations on those NFS lands where it is speciried by the Montana Board of Land Commissioners (The Board) that Federal law or Forest Servico regulations impose controls for reclamation on said lands substantlally equal to or greater than those imposed by the Metal Mine Reclamatlon Act. (See Section 82-4-309, MCA.)

The Opencut Mining Act, cited above, shall be applicable to mining operations located on NFS land to the extent provided by law, and upon all private lands located within the boundarles of tho Natlonal Forests. However, the Opencut Mining Act shall not be applicable to operations on those NFS lands where it is specified by the Board that Federal law or FS reguiatlons impose controls for reclamatlon on said lands equal to or groater than those imposed by the Oponcut MIning Act. (S80 Section 32-4406, MCA).

The Board shatl make an inttial decision, and as many subsequent decisions as are requested by $\mathrm{FS}$ as to the applicability of the Motal Mine Reclamation Act and the Cpencut Mining act to mining operations on NFS lands.

\section{ENVIRONMENTAL ANALYSES AND DOCUMENTS}

Where both DSL and FS have regulatory responsibilitles over a proposed mineral operation, environmental studies, anatyses and documents will be prepared jointy in order to meet the objective of etflclency and elimination of duplication to the extent possible. It is the poticy of both agencies to prepare such analyses and documents that will meet the requlrements of both NEPA and MEPA and other applicable State and Federal laws and regulations.

Both agencies will cooperate and coordinate through the initial environmental analysis phase and will strive to reacl joint agreement on the type of environmental document appropriate to meet the requirements of MEPA and NEPA. Netther agency will release internal working documents, or portions thereot, withour notifying the other agency prior to release: If agreement cannot be reached as to the appropriate type of envlronmental document, or release of working documents, the issue will be ralsed to the next administrative level for resolution before publlc announcements are made. The final arbiters of disagreements that fall within the context of this MOU are the Commissioner, Montana Department of State Lands, and the Regionai Forester, Northern Reglon U.S. Forest Service.

When jolnt DSL/FS projects arise, the Commissioner and Reglonal Forester will decide the respective agency poles on each prolect. Il appropriate, a lead agency will be jointly designated. Specitic action plans will bo developed consistem with the overall purpose and policy directions contained in this MEMORANDUM, and the lead agency, if designated, will assume overall responsiblity for management of the project with assis. ance as requlred being provlded by the cooperating agency. Such actlon plans will adoress work schedules; peiso nnel assignments; scoping. publle issues and management concerns; publle involvement; writing, evitlng and publishing assignments and schedules, funding responsibilities; and coordinatlon with local, State, and Federal agencies; and use of third party or other contracts. To insure local government partlclpation and input, the agencies will encourage local county governments to participate in development and implememation of the action plan. 


\section{E. PERMITTING}

Where both DSL and FS have approval authority over proposed mineral operations, each agency will coordinate the approval conditions and timing of its respective decision documents with the other agency to the extent possible.

\section{F. ADMINISTRATION OF APPROVED OPERATIONS}

Either agency may be designated as the "administering agency" for the purpose of administration of opera. tions, bonding, and all other responsibilities concerning approved mineral operations to the extent legally possible. In those instances where operations on NFS land are exempt from State statutes, the FS will be the administering agency. in those instances where FS progran interests aro minor, the Regional Forester may determine that the DSL is the administering agency. In all other cases, the Commissioner and Regional Forester will jointy decide the appropriate agency roles, consistent whth the purposes of thls Memorandum. After the administering agency is designated, the other agency will cooperato with the administering agency. DSL and FS will each consider the requirements and recommendations of the other agency in their respective administration of mineral operations.

\section{Q. BONDINA}

The DSL is required to collect and hold reclamation bunds for activilles conducted under the exploration licenses (Section 82-4331, MCA), operating permits (Sectlon 82-4-335. MCA), placer and dredge operations not otherwise required to obtain an operating permit (82-4-305(3). MCA), and opencut contracts (Section 82-4-431, MCA). FS may require bonds for similar actwitles under Plans of Operation (38 CFR 228.13). Material Contracts (36 CFA 228.51) and Mineral Leases, Licenses or Permits involving phosphate. Since the purpose of this agreement is to reduce duplication of effort and administration, where both agencies are required to hold reclamation bonds, a single joint bond payable to both agencles may sutfice. In those instances where mineral-related actwites are not required to be bonded by one agency, the other agency may require a separate bond. Jolnt bonds will generally be held by the administering agency.

The agency holding the bond will incorporate the recommendations and requirements of the other agency to the extem legaily defensible when determining the amount of the peclamation bond, the acceptability of the bond, and conditions of bond release. A joint reclamation bond cannot be released without written concurrence from both agencles.

\section{H. COORDINATION, COMMUNICATIONS, TRAINING}

DSL and FS murualy agree to share Information conceming every aspect of their joint responsibliiles over mineral operations, whth the exception of those matters which must remain confidential pursuant to applicable statutes and regulations: of ether. agency: This.sharing of information shall be comprehensive, including proposals and plans by operators; speclal knowledge and expertise held by personnel of the agencies, compliance inspectons, monitoring, enforcernent, and reclarnation.

As part of their coordination responsibilities under this agreement each agency shall inform and educate the other's personnel conceming that agency's aurhorities, proceduress, and requirements. This shall include such things as conducting joint technical training sessions, and encouraging foint attendance at appropriate agency-sponsored sessions. The agencles stall meet at leasi once annually to consider whether this MOU needs revision, and to discuss other appropriate issues. 


\section{TERM, MODIFICATIONS, TERMINATION}

This Memorandum shall become effective upon signature by both agencles and shall remain in effect until moditied or terminated in accordance with this section. Modifications to this Memorandum may only be made by mutual written agreement of the slgnatorles. This Memorandum may be terminated by either party upon prior written notico.

In witness whereof, the parties nereto have executed this agreement dated this 1989.
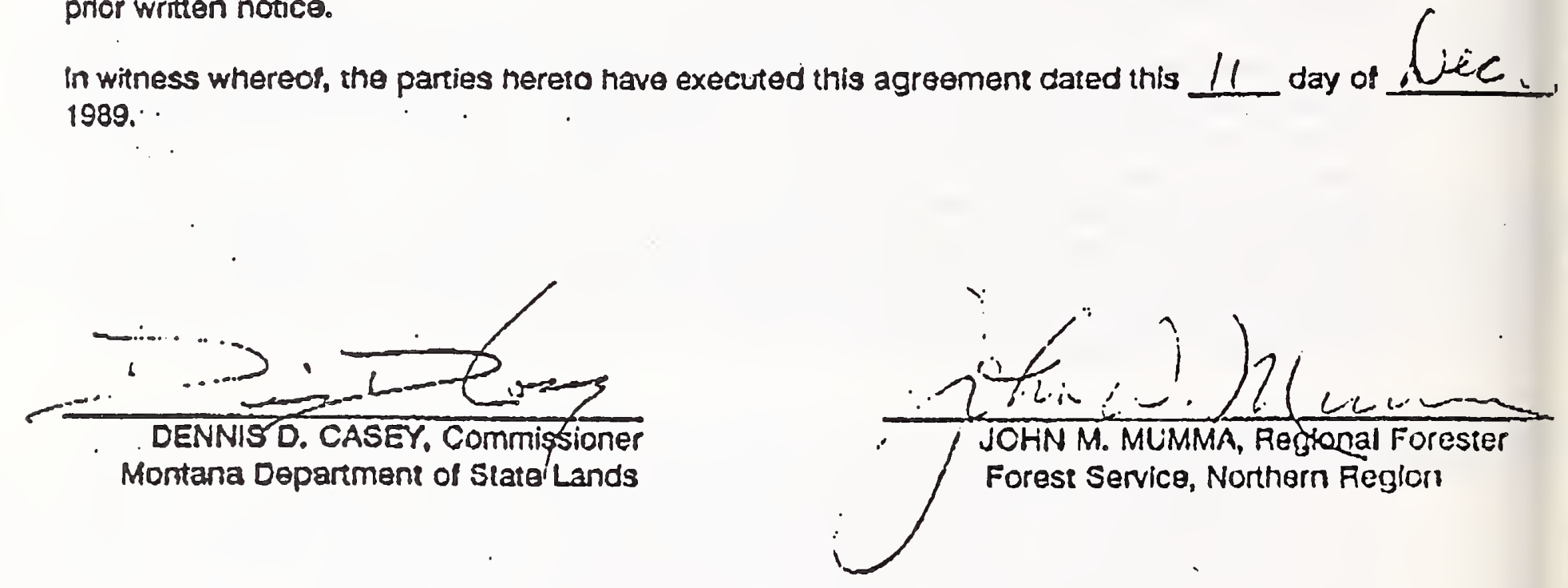
APPENDLX 7.

H-3809-1, BLM STATE OFFICE HANDOOK, SURFACE MANAGEMENT OF MINING CLAIMS

CHAPTER 7 


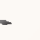

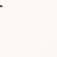




\section{H-3809-1 - SURFACE MANAGEMENT Chapter 7}

\section{CHAPTER 7 - RECLAMATION}

\section{Introduction.}

Reasonable reclamation of surface disturbance is required of all operators, regardless of the level of operations (43 CFR 3809.1-1). Reasonable reclamation is not always easy to define. It may help to look at the Bureau's policy of not allowing unnecessary and undue degradation and realize that due and necessary degradation is allowed.

All operations should be planned with final reclamation in mind. The reclamation requirements, as well as interim stabilization needs, may affect how the operator strips overburden, locates roads and buildings, stores fuel, selects rehabilitation equipment, and in general, plans all phases of his operation.

\section{Responsibility.}

The $\mathrm{AO}$ and the $\mathrm{AOR}$ are responsible for ensuring that operators perform adequate reclamation. A statement that reclamation of all areas disturbed will be completed to the standards described in 43 CFR 3809.1-3(d), and that measures will be taken to prevent unnecessary and undue degradation of the Federal lands, must accompany a notice. A plan of operation must include a reclamation plan, either developed by the operator, or in conjunction with the $\mathrm{AO}$ or $A O R$, that has been determined by the $A O$ to be sufficient to prevent unnecessary and undue degradation. The Bureau of Land Management, if requested, must assist operators in developing this reclamation plan.

Many mining claims are leased by the claimants to operators. The claimant remains responsible for completing any reclamation requirements not satisfactorily performed by the operator.

\section{A. Exempt Areas.}

The following areas are exempt from reclamation requirements:

1. Lands that were disturbed prior to the enactment of the 3809 regulations (January 1 , 1981), unless the land is redisturbed by an ongoing operation.

2. Locations necessary to preserve evidence of mineralization.

3. Areas that will be redisturbed by ongoing operations.

\section{B. Timeframes.} time.

43 CFR 3809.1-3(d) states that the operator shall perform reclamation at the earliest feasible

For a plan of operation, the reclamation timeframes should be spelled out in the final approved reclamation plan.

On notices, the operator should be required to perform, at a minimum, stabilization measures if the operation is to sit idle longer than 2 years, with indications that it will start up again (i.e., equipment present on site). If more than one field season of nonoperation elapses without any indications of resumption in operations, then the operator may be required to perform complete reclamation measures (43 CFR 3809.3-7). Any operator who fails to complete reclamation within a feasible time after operations cease will be subject to a notice of noncompliance (see Chapter 6).

\section{Stabilization Measures.}

During periods of nonoperation, or in large operating areas where only a portion of the surface is being disturbed, stabilization measures may be necessary to prevent unnecessary and undue degradation. These measures may include: 


\section{H-3809-1 - SURFACE MANAGEMENT Chapter 7}

1. Saving available topsoil (this includes the organic mat) for final respreading after reshaping the disturbed areas.

2. Stabilizing saved topsoil, overburden and disturbed areas used during the operation to prevent erosion, landslides or degradation to adjacent waters.

3. Isolating, removing or controlling toxic materials.

4. Reshaping or grading disturbed slopes and placing erosion control devices.

5. Revegetating disturbed lands to prevent erosion prior to final reclamation.

\section{Reclamation Standards - Performance versus Design.}

In most cases, the standards required in reclamation efforts are to be performance rather than design standards. Design standards prescribe a specific technology, or a precise procedure to be followed. Performance standards prescribe the end result that must be achieved for regulatory compliance. Design standards are inappropriate when an operator has established a record of compliance. Design standards are only appropriate when specific reclamation or mitigation techniques are necessary to:

1. Protect threatened or endangered species.

2. Protect cultural resources or scientifically significant fossils.

3. Meet standards required by a regulatory agency as a condition of compliance with a substantive environmental law.

4. Prevent unnecessary and undue degradation of wilderness character.

5. Comply with a notice of noncompliance issued by the $\mathrm{AO}$.

\section{E. Reclamation Standards - General.}

Reclamation standards for operating areas covered by a notice are detailed in 43 CFR 3809.1-3(d). These same standards should be a part of the reclamation plan contained within an approved plan of operations. These general standards are:

1. All tailings, dumps, deleterious materials or substances, and other waste produced by the operations shall be disposed of so as to prevent unnecessary or undue degradation, and in accordance with applicable Federal and state laws.

2. At the earliest feasible time (see Chapter 7.II.B), the operator shall reclaim the area disturbed, except to the extent necessary to preserve evidence of mineralization, by taking reasonable measures to prevent or control on-site and off-site damage of the Federal lands.

3. Reclamation shall include the following practices:

a. Saving of topsoil for final application after reshaping of disturbed areas.

b. Controlling of erosion, landslides, and water runoff.

c. Isolating, removing, or con'roling, toxic materials.

d. Reshaping disturbed areas and reapplying topsoil and vegetation where reasonably practicable.
e. Rehabilitating fisheries and wildlife habitat.

4. Notify the AO when final reclamation of the disturbed area has been completed, so that an inspection of the area can be made. 


\section{H-3809-1 - SURFACE MANAGEMENT \\ Chapter 7}

\section{F. Final Inspection.}

The final inspection of a project area should be carried out in cooperation with DSL in areas where DSL has bonded the operator. DSL will usually seek Bureau of Land Management concurrence before releasing bond. It is important that any problem the Bureau of Land Management has with an operator's reclamation job be settled before bond release. Therefore, a final ins pection of the area by the AOR is necessary. Some things to look for at the final inspection are:

1. Measures taken to control erosion, landslides and water runoff.

2. Evidence that reshaping of disturbed area is as near to the original surface as practical.

3. Indication that all drill holes are properly plugged, casing is cut off below surface, and cuttings are properly dispersed.

4. Establishment of vegetation cover to a self-sustaining point.

5. Evidence of substances or features which may pose a hazard to public health and safety.

6. Ability of the disturbed area to, unaided, reach a post-operation condition compatible with the surrounding land. In other words, with the reclamation measures that have been taken, will the land proceed to heal itself fully, or will its condition decline after the operator has withdrawn.

\section{G. Secondary Uses.}

Some situations may lend themselves to secondary uses of a disturbed area, rather than merely recontouring and revegetation. Secondary uses may include the development of wildlife habitat or other uses authorized by Section 302(b) of FLPMA. If a secondary use is consistent with land use planning (RMP, activity plan, etc.), and the operator chooses to incorporate such secondary uses into the reclamation plan, such uses will be considered as an option to standard reclamation practices. 

APPENDDX 8.

DNRC LEGAL COUNCL MEMORANDUM DATED MARCH 21, 1984 
TO: Ray Beck

Conservation District Division

FROM: $\quad$ Tim D. Hall

Legal Counsel

RE:

Changing Conservation surety Bonds

DATE: $\quad$ March 21,1984

\section{ISSUE}

I previously wrote a memorandum concluding that conservation districts do have the power to require surety bonis from those seeking 310 permits. I stated that such a requirement should be stated in a.conservation district's rules, however. Various conservation districts now have assorted questions as to how te properly implement a rules change, if security cther than a surety tond can be used, etc. that I will attempt to address in this memo.

\section{NDTIRE OF RULES CHANGE}

Nothing in the Montana Code Annotated sets out specifically what notice is required prior to a rules change by a conservation district. However, in looking at other notice laws, including those in the Montana Administrative procedures Act, I would recommend notice te given in the form of two paid notices in a paper of general circliation $\vdots$ n the conservation district, beginning with the first notice at least 30 days in advance of the meeting on the rules change. Any rules change must be adopted, according to $\$ 26-1520$, R.C.M. 1947, by resolution only "after a public hearing." (see also Rule 15(2) of Model Rules). Thus, the metting shculd be set on a rules change with an opportunity for discission before the actual change or amenament is mace by resolutior. I have attached a arart "Notice" that can be used as is or charged to suit your personal tastes. I would additionally post a copy of the notice in the county courthouse, conservation district office or other conspicuous public place at least 30 da's in advance of the metting. If the above recommendations concerring notice are followed, any anendment to a corservation district's rules should comply with all legal requirenent: regarding notice.

\section{PROPOSED SURETY RONID RULES}

I have attached to this memo a draft of proposed rules requiring sur:ty bonds of 310 permittees. These proposed rules represent a working oraft that can be changed to include your 
Memorandum

March 21, 1984

Page -2-

individual ideas on how your conservation district wants its surety bond requirement to work. After the public hearing, ard after discussion among yourselves, you will be able to taylor-fit these draft rules to your specific needs.

The Missoula County Conservation District cn March 14, 1984 , submitted the following questions on adopting surety bond requirements which I will now answer in this memo since other conservation districts may have the same questions:

1. In what form would we require the bond?

This is up to the supervisors. It would be useful for the supervisors to meet with someone from a bonding company to see what kinds of bonds are available and what would best fit a conservation district's needs regarding issuing 310 permits. The bottom line is whatever is surficient to cover the restoration of a project's streambed if a 310 permittee fails to reclaim it. Any particular surety bond requirements could also be put in the rules.

bould cash or some other security do?

If a conservation district starts accepting cash or other security instead of a surety bond, I think it will be acquiring countless new headaches for itself that it will be without the resources to decl with and which this Deoartment will also not rave the time or manpower to ceal with. For instance, if $a$ security interest is taken in real property or persorial property, you have the problem of needing to make a record of your security interest in that property. You may find that others also have a security interest in that Eroperty. Supposing you want to tap that security interest to properly restore a streamied because the permittee has refused to, you will be faced with all the lecal hassles associated with liquicating that security interest. All of this will requirn legal work. Adoitionally, you face the problin of what happens to your security interest if the permittee goes 
bankrupt. All in all, if a district wants to require some security interest, I would recommend no other type of security besides a surety bond be allowed.

There was concern that the expense of the bond purchased through an insurance company would keep some people from being able to obtain them. If cash was used, how would the district handle it?

Again, more problems arise if anything besices a surety bond is allowed. If a conservation. district allows cash to be used, though, it will probably have to be held by the conservation district with a receipt given to the permittee along with an agreement that the money will be returned if the project is properiy reclaimed and all conditions of the permit conformed with. The money should probably be handled $i n$ a separate, interest-bearing account. It is doubtful any bank or other institution would be willing to be the escrow holder where litigation over disbursement of the money could easily arise. f.gein, allowing anything other than a surety bond creates numerous additional problems that must be dealt with along with an increase in legal work. I would not recommend cash being lised as security unless it was found surety bonds bere prohibitively expensive: or virtually unavailable to permittees.

2. What provisions are there for a release from the bond?

Any surety bond will have to te conditioned on proper reclamation of the project and conformance with any conditions placed on the permit by the supervisors.

Who would determine if a project wis done right? There would have to be scrieone who would work from start to finish on a 
Memorandum

March 21, 1984

Page $-4-$

project to insure that there was an agreement on what was expected and what was done.

The supervisors would have to determine if a project was done right. The best way to insure that there is agreement on what is expected is to make that clear in any conditions to the permit. If the permittee agrees to do his project with the conditioned permit, he is agreeing to meet those conditions. If the permittee refuses to do as agreed, the supervisors can look at the terms of the permit and take the required legal action to tap the surety bond for an amount sufficient to correct any deficiencies. It will be up to the supervisors as to how much time they want to take to monitor the project, but it should not take that much more time than it now takes to monitor projects.

3. Some guidelines would have to be set to determine when a surety bond would be required. This could not just be determined on a case-by-case basis.

If a conservation district wants to draw up quidelines as to when a surety bond is required, that is fine. However, requiring surety bords can be done on a case-by-case basis as long as all similar situations are treated the same. consistency is the key here. If a surety borid has been required in one situation, all similar situations must also be treated as requiring a surety bond or the conservation district will be accused of inconsistent treatsment of permittees and possibly favoritism or ciscrimination.

4. Doesn't the lä, as i.t is written, provide districts with the same ability to prevent damage or make sure proper restoration is made, agreeing that this way is an expense to the counties, but collecting the tord would also be one. 
1. The supervisors may require the project applicant to furnish, prior to the commencement of a. project and as a condition of the 310 permit, a sufficient surety bond approved by the supervisors, conaitioned upon the proper reclamation of the streambed and land involved in the project and conformance with any conditions in the project permit.

2. Once an applicant has posted a sufficient surety bond and prior to the release of that bond, the supervisors shall inspect the applicant's completed project for proper reclamation and conformance with any conditions placed on the applicant's project permit. If the project passes inspection, the supervisors shall release the surety bond.

3. If an apolicant's project is not properly reclaimed and dces not properly conform to conditions placed on the applicant's project permit, and the applicant refuses after receiving a written warning contairing notice of all deficiencies to properly reclaim the area in question or conform the project to the conditions on the permit, the supervisors shall, after granting the applicant an opportunity for a hearing before them, refuse to release said bond and shall take such legal action as is necessary to lise such bond to the extent required to have the project properly reclaimed or to have all conditions of the approved project plan or permit conformed with. 
No. The present law is vague about the enforcement powers of conservation districts once a 310 permit has been granted. Section 75-7-123, MCA, is clear that "[a]ny person initiating a project without written consent of the supervisors is guilty of a misdemeanor, ${ }^{n}$ and that restcration of the stream can be ordered by the court, but nothing specifically acdresses what happens when a person vioiates the conditions of their 310 permit. Section 75-7-122, MCA, also declares as a public nuisance any project, except for emergency action, that is engaged in without prior approval as described in the 310 law. But again, nothing specifically covers not living up to the teris of the 310 permit. The use of a surety bond gives a conservation district control in this area and is within the legislature's intent in providing for protection of Montana's streambeds by conservation districts.

Eirally, if any rule requiring a surety bond is adopted, I would recommend designating it as RLI.e 10., SURETY BCND REOUIEEMENT, fOIICWIng RUIE IC, CONSTRUCTION STANDARES, of the Model kules. 
NOTICE of Proposed Amerdments to the "

Conservation District Rules for Implementation of tie Natural Streambed and Land Preservation Act of $2975^{\prime \prime}$ (the n3zon law).

The sugervisors of the Conservation

District will conduct a public hearing on

at p.r. at the to

determine whether to amend the above Rules to incluce the requicement that any person obtaining a "310" permit must, as a condition of the permit, post a sufficient surety bond conditioned on proper reclamation of the streamided ard lend involved in the "3io" project. All interested persons are invited to attend and present theis views.

This notice srould be placed in a paper of general circulation in the county of the conservation district with the first rotice appearing at lezst 30 days prior to the meeting. A copy of this notice should also be placed in a corspicuous public place, such as the county courthouse or conservation iistrict office at least 30 days prior to the meeting.l 


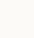


APPENDD 9.

EPA GOLD PLACER MINE EFFLUENT GUIDELINES

(40 CFR 440.140-148) 

lacidental lesching of uranfum by mine dralnase, nor the rebabilltation of aquiflers and the monitoring of these squiflers.

(f) "Mull" is a preparation facillty within which the metal ore is cleaned, concentrated, or otherpise processed before it is shipped to the customer. refiner, smelter, or manufacturer. A mill Includes all ancillary operations and strictures necessary to clesa, concentrate, or otherwise process metal ore, such as ore and gangue storage areas and loading facilities.

(g) "Mine" is an active mining area, including all land and property placed under, or above the surface of such land used in or resulting from the work of extracting metal ore or miner. als from their natural deposits by any means or method, including secondary recovery of metal ore from refuse or other storage piles, wastes, or rocs dumps and mill taillags derived from the mining. clesaing, or concentration of metal ores.

(b) "Mine drainage" means ang water drained, punped, or siphoned from a mine.

(1) "Ten.(10)-gear, 24-bour precipitation event" is the maximum 24-hour precipitation event with a probable recurrence interval of once in 10 years as established by the U.S. Departoment of. Commerce, National Ocearic and At. mospheric Administration. National Weather Service, or equiralent regional or rainfall probabillty information.

(j) " $"$ " (Oranium) is measured by the procedure discussed in 40 CFR $141.25(b)(2)$, or an equivalent method

\section{Subpart M-Gold Placar Mine Subcategory}

SoJir 53 FR 18788, May 24, 1988, unless ot.kermise noted

\$ 140.140 Applicability; description of the gold placer mine subcategory.

(a) The provisions of this Subpart M are appllcable to discharges from-

(1) Mines and dredges that produce gold or gold bearing ores from placer deposits; and

(2) The beneficiation processes which use gravity separation methods for recovering gold from placer deposits. (b) The provistons of this Subpart $M$ are not applicable to ang mines or beneflciation processes which process less than 1500 cubic gards (cu gd) of ore per gear, or to dredges which process less than 50,000 cu yd of ore per year. or to dredges located in open paters (Le., open bays, marine waters, or major Iivers).

\subsection{Specialized definitions and pro- visions}

For the purpose of this Subpart M. the general definitions, abbreviations, methods of analysis, and general provisions set forth in 40 CF'R Part 401 shall apply except as superseded by those below. The general provisions and definitions set forth in 40 CFR Part 40 Subpart L shall not apply to this subpart.

(a) Specialized Definitions. The following specialized definitions apply to this subpart onls.

(1) "Beneficiation area" means the area of land used to stockpile ore iromediately before the beneflciation process, the ares of land used for the beneficiation process, the ares of land used to stockpile the tailings immediatels after the beneflciation process, and the area of land from the stockpiled tailings to the treatwent system (e.g., holdiag pond or settling pond. and the ares of the treatment syster.).

(2) "Beneficiation process" means the dressing or processing of gold bearing ores for the purpose of -

(1) Regulating the size of, or recovering, the ore or product.

(ii) Removing unwanted constituents from the ore, and

(iii) Inproving the quality, purity, or assay grade of a desired product.

(3) "Drainage water" means incidental surface waters from diverse sources such as rainfall, snow melt or permafrost melt.

(4) "Dredge" means a self-contained combination of an elevating excavator (e.g., bucket line dredge), the beneficiation or gold-concentrating plant, and a tairloss disposal plant, all mounted on a floating barge.

(5) "Flve (5) year, 6-hour precipitation event" means the maximum 6hour prectpitation event with a probable recurrence toterval of once in 5 
years as established by the U.S. Deparment of Commerce, National Oceadic and Atmospheric Administratton. National Weather Service, or equitalent regional or rainfall probability information.

(8) "Gravity separation methods" means the treatment of mineral partfcles which exploits differences between their specific gravities. The separation is usually performed by means of sluices, jigs, classillers, spirals, bydrocjclones, or shaking tables.

(7) "Inflltration water" means that water which permeates through the earth into the plant site.

(8) "Mine" means a place where wort or other activity related to the estraction or recovers of ore is performed.

(9) "Mine area" means the land area from which overburden is stripped and ore is removed prior to moving the ore to the beneficiation area.

(10) "Mine drainage" means any water drained pumped or siphoned from a mine.

(11) "New water" means water trom ang discrete source such as a tiver, creek. lake or well which is dellberateis allowed or brought into the plant site.

(12) "Open cut mine" means any form of recovers of ore from the earth except by a dredge.

(13) "Ore" means gold placer deposit consisting of metallic gold-bearing gravels, which maj be: residual, from weatbering of rocks in-situ; river gravels in active streams; river gravels in abandoned and often buried channels; alluvial fans; ses-berches; and sesbeaches now elevated and inland. Ore is the raw "bank ru" material meas. ured in place, beiore being moved by mechanical or brdraulic means to a bezeficiation process.

(14) "Permit Area" means the ares of land specified or referred to in an NPDES permit in which active mining and related activitles may occur that result in the discharge regulated under the terms of the permit. Usually this is specifically delloeated in an NPDES perwait or perroit application. but in other cases may be ascertainable from an Alaska Tri-agency permit application or similar document speci- fylag the mine location, wining plan and similar data.

(15) "Plant site" means the area oc. cupied by the mine, necessary haulage ways from the mine to the benefleda Hou process, the beneficiation area, the area occupied by the prostewater treatment facillities and the storage aress for maste materials and sollds re. moved from the wastepaters duriag treatement.

(16) "Process wastepater" means all whter used in and resulting from the benefleiation process, including but not limited to the water used to move the are to and through the beneflicis thon process, the pater used to ald in classification, and the water used in gravity separation, mine drainage, and inflltration and drainage waters which commingle with mine drainage or waters resulting from the beneficiathon process.

(17) "Settleable solids" means the partlculate material (both organic or inorganic) which will settle in ane hour expressed in millniters per liter (mi/1) as determined using an Imoholf cone and the method described for Residue-Settleable in 10 CFR Part 138.

(b) Specialized Provisions-Storm Exemption This specisilized provision applies to this Subpart $M$ only. If, as a result of precipitation (rainfall or smowrellt), a source subject to this subpart bas an overlow or discharge of effluent which does not meet the limitattons or standards of this subpart, the source may qualify for an exemption from such limitations and standards with respect to such discharge if the following conditions are met:

(1) The treatment system is de signed, constructed, and maintained to contain the maximun volume of untreated process pastepater which would be discharged, stored, contained and used or recjcled by the beneficis. Hon process into the treatment system during a 4hour operating period with. out an increase in volume trom pre cipitation or infiltration. plus the masinum volume of water runoff result ing from a 5-year, 6-hour precipitation event. In computing the maximum volume of water which would result from a 5-year, 6-hour precipitation 
erent the operator onust faclude the rolume which pould result from the plant site contributiag 5uadif to the individual trestment facillty.

(2) The operator takes all regsonable steps to rasintain trestrent of the wastepater and minimize the amount of overtlow.

(3) The source is in compliance with the BMD in \& 140.148 and related provisions of its NPDES permit.

(4) The operator complies with the notification requirenents of $\$ 122.41$ (II) and (II) of this title. The storm exemption is designed to provide an affirmative defense to an eaforcement action. Therefore, the operator has the burden of demonstrating to the appropriate authority that the above conditions bare been met.

\$ 440.142 Effluent limitations representing the desree of effluent reduction attain. able by the application of the best practicable control technologo currentis arailabie (BPT).

Except as provided in 40 CFR 125.30-125.32 ang existing point source subject to this subpart must achieve the following effluent linita. ttons representing the degree of efflu. ent reduction attaiaable by the application of the best practicable control techaology curreatls available (BPT):

(a) The concentration of pollutants discharged in process wastepater from an open-cut mine plant site shall not exceed:

\begin{tabular}{|c|c|}
\hline \multicolumn{2}{|c|}{ Effuemt limrintors } \\
\hline Ehruem cranacsenstic & $\begin{array}{l}\text { Insermaneous } \\
\text { maxpmum }\end{array}$ \\
\hline Sotrende sotids. & $02 \mathrm{mt} / \mathrm{t}$ \\
\hline
\end{tabular}

(b) The concentration of pollutants discharged in process wastemater from a dredge plant site shall not exceed:

\begin{tabular}{|c|c|}
\hline Etruent craractemsocs & $\begin{array}{l}\text { Efruom } \\
\text { limpabons- } \\
\text { Instamanocen } \\
\text { masmem }\end{array}$ \\
\hline mecole so & $02 \mathrm{md} /$ \\
\hline
\end{tabular}

840.143 Efluent limitations representing the degree of eflluent reduction atrinable by the application of the best arailable technolog economically achierable (BAT).

Except as provided in 40 CFr 125.30-125.32, ans existiag point source subject to this subpart must achieve the following efflueat limitatlons representing the degree of effluent reduction attainable by the application of the best arailable technology economically achievable (BAT).

(a) The volume of process mastepater which may be discharged from an open-cut mine plant site stall not exceed the vilume of infiltration, drainage and mine drainage praters which is in excess of the rake up water required for operation of the beneficiation process. The concentri: tion of pollutants in process prastepaters discharged from an opencut mine plant site saall not exceed:

\begin{tabular}{|c|c|}
\hline Etrement craractarsocs & 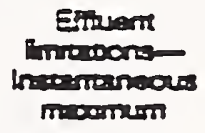 \\
\hline renole solids. & $02 \pi /$ \\
\hline
\end{tabular}

(b) The voluone of process wastepater which maj be discharged from a dredge plant site shall not exceed the volume of inflitration. drainage and mine drainage waters which is in excess of the make up water required for operation of the beneficiation process. The concentrathon of pollutants in process wastewater discharged from a dredge plant site shall not exceed:

\begin{tabular}{|c|c|}
\hline Eltuent craracterstoo & 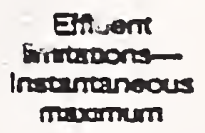 \\
\hline Serteade solids. & $0.2 \mathrm{~m} / 1$ \\
\hline
\end{tabular}

9 440.144 Ner Source Performance Standards (NSPS).

Any new source subject to this subpart must achieve the following NSPS representiag the degree of effluent re duction attainable by the applleation 
of the best arallable demonstrated technology.

(a) The voluose of pracess wastepater which may be discharged from an open-cut mine plant site sall not ercesd the volume of inflitration, drainage and mine drainage waters which is in ercess of the make up water required for operation of the beneficiation process. The concentratron of pollutants in process prastepaters discharged from an opencut mine plant site shall not exesed:

\begin{tabular}{|c|c|}
\hline Efirem charecontiatics & 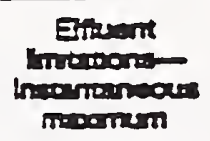 \\
\hline Sortuable sotids & $22 \mathrm{ml}$ \\
\hline
\end{tabular}

(b) The volume of process wastewater phich way be discharged from a dredge plant site shall not exceed the volume of inflition. drainage and mine drainage praters Thich is in excess of the make up pater required for operation of the beneficiation process. The concentra. thon of pollutarts in process pastepater discharged trom a dredge plant site stall not exceed:

\begin{tabular}{|c|c|}
\hline 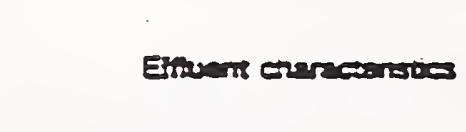 & 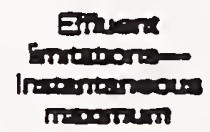 \\
\hline Sowande s & $0.2 \mathrm{mt}$ \\
\hline
\end{tabular}

(c) Notwithstanding ang other provision of this chapter, the Regional Admainistrator or Director of 8 State agenes with authority to administer the NFDES program shall in designat ing new source gold placer mines, take into account and base the decision on whether one or more of the following factors bas occurred after Maj 24. 1988.

(1) The mine will operate outside of the perwit ares mbich is covered by a currentls valld NPDES Permit.

(2) The mine sigmificantly alters the vature or quantity of pollutants discharged.

(3) The mine discharges into a stream into proich it bas not discharged under its curreatis ralid NPDES permit.
(4) The mine will operate in a permatt ares that bas not bean wined durias the term of the currently pallid NPDES permit.

(5) Such other factors as the Region. a) Adataistrator or state Direxior deems relegant.

\section{$88440.145-140.147$ [Reserved]}

\subsection{Best Management Practica (BMP).}

The followiag best management practices are spectic requirements wbich shall be included in esci NPDES permit for all mining oper. attons regulated under this subpart to the greatest extent applicable in each such mining operation.

(a) Surfoce Water Diversion The Ilow of surface paters into the plan site stall be interrupted and these waters diverted around and apar trom incursion into the plant site.

(b) Berm Corstruction: Berms, in. cluding ang pond pants, dikes low dams and similar water retention strucrures shall be constructed in a manner such that they are reasonably expected to reject the passage of mater.

(c) Pollutart materials storage: Measures shall be taken to assure that pollutant materials removed from the process water and pastepater streams will be retained in storge areas and not discharged or released to the waters of the United States.

(d) New Water Control: The amount of nex water allowed to enter the plant site for use in ore processins shall be limited to the minimum amount required as make-up water for processing operations.

(P) Vaintenarce of water cortrol agid Jlids retention devices: All water control devices such as diversion structures and berms and all sollds reter. tion structures such as berms dikes. pond suructures and dams shall be maintained to continue their effectite ness and to protect from unerpected and catastrophic failure. 
